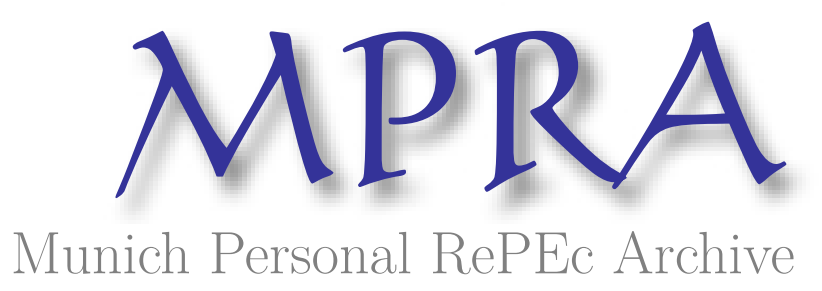

\title{
Simultaneous Generalized Method of Moments Estimator for Panel Data Models with Spatially Correlated Error Components
}

\author{
AMBA OYON, Claude Marius and Mbratana, Taoufiki \\ University of Yaounde II-Soa, Cameroon, University of Yaounde \\ II-Soa, Cameroon
}

2018

Online at https://mpra.ub.uni-muenchen.de/84746/

MPRA Paper No. 84746, posted 21 Feb 2018 15:12 UTC 


\title{
Simultaneous Generalized Method of Moments Estimator for Panel Data Models with Spatially Correlated Error Components
}

\author{
Marius Claude Oyon Amba* \\ Taoufiki Mbratana ${ }^{\dagger}$
}

\begin{abstract}
This paper develops estimators for simultaneous equations with spatial autoregressive or spatial moving average error components. We derive a limited information estimator and a full information estimator. We give the simultaneous generalized method of moments to get each component of the variance covariance of the disturbance in spatial autoregressive case as well as spatial moving average case. The results of our Monte Carlo suggest that our estimators are consistent. When we estimate the coefficient of spatial dependence it seems better to use instrumental variables estimator that takes into account simultaneity. We also apply these set of estimators on real data.
\end{abstract}

Keywords: Simultaneous GMM, Panel data, SAR, SMA.

JEL Classification: C13, C33.

January, 2018

\footnotetext{
${ }^{*}$ Corresponding author: Department of Quantitative techniques, University of Yaounde II, Cameroon. Email: mariusamba@gmail.com

${ }^{\dagger}$ Faculty of Economics and Managment, University of Yaounde II, Cameroon. Email: tao.mbratana@gmail.com
} 


\section{Introduction}

Nowadays, when study econometric models for panel data, the error components model is one of the most frequently used. This frequency comes from its parsimonious specifcation of heterogeneity accros the cross sectional units. And recently, there has been increasing consideration in models with spatial interactions. In view of that, spatial regression methods are becoming an important part of the toolbox of applied econometrics and the interest is increasingly shifting away from the single-equation cross-sectional background to more sophisticated settings such as panel data models, qualitative variables models, simultaneous models or multilevel models in a spatial context (see Anselin, 2006, for a related literature review). The literature on the estimation of simultaneous systems of spatially interrelated cross sectional equations has so far been limited with some exceptions. Kelejian and Prucha (2004) extend the methodology developed in Kelejian and Prucha (1998) and Kelejian and Prucha (1999) for single equations, an early development of generalized method of moments (GMM) estimators for the simultaneous equation SAR model. They propose both limited information two stage least squares (2SLS) and full information three stage least squares (3SLS) estimators and derive for these estimators their asymptotic properties. Liu (2014) and Zenou (2017) exploit the methodology of Kelejian and Prucha (2004) within the context of social interaction models, and provide further refinements. Other recent contribution to the literature on spatial simultaneous equation models are Wang et al. (2014) who analyse the quasi maximum likelihood (QML) estimator for such a system in the cross section. Prucha et al. (2016) developed an estimation methodology for network data generated from a system of simultaneous equations. Their specification allows for network interdependencies via spatial lags in the endogenous and exogenous variables, as well as in the disturbances. By allowing for higher-order spatial lags, their specification provides important flexibility in modeling network interactions. For a simultaneous equation SAR model, Liu and Saraiva (2017) provided a GMM estimator and its heteroskedasticity-robust standard error. They established the consistency and asymptotic normality of the proposed GMM estimator and also show that it performs well in finite samples. Yang and Lee (2017) studied parameter spaces, parameter identification and asymptotic properties of the QML estimation in the framework of the simultaneous equation SAR model which includes simultaneity effects, own-variable spatial lags and cross-variable spatial lags as explanatory variables, and allows for correlation between disturbances across equations.

The specific innovatory aspects of the current paper are: (i) the extension of the generalized moments estimators (GMM) estimation procedure that allow a spatial autoregressive (AR) error process to simultaneous GMM (SGMM) with AR process. (ii) the extension of the GMM estimation procedure that allow a spatial moving average (MA) error process to SGMM with MA process. (iii) application of the method to real data.

For this purpose, the rest of the paper is organized as follow. Section 2 completly define the model (equation and system); in section 3, we derive the simultaneous moment equations for

a SAR process as well as a SMA process. Section 4 derive the limited information estimator and the full information estimator. In section 5 we regroup a battery of simulations in model's parameters and apply theses estimators on real data. 


\section{The model}

\subsection{The Single equation}

Consider the following $l$ th structural equation,

$$
y_{l}=Y_{l} \alpha_{l}+X_{l} \beta_{l}+v_{l}=Z_{l} \delta_{l}+v_{l} \quad l=1, \ldots, L
$$

where, $y_{l}$ are endogenous variables with dimension $T N \times 1, Y_{l}$ is the set of $T N \times\left(M_{l}-1\right)^{1}$ right-hand side endogenous variables included in equation $l, X_{l}$ is a $T N \times K_{l}$ of right-hand side exogenous variables of the model included in the equation and $Z_{l}=\left[Y_{l}, X_{l}\right]$ is a matrix of explanatory variables of the equation; $\delta_{l}^{\top}=\left(\alpha_{l}^{\top}, \beta_{l}^{\top}\right)$ are the associate coefficients of $Z_{l}$. The $(\cdot)^{\top}$ is the transpose operator of an input matrix.

We assume that the disturbances are generated either by a spatially autoregressive (SAR) process or a spatially moving average (SMA) process,

$$
v_{l}=\Lambda_{l}\left(\rho_{l}\right) \epsilon_{l}= \begin{cases}\rho_{l} W_{l} v_{l}+\epsilon_{l}=\left(I-\rho_{l} W_{l}\right)^{-1} \epsilon_{l} & \text { for SAR } \\ \rho_{l} W_{l} \epsilon_{l}+\epsilon_{l}=\left(I+\rho_{l} W_{l}\right) \epsilon_{l} & \text { for SMA }\end{cases}
$$

In this section, $i=1, \ldots, N$ and $t=1, \ldots, T$; where $N$ denotes the number of individuals and $T$ the number of time periods. We order the observations first by time and then individuals because this grouping is more convenient for modelling spatial correlation via equation (2). $W_{l}=I_{T} \otimes W_{l N}$ with $I_{T}$ being an identity matrix of dimension $T$ and $W_{l N}$ being a $N \times N$ spatial weighting matrix of known constants which does not involve time and is usually row-normalized. For $1 \leq l \leq L$, all diagonal elements of $W_{l N}$ are zero. $\left|\rho_{l}\right|<1$ is a scalar autoregressive parameter, and $\epsilon_{l}$ is a $T N \times 1$ vector of innovations. The motivation behind the double approach in the disturbance comes from the fact that: in SAR error processes, the effect of shock at $\mathrm{j}$ is not the shock itself but the initial shock plus the feedback to other location via the powers of $\mathrm{W}$. In other words, a shock to $\mathrm{j}$ affects the neighbours, and the neighbours of the neighbours, and eventually works its way back to j. In contrast, the MA error process, so that a shock at location $\mathrm{j}$ will only affect the directly interacting locations as given by the non-zero elements in the spatial matrix W. Hence shock-effects are local rather than global.

To allow for the innovations to be correlated over time, we assume the following error component structure for the innovation vector $\epsilon_{l}$,

$$
\epsilon_{l}=Z_{\eta} \eta_{l}+\xi_{l}
$$

where $Z_{\eta}=\iota_{T} \otimes I_{N}, \eta_{l}^{\top}=\left(\begin{array}{lll}\eta_{1 l} & \ldots & \eta_{N l}\end{array}\right)^{\top}$ represents the vector of unit specific error components; and $\xi_{l}^{\top}=\left(\begin{array}{llll}\xi_{11 l} & \xi_{12 l} & \ldots & \eta_{T N l}\end{array}\right)^{\top}$ contains the error components that vary over both the cross-sectional units and time periods; $\iota_{T}$ is a $T \times 1$ vector of ones. Let $\mathrm{E}(\cdot)$

\footnotetext{
${ }^{1}$ If we let $M_{-l}$ the set of right-hand side endogenous variables excluded of the $l$ th, we have $M_{l}+M_{-l}=L$.
} 
represents the expected value of an input random variable. Hence, $\eta_{l}$ and $\xi_{l}$ are centered random vector with covariance matrix,

$$
\mathrm{E}\left(\begin{array}{l}
\eta_{l} \\
\xi_{l}
\end{array}\right)\left(\begin{array}{ll}
\eta_{q}^{\top} & \xi_{q}^{\top}
\end{array}\right)=\left[\begin{array}{cc}
\sigma_{\eta_{l q}}^{2} I_{N} & 0 \\
0 & \sigma_{\xi_{l q}}^{2} I_{T N}
\end{array}\right]
$$

In light of equation (3), the covariance matrix $\Omega_{\epsilon_{l q}}=\mathrm{E}\left(\epsilon_{l} \epsilon_{q}^{\top}\right)$ between the $l$ th and the $q$ th equation is,

$$
\Omega_{\epsilon_{l q}}=\sigma_{\eta_{l q}}^{2}\left(J_{T} \otimes I_{N}\right)+\sigma_{\xi_{l q}}^{2} I_{T N} \quad \text { for } \quad l, q=1, \ldots, L
$$

and its spectral decomposition can be written in compact form as below,

$$
\Omega_{\epsilon_{l q}}=\sum_{h=0}^{1} \sigma_{h_{l q}}^{2} Q_{h} \quad \text { for } \quad l, q=1, \ldots, L
$$

where,

$$
Q_{h}=B_{h} \otimes I_{N},
$$

$B_{h}$ is a square matrix of order $T$ with $B_{0}=E_{T}$ and $B_{l}=\bar{J}_{T} ; \bar{J}_{T}=\iota_{T} \iota_{T}^{\top} / T$ denoting average matrix over time, $E_{T}=I_{T}-\bar{J}_{T}, \sigma_{0_{l q}}^{2}=\sigma_{\xi_{l q}}^{2}$ and $\sigma_{1_{l q}}^{2}=T \sigma_{\eta_{l q}}^{2}+\sigma_{\xi_{l q}}^{2}$. The matrices $Q_{0}$ and $Q_{1}$ are standard transformation matrices utilized in the error component literature, with the appropriate adjustments implied by our adopted ordering of the data; compare, e.g., Baltagi (2008). They are symmetric, idempotent and orthogonal to each other. Furthermore, by letting $\operatorname{tr}(\cdot)$ the trace operator, which returns the sum of the diagonal elements of an input matrix,

$$
Q_{0}+Q_{l}=I_{T N}, \operatorname{tr}\left(Q_{0}\right)=(T-1) N \text { and } \operatorname{tr}\left(Q_{l}\right)=N
$$

and the covariance matrix of $\Omega_{v_{l q}}$ between the $l$ th and the $q$ th equation is,

$$
\begin{aligned}
\Omega_{v_{l q}} & =\Lambda_{l}\left(\rho_{l}\right) \mathrm{E}\left(\epsilon_{l} \epsilon_{q}^{\top}\right) \Lambda_{q}^{\top}\left(\rho_{q}\right) \\
& =\Lambda_{l}\left(\rho_{l}\right)\left(\sigma_{0_{l q}}^{2} Q_{0}+\sigma_{1_{l q}}^{2} Q_{l}\right) \Lambda_{q}^{\top}\left(\rho_{q}\right) \\
& =\sigma_{0_{l q}}^{2} \Lambda_{l}\left(\rho_{l}\right) Q_{0} \Lambda_{q}^{\top}\left(\rho_{q}\right)+\sigma_{1_{l q}}^{2} \Lambda_{l}\left(\rho_{l}\right) Q_{l} \Lambda_{q}^{\top}\left(\rho_{q}\right) \\
& =\sigma_{0_{l q}}^{2} Q_{0} \Lambda_{l}\left(\rho_{l}\right) \Lambda_{q}^{\top}\left(\rho_{q}\right)+\sigma_{1_{l q}}^{2} Q_{l} \Lambda_{l}\left(\rho_{l}\right) \Lambda_{q}^{\top}\left(\rho_{q}\right) \\
& =\sigma_{0_{l q}}^{2} Q_{0} \Lambda_{l q}\left(\rho_{l}, \rho_{q}\right)+\sigma_{1_{l q}}^{2} Q_{l} \Lambda_{l q}\left(\rho_{l}, \rho_{q}\right)
\end{aligned}
$$

where $\Lambda_{l q}\left(\rho_{l}, \rho_{q}\right)=\Lambda_{l}\left(\rho_{l}\right) \Lambda_{q}^{\top}\left(\rho_{q}\right)$ and $\Lambda_{l}\left(\rho_{l}\right)$ non-singular $\forall l$; This comes from the fact that, for SMA process, 


$$
\begin{aligned}
\Lambda_{l}\left(\rho_{l}\right) Q_{h} & =\left(I+\rho_{l} W_{l}\right) Q_{h} \\
& =\left[Q_{h}+\left(I_{T} \otimes W_{l N}\right)\left(B_{h} \otimes I_{N}\right)\right] \\
& =\left[Q_{h}+\left(B_{h} \otimes I_{N}\right)\left(I_{T} \otimes W_{l N}\right)\right] \\
& =Q_{h}\left(I+\rho_{l} W_{l}\right) \\
& =Q_{h} \Lambda_{l}\left(\rho_{l}\right)
\end{aligned}
$$

while for SAR process, since each $\left|\rho_{l}\right|<1$, we have,

$$
\begin{aligned}
\Lambda_{l}\left(\rho_{l}\right) Q_{h} & =\left(I-\rho_{l} W_{l}\right)^{-1} Q_{h} \\
& =\left(I+\rho_{l} W_{l}+\rho_{l}^{2} W_{l}^{2}+\rho_{l}^{3} W_{l}^{3}+\ldots\right) Q_{h} \\
& =\left(Q_{h}+\rho_{l} W_{l} Q_{h}+\rho_{l}^{2} W_{l}^{2} Q_{h}+\rho_{l}^{3} W_{l}^{3} Q_{h}+\ldots\right) \\
& =Q_{h}\left(I+\rho_{l} W_{l}+\rho_{l}^{2} W_{l}^{2}+\rho_{l}^{3} W_{l}^{3}+\ldots\right)=Q_{h}\left(I-\rho_{l} W_{l}\right)^{-1} \\
& =Q_{h} \Lambda_{l}\left(\rho_{l}\right)
\end{aligned}
$$

\subsection{The System}

The system of $L$ equations can be obtained from equation (1), by iterate $l=1, \ldots, L$ and stack these $L$ equations,

$$
y=Z \delta+v
$$

where, $y^{\top}=\left(\begin{array}{lll}y_{1}^{\top} & \cdots & y_{L}^{\top}\end{array}\right), Z=\operatorname{diag}\left(Z_{l}\right), \delta^{\top}=\left(\begin{array}{lll}\delta_{1}^{\top} & \cdots & \delta_{L}^{\top}\end{array}\right)$ and $v^{\top}=\left(\begin{array}{lll}v_{1}^{\top} & \cdots & v_{L}^{\top}\end{array}\right)$ with $Z_{l}=\left[\begin{array}{ll}Y_{l} & X_{l}\end{array}\right]$. By letting, $\operatorname{diag}(\cdot)$ the operator which use an input matrix as a block diagonal element of a block diagonal matrix, the disturbance process of the system can be written as,

$$
v=\Lambda(\rho) \epsilon= \begin{cases}\operatorname{diag}\left(\rho_{l} W_{l}\right) v+\epsilon=\operatorname{diag}\left(I-\rho_{l} W_{l}\right)^{-1} \epsilon & \text { for SAR } \\ \operatorname{diag}\left(\rho_{l} W_{l}\right) \epsilon+\epsilon=\operatorname{diag}\left(I+\rho_{l} W_{l}\right) \epsilon & \text { for SMA }\end{cases}
$$

where $\Lambda(\rho)=\operatorname{diag}\left(\Lambda_{l}\left(\rho_{l}\right)\right), \rho=\left(\rho_{1}, \ldots, \rho_{L}\right)$ and $\epsilon^{\top}=\left(\begin{array}{lll}\epsilon_{1}^{\top} & \cdots & \epsilon_{L}^{\top}\end{array}\right)$; with,

$$
\epsilon=\left(I_{L} \otimes \iota_{T} \otimes I_{N}\right) \eta+\xi=I_{L} \otimes Z_{\eta} \eta+\xi
$$

where $\eta^{\top}=\left(\begin{array}{lll}\eta_{1}^{\top} & \cdots & \eta_{L}^{\top}\end{array}\right)$ and $\xi^{\top}=\left(\begin{array}{lll}\xi_{1}^{\top} & \cdots & \xi_{L}^{\top}\end{array}\right)$.

We note that if the row-standardized spatial matrix $W_{l}$ is common to all equation,i.e., $W_{l}=W$ hence, 


$$
\left(\begin{array}{ccc}
\rho_{1} W & \cdots & 0 \\
\vdots & \ddots & \vdots \\
0 & \cdots & \rho_{L} W
\end{array}\right)=\operatorname{diag}\left(\rho_{l}\right) \otimes W=\rho \otimes W
$$

The covariance matrix of innovations for the system $\Omega_{\epsilon}$ is,

$$
\Omega_{\epsilon}=\left(\Omega_{\epsilon_{l q}}\right)=\left(\sigma_{0_{l q}}^{2}\right) \otimes Q_{0}+\left(\sigma_{1_{l q}}^{2}\right) \otimes Q_{1}=\Omega_{0} \otimes Q_{0}+\Omega_{1} \otimes Q_{1}
$$

with $\Omega_{1}=\left(\sigma_{1_{l q}}^{2}\right)$ and $\Omega_{0}=\left(\sigma_{0_{l q}}^{2}\right)$. Using equation (8) the covariance matrix of the disturbance $v$ can be written as follow,

$$
\Omega_{v}=\Lambda(\rho) \Omega_{\epsilon} \Lambda(\rho)^{\top}=\Lambda(\rho)\left(\Omega_{0} \otimes Q_{0}\right) \Lambda(\rho)^{\top}+\Lambda(\rho)\left(\Omega_{1} \otimes Q_{1}\right) \Lambda(\rho)^{\top}
$$

\section{The Simultaneous Moment Equations}

\subsection{Notation}

For notation convenience, let

$$
\bar{\epsilon}_{l}=W^{a} \epsilon_{l}
$$

this means that $\frac{0}{\bar{\epsilon}_{l}}=W^{0} \epsilon_{l}=\epsilon_{l}, \frac{1}{\bar{\epsilon}_{l}}=W \epsilon=\bar{\epsilon}_{l}$ and $\frac{2}{\bar{\epsilon}_{l}}=W^{2} \epsilon_{l}=\overline{\bar{\epsilon}}_{l}$. Such that $Q_{h} \mathrm{E}\left(\epsilon_{l} \epsilon_{q}^{\top}\right)=$ $Q_{h} \Omega_{\epsilon_{l q}}=\sigma_{h_{l q}}^{2} Q_{h}$, we have the following general relation,

$$
\begin{aligned}
\mathrm{E}\left(\bar{\epsilon}_{q}^{\top} Q_{h} \frac{b}{\epsilon_{l}}\right) & =\mathrm{E}(\epsilon_{q}^{\top} \underbrace{W_{q}^{\top} \ldots W_{q}^{\top}}_{a \text { times }} Q_{h} \underbrace{W_{l} \ldots W_{l}}_{b \text { times }} \epsilon_{l}) \\
& =\mathrm{E}\left(\epsilon_{q}^{\top} W_{q}^{\top a} Q_{h} W_{l}^{b} \epsilon_{l}\right) \\
& =\operatorname{tr}\left(\left(W_{q}^{\top a}\right) W_{l}^{b} Q_{h} \Omega_{\epsilon_{l q}}\right) \\
& =\sigma_{h_{l q}}^{2} \operatorname{tr}\left(B_{h}\right) \operatorname{tr}\left(\left(W_{l N}^{\top}\right)^{a} W_{l N}^{b}\right)
\end{aligned}
$$

with $\operatorname{tr}\left(W_{l N}^{0}\right)=\operatorname{tr}\left(I_{N}\right)=N$ and $\operatorname{tr}\left(W_{l N}\right)=0$;

\subsection{SAR case}

Recently, a number of approaches have been outlined to estimate the coefficients in a spatial error model as an application of general principles underlying the method of moments. Kele- 
jian and Prucha (1998) develop a set of moment conditions that yield estimation equations for the parameter of an SAR error model. We follow and adapt the moments conditions in simultaneous equations case. For spatial autoregressive process, the general form of the six moment conditions can be derived as follow:

$$
\begin{aligned}
& \mathrm{E}\left(\epsilon_{q}^{\top} Q_{h} \epsilon_{l}\right)=\sigma_{h_{l q}}^{2} \operatorname{tr}\left(Q_{h}\right) \\
& \mathrm{E}\left(\bar{\epsilon}_{q}^{\top} Q_{h} \bar{\epsilon}_{l}\right)=\sigma_{h_{l q}}^{2} \operatorname{tr}\left(B_{h}\right) \operatorname{tr}\left(W_{l N} W_{q N}^{\top}\right) \\
& \mathrm{E}\left(\bar{\epsilon}_{q}^{\top} Q_{h} \epsilon_{l}\right)=\sigma_{h_{l q}}^{2} \operatorname{tr}\left(B_{h}\right) \operatorname{tr}\left(W_{l N}\right)=0
\end{aligned}
$$

which lead to general system for $T \geq 2$

$$
\begin{aligned}
& \mathrm{E}\left[\frac{\epsilon_{q}^{\top} Q_{h} \epsilon_{l}}{\operatorname{tr}\left(Q_{h}\right)}\right]=\sigma_{h_{l q}}^{2} \\
& \mathrm{E}\left[\frac{\bar{\epsilon}_{q}^{\top} Q_{h} \bar{\epsilon}_{l}}{\operatorname{tr}\left(Q_{h}\right)}\right]=\sigma_{h_{l q}}^{2} \frac{\operatorname{tr}\left(W_{l N} W_{q N}^{\top}\right)}{N} \\
& \mathrm{E}\left[\frac{\epsilon_{q}^{\top} Q_{h} \bar{\epsilon}_{l}}{\operatorname{tr}\left(Q_{h}\right)}\right]=0
\end{aligned}
$$

To get each equation, one should replace each notation by its corresponding form (see Kapoor et al., 2007, for more details). Our three GMM estimators of $\rho_{l}, \sigma_{0_{l q}}^{2}$ and $\sigma_{l_{l q}}^{2}$ are based on these moment relationships. If $\epsilon_{l}$ were observed, then $\epsilon_{q}^{\top} Q_{h} \epsilon_{l} / \operatorname{tr}\left(Q_{h}\right)$ represents the (unbiased) analysis of variance estimators of $\sigma_{h_{l q}}^{2}$.

Starting with,

$$
v_{l}=\left(I-\rho_{l} W_{l}\right)^{-1} \epsilon_{l} \Longrightarrow\left\{\begin{array}{l}
\epsilon_{l}=v_{l}-\rho_{l} \bar{v}_{l} \\
\bar{\epsilon}_{l}=\bar{v}_{l}-\rho_{l} \overline{\bar{v}}_{l}
\end{array}\right.
$$

and substituting these expressions for $\epsilon_{l}$ and $\bar{\epsilon}_{l}$ into equations (13) to (15), we obtain the general form of system of three equations,

$$
\left\{\begin{aligned}
\epsilon_{q}^{\top} Q_{h} \epsilon_{l} & =\left(v_{q}^{\top} Q_{h} v_{l}\right)-\rho_{l}\left(v_{q}^{\top} Q_{h} \bar{v}_{l}\right)-\rho_{q}\left(\bar{v}_{q}^{\top} Q_{h} v_{l}\right)+\rho_{l} \rho_{q}\left(\bar{v}_{q}^{\top} Q_{h} \bar{v}_{l}\right) \\
\bar{\epsilon}_{q}^{\top} Q_{h} \bar{\epsilon}_{l} & =\left(\bar{v}_{q}^{\top} Q_{h} \bar{v}_{l}\right)-\rho_{l}\left(\bar{v}_{q}^{\top} Q_{h} \overline{\bar{v}}_{l}\right)-\rho_{q}\left(\overline{\bar{v}}_{q}^{\top} Q_{h} \bar{v}_{l}\right)+\rho_{l} \rho_{q}\left(\overline{\bar{v}}_{q}^{\top} Q_{h} \overline{\bar{v}}_{l}\right) \\
\epsilon_{q}^{\top} Q_{h} \bar{\epsilon}_{l} & =\left(v_{q}^{\top} Q_{h} \bar{v}_{l}\right)-\rho_{l}\left(v_{q}^{\top} Q_{h} \overline{\bar{v}}_{l}\right)-\rho_{q}\left(\bar{v}_{q}^{\top} Q_{h} \bar{v}_{l}\right)+\rho_{l} \rho_{q}\left(\bar{v}_{q}^{\top} Q_{h} \overline{\bar{v}}_{l}\right)
\end{aligned}\right.
$$

Hence the six equations can be easily obtained by simply iterate $h=0,1$ on system (17). This system involves $\rho_{l}, \rho_{q}$ and $\sigma_{h_{l q}}^{2}$ and can be expressed as,

$$
\Gamma^{l q, h} \Xi^{l q, h}-\Theta^{l q, h}=0
$$

where 


$$
\Gamma^{l q, h}=\left[\begin{array}{cccc}
\gamma_{01}^{l q, h} & \gamma_{10}^{l q, h} & -\gamma_{11}^{l q, h} & 1 \\
\gamma_{12, h}^{l q, h} & \gamma_{21}^{l q, h} & -\gamma_{22}^{l q, h} & \phi^{l q} \\
\gamma_{02}^{l q, h} & \gamma_{11}^{l q, h} & -\gamma_{21}^{l q, h} & 0
\end{array}\right] \quad \Theta^{l q, h}=\left[\begin{array}{c}
\gamma_{00}^{l q, h} \\
\gamma_{11}^{l q, h} \\
\gamma_{01}^{l q, h}
\end{array}\right] \quad \Xi^{l q, h}=\left(\begin{array}{c}
\rho_{l} \\
\rho_{q} \\
\rho_{l} \rho_{q} \\
\sigma_{h_{l q}}^{2}
\end{array}\right)
$$

where the elements of the matrices $\gamma_{a b}^{l q, h}$ and $\phi^{l q}$ have the following form,

$$
\gamma_{a b}^{l q, h}=\frac{\bar{v}_{q}^{\top} Q_{h} \bar{v}_{l}}{\operatorname{tr}\left(Q_{h}\right)}, \quad \phi^{l q}=\frac{\operatorname{tr}\left(W_{q N}^{\top} W_{l N}\right)}{N} .
$$

The system (18) is non-linear and overidentified due to the presence of the product $\rho_{l} \rho_{q}$. However, the overidentification can be resolve by focusing on each equation. Indeed, for the $l$ th specified equation we have $\gamma_{a b}^{l q, h}=\gamma_{a b}^{l, h}, \phi^{l q}=\phi^{l}$ and $\rho_{l}=\rho_{q}$. Now system (18) becomes,

$$
\Gamma^{l, h} \Xi^{l, h}-\Theta^{l, h}=0
$$

where,

$$
\Gamma^{l, h}=\left[\begin{array}{ccc}
2 \gamma_{01}^{l, h} & -\gamma_{11}^{l, h} & 1 \\
2 \gamma_{12}^{l, h} & -\gamma_{22}^{l, h} & \phi^{l} \\
\left(\gamma_{02}^{l, h}+\gamma_{11}^{l, h}\right) & -\gamma_{21}^{l, h} & 0
\end{array}\right] \quad \Theta^{l, h}=\left[\begin{array}{c}
\gamma_{00}^{l, h} \\
\gamma_{11}^{l, h} \\
\gamma_{01}^{l, h}
\end{array}\right] \quad \Xi^{l, h}=\left(\begin{array}{c}
\rho_{l} \\
\rho_{l}^{2} \\
\sigma_{h l l}^{2}
\end{array}\right)
$$

where the elements of the matrices $\gamma_{a b}^{l, h}$ and $\phi^{l q}$ have the following form,

$$
\gamma_{a b}^{l, h}=\frac{\bar{v}_{l}^{\top} Q_{h} \bar{v}_{l}}{\operatorname{tr}\left(Q_{h}\right)}, \quad \phi^{l}=\frac{\operatorname{tr}\left(W_{l N}^{\top} W_{l N}\right)}{N} .
$$

\subsection{SMA case}

If the disturbance is generate as spatial moving average process we have,

$$
v_{l}=\left(I+\rho_{l} W_{l}\right) \epsilon_{l} \Longrightarrow\left\{\begin{array}{l}
v_{l}=\epsilon_{l}+\rho_{l} \bar{\epsilon}_{l} \\
\bar{v}_{l}=\bar{\epsilon}_{l}+\rho_{l} \overline{\bar{\epsilon}}_{l}
\end{array}\right.
$$


then,

$$
\begin{aligned}
& v_{q}^{\top} Q_{h} v_{l}=\epsilon_{q}^{\top} Q_{h} \epsilon_{l}+\rho_{l}\left(\epsilon_{q}^{\top} Q_{h} \bar{\epsilon}_{l}\right)+\rho_{q}\left(\bar{\epsilon}_{q}^{\top} Q_{h} \epsilon_{l}\right)+\rho_{l} \rho_{q}\left(\bar{\epsilon}_{q}^{\top} Q_{h} \bar{\epsilon}_{l}\right) \\
& \bar{v}_{q}^{\top} Q_{h} \bar{v}_{l}=\bar{\epsilon}_{q}^{\top} Q_{h} \bar{\epsilon}_{l}+\rho_{l}\left(\bar{\epsilon}_{q}^{\top} Q_{h} \overline{\bar{\epsilon}}_{l}\right)+\rho_{q}\left(\overline{\bar{\epsilon}}_{q}^{\top} Q_{h} \bar{\epsilon}_{l}\right)+\rho_{l} \rho_{q}\left(\overline{\bar{\epsilon}}_{q}^{\top} Q_{h} \overline{\bar{\epsilon}}_{l}\right) \\
& v_{q}^{\top} Q_{h} \bar{v}_{l}=\epsilon_{q}^{\top} Q_{h} \bar{\epsilon}_{l}+\rho_{l}\left(\bar{\epsilon}_{q}^{\top} Q_{h} \bar{\epsilon}_{l}\right)+\rho_{q}\left(\epsilon_{q}^{\top} Q_{h} \overline{\bar{\epsilon}}_{l}\right)+\rho_{l} \rho_{q}\left(\bar{\epsilon}_{q}^{\top} Q_{h} \overline{\bar{\epsilon}}_{l}\right)
\end{aligned}
$$

to obtain the expectation of each equation of system (20), we use relation (12)

$\mathrm{E}\left(v_{q}^{\top} Q_{h} v_{l}\right)=\sigma_{h_{l q}}^{2} \operatorname{tr}\left(B_{h}\right)\left\{N+\rho_{l} \operatorname{tr}\left(W_{l N}\right)+\rho_{q} \operatorname{tr}\left(W_{l N}\right)+\rho_{l} \rho_{q} \operatorname{tr}\left(W_{q N}^{\top} W_{l N}\right)\right\}$

$\mathrm{E}\left(\bar{v}_{q}^{\top} Q_{h} \bar{v}_{l}\right)=\sigma_{h_{l q}}^{2} \operatorname{tr}\left(B_{h}\right)\left\{\operatorname{tr}\left(W_{q N}^{\top} W_{l N}\right)+\rho_{l} \operatorname{tr}\left(W_{q N}^{\top} W_{1 N}^{2}\right)+\rho_{q} \operatorname{tr}\left(W_{q N}^{\top 2} W_{l N}\right)+\rho_{l} \rho_{q} \operatorname{tr}\left(W_{q N}^{\top 2} W_{1 N}^{2}\right)\right\}$

$\mathrm{E}\left(v_{q}^{\top} Q_{h} \bar{v}_{l}\right)=\sigma_{h_{l q}}^{2} \operatorname{tr}\left(B_{h}\right)\left\{\operatorname{tr}\left(W_{l N}\right)+\rho_{l} \operatorname{tr}\left(W_{l N}^{2}\right)+\rho_{q} \operatorname{tr}\left(W_{q N}^{\top} W_{l N}\right)+\rho_{l} \rho_{q} \operatorname{tr}\left(W_{q N}^{\top} W_{l N}^{2}\right)\right\}$

which lead to

$\mathrm{E}\left(\frac{v_{q}^{\top} Q_{h} v_{l}}{\operatorname{tr}\left(Q_{h}\right)}\right)=\sigma_{h_{l q}}^{2}\left[1+\rho_{l} \rho_{q} \frac{\operatorname{tr}\left(W_{q N}^{\top} W_{l N}\right)}{N}\right]$

$\mathrm{E}\left(\frac{\bar{v}_{q}^{\top} Q_{h} \bar{v}_{l}}{\operatorname{tr}\left(Q_{h}\right)}\right)=\sigma_{h_{l q}}^{2}\left[\frac{\operatorname{tr}\left(W_{q N}^{\top} W_{l N}\right)}{N}+\rho_{l} \frac{\operatorname{tr}\left(W_{q N}^{\top} W_{1 N}^{2}\right)}{N}+\rho_{q} \frac{\operatorname{tr}\left(W_{q N}^{\top 2} W_{l N}\right)}{N}+\rho_{l} \rho_{q} \frac{\operatorname{tr}\left(W_{q N}^{\top 2} W_{1 N}^{2}\right)}{N}\right]$

$\mathrm{E}\left(\frac{v_{q}^{\top} Q_{h} \bar{v}_{l}}{\operatorname{tr}\left(Q_{h}\right)}\right)=\sigma_{h_{l q}}^{2}\left[\rho_{l} \frac{\operatorname{tr}\left(W_{l N}^{2}\right)}{N}+\rho_{q} \frac{\operatorname{tr}\left(W_{q N}^{\top} W_{l N}\right)}{N}+\rho_{l} \frac{\operatorname{tr}\left(W_{q N}^{\top} W_{l N}^{2}\right)}{N}\right]$

Ignoring the expectations, and put these equations together using the $3 \times 3$ matrix $\Gamma^{l q, h}$, the $3 \times 1$ vector $\Theta^{l q, h}$ and by letting

$$
\phi_{a b}^{l q}=\frac{\operatorname{tr}\left(W_{q N}^{\top a} W_{l N}^{b}\right)}{N}, \quad \gamma_{a b}^{l q, h}=\frac{\frac{a}{v}_{q}^{\top} Q_{h} \bar{v}_{l}}{\operatorname{tr}\left(Q_{h}\right)} .
$$

so that,

$$
\Gamma^{l q} \Xi^{l q, h}-\Theta^{l q, h}=0
$$

where

$$
\Gamma^{l q, h}=\left[\begin{array}{cccc}
1 & 0 & 0 & \phi_{11}^{l q} \\
\phi_{11}^{l q} & \phi_{12}^{l q} & \phi_{21}^{l q} & \phi_{22}^{l q} \\
0 & \phi_{02}^{l q} & \phi_{11}^{l q} & \phi_{12}^{l q}
\end{array}\right], \quad \Theta^{l q, h}=\left[\begin{array}{c}
\gamma_{00}^{l q, h} \\
\gamma_{11}^{l q, h} \\
\gamma_{01}^{l q, h}
\end{array}\right] \quad \Xi^{l q, h}=\sigma_{h_{l q}}^{2}\left(\begin{array}{c}
1 \\
\rho_{l} \\
\rho_{q} \\
\rho_{l} \rho_{q}
\end{array}\right)
$$

As in SAR case, the SMA moment system (24) is non-linear and overidentified due to the presence of the product $\rho_{l} \rho_{q}$. the overidentification can be resolve by focusing on each 
equation. Hence, for the $l$ th specified equation we have $\phi_{a b}^{l q}=\phi_{a b}^{l}, \gamma_{a b}^{l q, h}=\gamma_{a b}^{l, h}$ and $\rho_{l}=\rho_{q}$. Now system (18) becomes,

$$
\Gamma^{l q} \Xi^{l q, h}-\Theta^{l q, h}=0
$$

where

$$
\Gamma^{l, h}=\left[\begin{array}{ccc}
1 & 0 & \phi_{11}^{l} \\
\phi_{11}^{l} & 2 \phi_{12}^{l} & \phi_{22}^{l} \\
0 & \left(\phi_{02}^{l}+\phi_{11}^{l}\right) & \phi_{12}^{l}
\end{array}\right], \quad \Theta^{l, h}=\left[\begin{array}{c}
\gamma_{00}^{l, h} \\
\gamma_{11}^{l, h} \\
\gamma_{01}^{l, h}
\end{array}\right] \quad \Xi^{l, h}=\sigma_{h_{l l}}^{2}\left(\begin{array}{c}
1 \\
\rho_{l} \\
\rho_{l}^{2}
\end{array}\right)
$$

Now,

$$
\phi_{a b}^{l}=\frac{\operatorname{tr}\left(W_{l N}^{\top a} W_{l N}^{b}\right)}{N}, \quad \gamma_{a b}^{l, h}=\frac{\frac{a}{v}_{l}^{\top} Q_{h} \bar{v}_{l}}{\operatorname{tr}\left(Q_{h}\right)} .
$$

\section{The Estimators}

\subsection{The GM-IV-S2SLS Estimator}

To obtain the limited Information Estimator of $\delta_{l}$, we follow this three-stage procedure:

1. In first stage, because of simultaneity problem, equation (1) is estimate using 2SLS approach based on the matrix of instruments X. Thus, the 2SLS estimator of $\delta_{l}$ is defined as,

$$
\hat{\delta}_{l, 2 S L S}=\left(Z_{l}^{\top} P_{X} Z_{l}\right)^{-1}\left(Z_{l}^{\top} P_{X} y_{l}\right)
$$

where $P_{X}=X\left(X^{\top} X\right)^{-1} X^{\top}$

2. In the second stage, the parameters $\rho_{l}, \sigma_{0_{l l}}^{2}$ and $\sigma_{1_{l l}}^{2}$ are estimated using GM approach from the corresponding sub-section of 3 based on 2SLS residuals, i.e. $\hat{v}_{l}=y_{l}-Z_{l} \hat{\delta}_{l, 2 S L S}$. The GM estimates are obtained from the sample counterpart of the reduced system (19) or (25) which is,

$$
e\left(\rho_{l}, \sigma_{h_{l l}}^{2}\right)=\left\{\begin{array}{l}
\hat{\Gamma}^{l, h} \Xi^{l, h}-\hat{\Theta}^{l, h} \quad \text { for SAR } \\
\hat{\Gamma}^{l} \Xi^{l, h}-\hat{\Theta}^{l, h} \quad \text { for SMA }
\end{array}\right.
$$

where,

$$
\Xi^{l, h}= \begin{cases}\Xi_{S A R}^{l, h}=\left(\begin{array}{lll}
\rho_{l} & \rho_{l}^{2} & \sigma_{h_{l l}}^{2}
\end{array}\right)^{\top} & \text { for SAR } \\
\Xi_{S M A}^{l, h}=\left(\begin{array}{lll}
\sigma_{h_{l l}}^{2} & \rho_{l} \sigma_{h_{l l}}^{2} & \rho_{l}^{2} \sigma_{h_{l l}}^{2}
\end{array}\right)^{\top} & \text { for SMA }\end{cases}
$$

and $e\left(\rho_{l}, \sigma_{h_{l l}}^{2}\right)$ is a vector of residuals. The unweighted GM estimators of $\rho_{l}$ and $\sigma_{h_{l l}}^{2}$ are the nonlinear least squares estimators based on (27),

$$
\left(\hat{\rho}_{1}, \hat{\sigma}_{h_{11}}^{2}\right)=\arg \min \left\{e\left(\rho_{l}, \sigma_{h_{l l}}^{2}\right)^{\top} e\left(\rho_{1}, \sigma_{h_{11}}^{2}\right)\right\}
$$

In practice, we only use the first three moments which do not involve $\sigma_{1_{l l}}^{2}$ and yield estimates 
of $\rho_{l}$ and $\sigma_{0_{l l}}^{2}$. The fourth moment condition is then used to solve for $\sigma_{1_{l l}}^{2}$ given estimates of $\rho_{l}$ and $\sigma_{0_{l l}}^{2}$ as,

$$
\sigma_{1_{l l}}^{2}=\left\{\begin{array}{l}
\sigma_{1_{S A R}}^{2}=\hat{\gamma}_{00}^{l, 1}-2 \rho_{l} \hat{\gamma}_{01}^{l, 1}+\rho_{l}^{2} \hat{\gamma}_{11}^{l, 1} \\
\sigma_{1_{S M A}}^{2}=\hat{\gamma}_{00}^{l, 1}\left(1+\rho_{l}^{2} \phi_{11}^{l}\right)^{-1}
\end{array}\right.
$$

with,

$$
\phi_{a b}^{l}=\frac{\operatorname{tr}\left(W_{l N}^{\top a} W_{l N}^{b}\right)}{N} \text { and } \hat{\gamma}_{a b}^{l, 1}=\frac{a_{\hat{\bar{v}}_{l}^{\top}}^{\top} Q_{1} \hat{\overline{\hat{v}}}_{l}^{b}}{\operatorname{tr}\left(Q_{1}\right)}
$$

1. In the third stage, using GM estimates of $\rho_{l}, \sigma_{0_{l l}}^{2}$ and $\sigma_{1_{l l}}^{2}$, one calculates the estimated spatial function $\Lambda_{l}\left(\rho_{l}\right)$ and then, the estimated variance-covariance matrix of $\Omega_{v_{l l}}$ as,

$$
\hat{\Omega}_{v_{l l}}=\hat{\sigma}_{0_{l l}}^{2} Q_{0} \Lambda_{l l}\left(\hat{\rho}_{l}\right)+\hat{\sigma}_{1_{l l}}^{2} Q_{l} \Lambda_{l l}\left(\hat{\rho}_{l}\right)
$$

such that $\Lambda_{l l}\left(\hat{\rho}_{l}\right)=\Lambda_{l}\left(\hat{\rho}_{l}\right) \Lambda_{l}^{\top}\left(\hat{\rho}_{l}\right)$ and,

$$
\Lambda_{l}\left(\hat{\rho}_{l}\right)= \begin{cases}\left(I-\hat{\rho}_{l} W_{l}\right)^{-1} & \text { for SAR } \\ \left(I+\hat{\rho}_{l} W_{l}\right) & \text { for SMA }\end{cases}
$$

Now, premultiply equation (1) by $\Sigma_{v_{l l}}^{-1 / 2}=\sigma_{0_{l l}} \Omega_{v_{l l}}^{-1 / 2}$ and apply 2SLS on the transformed equation using $X_{l}^{\star}=\Sigma_{v_{l l}}^{-1 / 2} X$ as a set of instruments gives the Feasible Generalized Moment IV S2SLS estimator of $\delta_{l}$,

$$
\begin{aligned}
\hat{\delta}_{l, F G M-I V-S 2 S L S} & =\left(\hat{Z}_{l}^{\star \top} P_{\hat{X}_{l}^{\star}} \hat{Z}_{l}^{\star}\right)^{-1}\left(\hat{Z}_{l}^{\star \top} P_{\hat{X}_{l}^{\star}} \hat{y}_{l}^{\star}\right) \\
& =\left[Z_{l}^{\top} \Sigma_{v_{l l}}^{-1} X\left(X^{\top} \Sigma_{v_{l l}}^{-1} X\right)^{-1} X^{\top} \Sigma_{v_{l l}}^{-1} Z_{l}\right]^{-1} \\
& \times\left[Z_{l}^{\top} \Sigma_{v_{l l}}^{-1} X\left(X^{\top} \Sigma_{v_{l l}}^{-1} X\right)^{-1} X^{\top} \Sigma_{v_{l l}}^{-1} y_{l}\right]
\end{aligned}
$$

with

$$
\hat{Z}_{l}^{\star}=\hat{\Sigma}_{v_{l l}}^{-1 / 2} Z_{l}, \quad \hat{y}_{l}^{\star}=\hat{\Sigma}_{v_{l l}}^{-1 / 2} y_{l}, \hat{X}_{l}^{\star}=\hat{\Sigma}_{v_{l l}}^{-1 / 2} X \text { and } P_{X^{\star}}=X^{\star}\left(X^{\star \top} X^{\star}\right)^{-1} X^{\star \top}
$$

The estimated variance-covariance matrix of the parameters is given by,

$$
\begin{aligned}
\operatorname{var}\left(\hat{\delta}_{l, F G M-I V-S 2 S L S}\right) & =\sigma_{0_{l l}}^{2}\left(\hat{Z}_{l}^{\star \top} P_{\hat{X}^{\star}} \hat{Z}_{l}^{\star}\right)^{-1} \\
& =\sigma_{0_{l l}}^{2}\left[Z_{l}^{\top} \Sigma_{v_{l l}}^{-1} X\left(X^{\top} \Sigma_{v_{l l}}^{-1} X\right)^{-1} X^{\top} \Sigma_{v_{l l}}^{-1} Z_{l}\right]^{-1}
\end{aligned}
$$

After the third step, we can improve the quality of the variance components by iterate theses steps. This means that, results of FGM-IV-S2SLS are used in simultaneous GM procedure to re-estimate parameters. We used this technique in our Monte Carlo to compare how much gain in efficiency we have. 


\subsection{The GM-IV-S3SLS Estimator}

The single equation estimation described in the previous section provides consistent estimators in the presence of a spatially autocorrelated error. But like all single equation estimators, this GM-IV-S2SLS estimator ignores the cross equation correlation between $v_{l}$ and $v_{q}$, and the information content of the full system of simultaneous equations. This is bound to result in loss of efficiency.

This section focuses on GM-IV-3SLS estimation which utilizes the correlation across equations and should lead to gains in efficiency over its 2SLS counterpart. Of course, this system estimation has to handle the spatial autocorrelation structure, the presence of right handside endogenous variables as well as individual random effect.

So, to obtain the Full Information Estimator of $\delta$, we follow this five-stage procedure:

1. In first stage equation (1) is estimate using 2 SLS approach based on the matrix of instrument X to obtain the 2SLS estimator of each $\hat{\delta}_{l, 2 S L S}$ defined as in equation (26).

2. In second stage, the parameters $\rho_{l}, \sigma_{h_{l l}}^{2}$ of each equation and their interaction $\sigma_{h_{l q}}^{2}$ are estimated using GM approach from the corresponding sub-section of 3 based on 2SLS residuals, i.e. $\hat{v}_{l}=y_{l}-Z_{l} \hat{\delta}_{l, 2 S L S}$. Let's note theses unweighted GM estimates as $\hat{\rho}_{l}, \hat{\sigma}_{h_{l l}}^{2}$ and $\hat{\sigma}_{h_{l q}}^{2}$. In fact, $\hat{\rho}_{l}, \hat{\sigma}_{0_{l l}}^{2}$ and $\hat{\sigma}_{1_{l l}}^{2}$ are estimated as in equation (28) and (29) while the $l q$-components $\hat{\sigma}_{h_{l q}}^{2}$ are obtained from the first and the fourth simultaneous moment condition of the reduced system (18) or (24) which is defined as,

$$
\sigma_{h_{l q}}^{2}=\left\{\begin{array}{l}
\sigma_{h_{l q, S A R}}^{2}=\hat{\gamma}_{00}^{l q, h}-\rho_{l} \hat{\gamma}_{01}^{l q, h}-\rho_{q} \hat{\gamma}_{10}^{l q, h}+\rho_{l} \rho_{q} \hat{\gamma}_{11}^{l q, h} \\
\sigma_{h_{l q, S M A}}^{2}=\hat{\gamma}_{00}^{l q, h}\left(1+\rho_{l} \rho_{q} \phi_{11}^{l q}\right)^{-1}
\end{array}\right.
$$

with,

$$
\phi_{a b}^{l q}=\frac{\operatorname{tr}\left(W_{q N}^{\top a} W_{l N}^{b}\right)}{N} \text { and } \hat{\gamma}_{a b}^{l q, h}=\frac{{ }_{\hat{\bar{v}}_{q}^{\top}} Q_{h} \hat{\bar{v}}_{l}}{\operatorname{tr}\left(Q_{h}\right)}
$$

3. In third stage, equation (7) is estimate using 3SLS approach based on the matrix of instruments $I_{L} \otimes X$ and the estimated variance-covariance matrix of the system $\hat{\Omega}_{\epsilon}$ (see equation (11)). Thus, the 3SLS estimator of $\delta$ is therefore defined as,

$$
\tilde{\delta}_{3 S L S}=\left(Z^{\top}\left(\hat{\Omega}_{\epsilon}^{-1} \otimes P_{X}\right) Z\right)^{-1}\left(Z^{\top}\left(\hat{\Omega}_{\epsilon}^{-1} \otimes P_{X}\right) y\right)
$$

where $P_{X}=X\left(X^{\top} X\right)^{-1} X^{\top}$

4. In fourth stage, the parameters $\rho_{l}, \sigma_{h_{l l}}^{2}$ of each equation and their interaction $\sigma_{h_{l q}}^{2}$ are re-estimated using GM approach from the corresponding sub-section of 3 based on 3SLS residuals, i.e. $\tilde{v}_{l}=y_{l}-Z_{l} \tilde{\delta}_{l, 3 S L S}$. We note theses unweighted GM estimates as $\tilde{\rho}_{l}, \tilde{\sigma}_{h_{l l}}^{2}$ and $\tilde{\sigma}_{h_{l q}}^{2}$.

5. In the fith stage, using GM estimates $\tilde{\rho}_{l}, \tilde{\sigma}_{h_{l l}}^{2}$ and $\tilde{\sigma}_{h_{l q}}^{2}$, one calculates the estimated spatial function $\Lambda(\tilde{\rho})$ and then, the estimated variance-covariance matrix of $\tilde{\Omega}_{v}$ as,

$$
\tilde{\Omega}_{v}=\Lambda(\tilde{\rho})\left(\tilde{\Omega}_{0} \otimes Q_{0}\right) \Lambda(\tilde{\rho})^{\top}+\Lambda(\tilde{\rho})\left(\tilde{\Omega}_{1} \otimes Q_{1}\right) \Lambda(\tilde{\rho})^{\top}
$$


such that $\Lambda(\tilde{\rho})=\operatorname{diag}\left(\Lambda_{l}\left(\tilde{\rho}_{l}\right)\right)$ and $\Lambda_{l}\left(\tilde{\rho}_{l}\right)$ defined as in equation (31). Now, premultiply equation (7) by $\Omega_{v}^{-1 / 2}$ and apply 3SLS on the transformed equation using $\Omega_{v}^{-1 / 2}\left(I_{L} \otimes X\right)$ as a set of instruments gives the Feasible Generalized Moment IV 3SLS estimator of $\delta$,

$$
\tilde{\delta}_{F G M-I V-3 S L S}=\left(\tilde{Z}^{\star \top} P_{\tilde{X}^{\star}} \tilde{Z}^{\star}\right)^{-1}\left(\tilde{Z}^{\star \top} P_{\tilde{X}} \tilde{y}^{\star}\right)
$$

with

$$
\tilde{Z}^{\star}=\tilde{\Omega}_{v_{l l}}^{-1 / 2} Z, \quad \tilde{y}_{l}^{\star}=\tilde{\Omega}_{v_{l l}}^{-1 / 2} y, \tilde{X}^{\star}=\tilde{\Omega}_{v}^{-1 / 2}\left(I_{L} \otimes X\right) \text { and } P_{X^{\star}}=X^{\star}\left(X^{\star \top} X^{\star}\right)^{-1} X^{\star \top}
$$

The estimated variance-covariance matrix of the parameters is given by the inverted of the right-hand side.

\section{Simulations}

\section{$5.1 \quad$ Design of sampling}

The purposes of our Monte Carlo experiment are threefolds: Firstly, we study the small sample behavior of our proposed estimators that can handle endogeneity, spatial error correlation and random individual effects in function of spatial coefficient, spatial matrix, variance covariance of specific component and the increase of time. These estimators are compared with those that may ignore one or more of these symptoms. For example, OLS ignores all these symptoms, while EC-2SLS only ignore spatial error correlation. Secondly, we also investigate the gain in efficiency; for example when we move from usual one way to spatial one way estimator. Also, when we move from spatial two stage that does not take into account simultaneity, to spatial three stage least squares. Thirdly, we study the sample properties of the spatial component $\rho_{l}$, which is necessary to get $\sigma_{h_{l q}}^{2}$ and our spatial estimators. We note that, the estimations of $\rho_{l}, \sigma_{h_{l l}}^{2}$ are done on each equation $l$; and we use four (04) values of $\rho_{l}$ namely, $-0.8,-0.4,0.4$ and 0.8 . Hence, we can write the linear simultaneous equation model in equation (1) as,

$$
\Gamma y_{i t}+\Lambda x_{i t}=v_{i t}
$$

Here $y_{i t}, x_{i t}$ and $v_{i t}$ are column vectors of dimensions 2, 4 and 2 respectively. We simplify the Monte Carlo design by using the same weight matrix $W$ in both equations. The disturbance $v_{i t l}, l=1,2$, for each equation has the following form,

$$
v_{i t l}=\left(I-\rho_{l} W\right)^{-1} \epsilon_{l}
$$

where $\epsilon_{i t l}=\eta_{i l}+\xi_{i t l} . \Gamma$ is a $2 \times 2$ matrix of coefficients of current endogenous variables and $\Lambda$ is a $2 \times 4$ matrix coefficients of predetermined variables,

$$
\Gamma=\left(\begin{array}{cc}
1 & 0.5 \\
4 & 1
\end{array}\right), \quad \Lambda=\left(\begin{array}{cccc}
2 & -1.5 & 0 & 0 \\
0 & 0 & 3 & -1.8
\end{array}\right)
$$


There are four exogenous variables $X_{11}, X_{12}, X_{21}$ and $X_{22}$ in the system, two for each equation. The data generating process for the exogenous variables follows the approach used in Baltagi et al. (2013),

$$
x_{p, i t}=\zeta_{p, i}+z_{p, i t} \quad p=11,12,21,22
$$

where $\zeta_{p, i} \rightsquigarrow i i d U[-10,10]$, and $z_{p, i t} \rightsquigarrow i i d U[-5,5]$. We follow two steps to generate the error terms. First, we generate $2(N+N T)$ independent $\mathcal{N}(0,1)$ random numbers. For each equation, the first $2 \mathrm{~N}$ are used for generating first cross section specific effects and the remaining $2 N T$ are used to generate the idiosyncratic errors.

Second, we transform these $\mathcal{N}(0,1)$ disturbances to obtain the appropriate covariance matrices $\Omega_{\eta}, \Omega_{\xi}$ respectively. Four combinations are considered:

V1. $\Omega_{\eta}=\left(\begin{array}{cc}16 & 8 \\ 8 & 16\end{array}\right)$ and $\Omega_{\xi}=\left(\begin{array}{ll}4 & 2 \\ 2 & 4\end{array}\right)$

V2. $\Omega_{\eta}=\left(\begin{array}{cc}12 & 6 \\ 6 & 12\end{array}\right)$ and $\Omega_{\xi}=\left(\begin{array}{ll}8 & 4 \\ 4 & 8\end{array}\right)$

V3. $\Omega_{\eta}=\left(\begin{array}{ll}8 & 4 \\ 4 & 8\end{array}\right)$ and $\Omega_{\xi}=\left(\begin{array}{cc}12 & 6 \\ 6 & 12\end{array}\right)$

V4. $\Omega_{\eta}=\left(\begin{array}{ll}4 & 2 \\ 2 & 4\end{array}\right)$ and $\Omega_{\xi}=\left(\begin{array}{cc}16 & 8 \\ 8 & 16\end{array}\right)$

For all experiments, we keep the total variance fixed at $\Omega_{\epsilon}=\left(\begin{array}{ll}20 & 10 \\ 10 & 20\end{array}\right)$

For the spatial weights matrices, we use regular ${ }^{2}$ structures. We decide to use four weight matrices, $W_{3}, W_{7}$ and $W_{9}$, which essentially differ in their degree of sparseness. In fact, the matrix $W_{J}$ where $J$ is a positive integer is labelled as "J ahead and J behind". Since in panel data many studies are not done in all the countries, we relax the hypothesis of a circular world in the construction of the matrix $W_{J}$. We consider several individuals $N=25$ and time dimensions $T=(7,10,15)$. First, we consider five simultaneous equation estimators of the one-way error component model which ignore spatial dependence:

1. Ordinary Least Squares (OLS).

2. Two Stage Least Square (2SLS).

3. Fixed Effects Two Stage Least Squares (FE-2SLS).

4. Error Component Two Stage Least Squares (EC-2SLS).

5. Error Component Three Stage Least Squares (EC-3SLS).

Second, we consider three simultaneous equation estimators which take into account crosssection spatial dependence:

1. Generalized moment instrumental variables two Stage Least Squares at initial value (GM-IV-S2SLS-I).

2. Generalized moment instrumental variables two Stage Least Squares at with the corrected parameters (GM-IV-S2SLS-C).

3. Generalized moment instrumental variables three Stage Least Squares (GM-IV-S3SLS).

\footnotetext{
${ }^{2}$ Irregular lattices structures are left for application on real data.
} 
To sum up, we will have a total of sixteen (15) Monte Carlo designs. We run 200 replications for each experiment.

\subsection{Efficiency Criteria}

To compare the performance of these estimators, we use three criteria. The first is an adjusted version of the root mean square error (RMSE) criterion proposed by Kelejian and Prucha (1998),

$$
\operatorname{RMSE}^{*}\left(\hat{\alpha}_{k}\right)=\left[\operatorname{bias}^{2}\left(\hat{\alpha}_{k}\right)+\left(\frac{I Q\left(\hat{\alpha}_{k}\right)}{1.35}\right)^{2}\right]^{1 / 2}
$$

where median is used instead of mean for bias. So bias is the difference between median and the true parameter. $I Q$ is the inter-quartile range defined as the difference between the 0.75 quantile and the 0.25 quantile of our estimates, $\hat{\alpha}_{k}$ is the estimator of $k$ th parameter $\alpha_{k}$.

As a supplement to $R M S E^{*}$ for each structural parameter, we employ two other comprehensive criteria proposed by Sasser (1969). The normalized mean absolute deviation (NOMAD) and normalized root mean square deviation (NORMSQD). These measures were also used by Baltagi (1984) in his Monte Carlo experiments. Specifically, NOMAD is defined as,

$$
\operatorname{NOMAD}(\hat{\alpha})=\frac{1}{R K} \sum_{k=1}^{K} \sum_{r=1}^{R}\left|\frac{\hat{\alpha}_{k, r}-\alpha_{k}}{\alpha_{k}}\right|
$$

where $K$ is the number of parameters, i.e., the dimension of parameter vector, $R$ is the number of replications, $\hat{\alpha}_{k, r}$ is the estimator of $k$ th parameter $k$ in $r$ th replication. Since NORMSQD relies on moments as well, we will also use quantiles instead to adjust for this criterion. Therefore, NORMSQD becomes,

$$
\operatorname{NORMSQD}^{*}(\hat{\alpha})=\left[\frac{1}{K} \sum_{k=1}^{K} \frac{\left[\operatorname{bias}^{2}\left(\hat{\alpha}_{k}\right)+\left(\frac{I Q\left(\hat{\alpha}_{k}\right)}{1.35}\right)^{2}\right]}{\hat{\alpha}_{k}^{2}}\right]^{1 / 2}
$$

where bias and $I Q$ are defined similarly to those in $R M S E$. For simplicity of notation, we still use RMSE and NORMSQD in the text when using these adjusted measures.

\subsection{Results}

\subsubsection{Changes in the Variance-Covariance matrix}

Tables 1, 2, 3 and 4 show the bias, the standard deviation, the RMSE, the NOMAD and the NORMSQD based on 200 replications. The structural parameters $\left(\alpha_{1}, \beta_{11}, \beta_{12}, \alpha_{2}, \beta_{21}, \beta_{22}\right)$ take the values $(-0.5,-2,1.5,-4,-3,1.8)$, the spatial coefficients $\left(\rho_{1}, \rho_{2}\right)$ are fixed at 
$(-0.8,0.8)$, and the weighting matrix is fixed at $W_{3}$. The four tables differ only in the degree of heterogeneity in the individual effects and in the cross-equation correlation ${ }^{3}$.

For the first three (03) usual estimators, with not surprise, OLS gives the largest NOMAD and NORMSQD. This is due to it inconsistency in a panel data (see Kelejian et al., 2004; Baltagi and Deng, 2015, for similar results). In contrast, when endogeneity is taken care of, i.e., we applied 2SLS, NOMAD gives an average gain of around 58.03\% over OLS. However when taking into account of simultaneity, by applying 3SLS, NOMAD exhibits a slighty average gain of around $1.35 \%$ over 2SLS. In addition of 2SLS, when we swipe off all the specific effects, i.e., FE-2SLS is applied, NOMAD exhibits an average gain of around $49.38 \%$ over 2SLS. Whereas, as we move from V1 to V4, i.e. the variances of the individual effects decrease, 2SLS shows smaller RMSE as well as NOMAD and NORMSQD than FE-2SLS (see the second graph of Figure 1). For example, in Table 4 the NORMSQD gives an average gain of $32.1 \%$ over FE-2SLS ${ }^{4}$.

Next, we compare 2SLS, FE-2SLS, EC-2SLS and EC-3SLS. As we see, as the variance covariance of the idiosyncratic term becomes small (i.e. we move from Table 4 to Table 1), Fixed Effect estimators become more close of EC estimators whereas, when the variance-covariance $\sigma_{\xi}^{2}$ increase, now we move from Table 1 to Table 4, 2SL and 3SLS estimators become more close of EC (see Figure 1). According to NOMAD and NORMSQD, EC-(3SLS and 2SLS) give better results than FE and 2SLS.

Now, comparing EC estimators, EC-3SLS exhibits better results than EC-2SLS This is not surprising considering the fact that 2SLS does not take into account simultaneity. However, an interesting result is that, when the $l q$-covariance of the specific individual component, $\sigma_{\eta_{12}}^{2}$, decreases this gain in efficiency also decreases. Indeed, in Table 1 the gain is around of $5 \%$ while in Table 4 it's almost null (see first graph of figure 1).

Next, we compare classical error component estimators and GM-IV-spatial estimators. As we see, when the spatial component structure is taking into account, NOMAD (respectively NORMSQD) exhibits an average gain in efficiency of $25 \%$ for V1 to $19.61 \%$ for V4 (resp. NORMSQD of $5 \%$ for V1 to $18.92 \%$ for V4). Finally, we focus on GM-IV spatial estimators group. They give better results than all our estimator considered when equation (1) holds. A graphical analysis reveals the following inequalities: GM-IV-S2SLS initial $\leq$ GM-IV-S2SLS corrected $\leq$ GM-IV-S3SLS. This means that: (i) iterate GM procedure leads to a gain in efficiency than GM initial estimator classes. For example in Table 1 NOMAD exhibits an average of 3.33\%; (ii) When have an identified system taking into account of simultaneity also leads to gain in effeciency than S2SLS Iterate estimator classes. And, move from V1 to $\mathrm{V} 4$, i.e. when $l q$-component of idiosyncratic terms of $\xi$ increase, leads to an increase of the gain in efficiency between GM-IV-S2LS classes and GM-IV-S3SLS classes.

\subsubsection{Change in the number of Neighbours}

Tables 5 and 6 differ from Table 1 in the number of neighbours $J$. In Table $1 J=3$, in Table $3 J=7$ and $J=9$ in Table 6 . The structural parameters $\left(\alpha_{1}, \beta_{11}, \beta_{12}, \alpha_{2}, \beta_{21}, \beta_{22}\right)$ take the value $(-0.5,-2,1.5,-4,-3,1.8)$ with the spatial coefficients $\left(\rho_{1}, \rho_{2}\right)$ are fixed at $(-0.8,0.8)$,

\footnotetext{
${ }^{3}$ This respectively correspond to the following covariance setup: V1, V2, V3 and V4.

${ }^{4}$ one can revisit Baltagi and Deng (2015) for similar results
} 


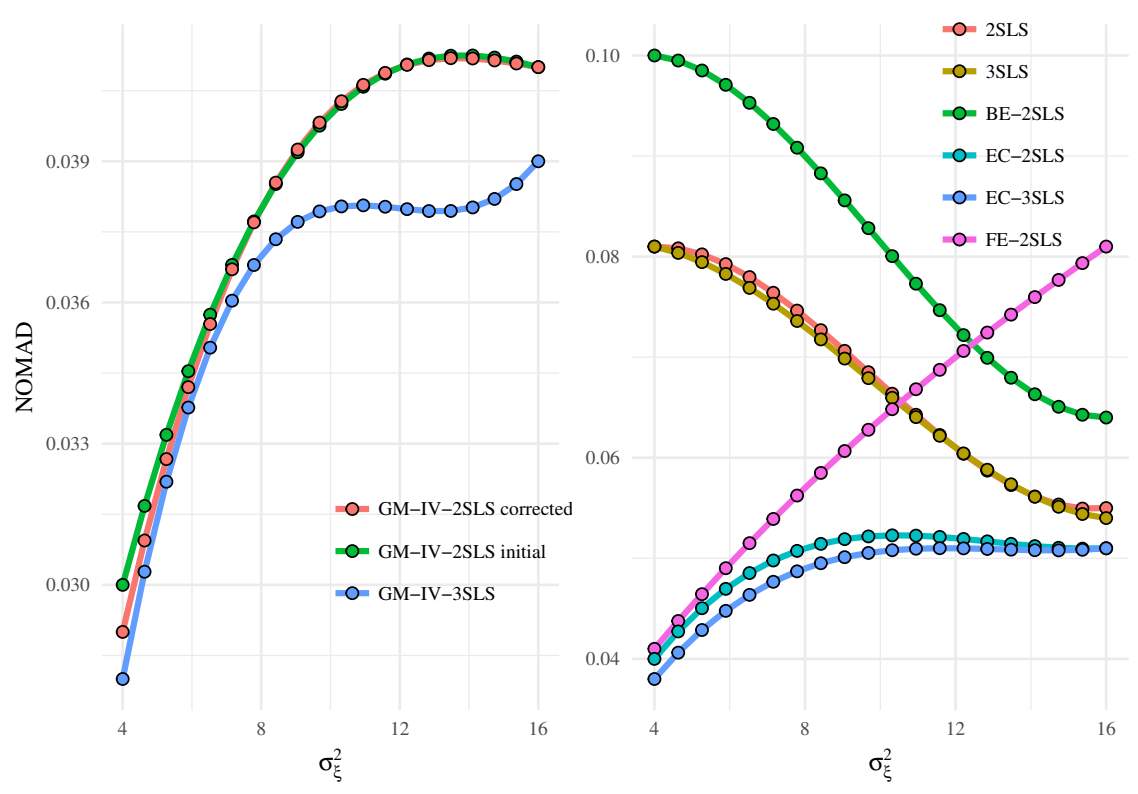

Figure 1: Estimators Average NOMAD evolution under covariance.

and the variance covariance matrix design is fixed at $V_{1}$. This means that, the four tables differ only in the degree of sparseness. The non-zero rate of spatial matrices $W_{3}, W_{7}$ and $W_{9}$ are respectively $22.08 \%, 47.04 \%$ and $57.6 \%$. For three neighbours ahead $\left(W_{3}\right)$, results reveal that spatial three stage least squares give better results than spatial two stages. The average gain in effeciency of NOMAD is $3.45 \%$. And as the number of neighbours increase i.e. as we move from $W_{3}$ to $W_{9}$, this inequality holds. A graphical analysis of Figure 1 reveal that GM-IV estimators NOMADs and NORMSQD increase with the number of neighbours however, this augmentation is less than that caused by an increase in the variance covariance matrix of the rest of the disturbance.

\subsubsection{Change in time}

Tables 1, 7 and 8 deal with the change in temporal size. Indeed, the first table consider $T=7$ the second $T=10$ and the third $T=15$. The structural parameters $\left(\alpha_{1}, \beta_{11}, \beta_{12}, \alpha_{2}, \beta_{21}, \beta_{22}\right)$, the coefficient of spatial dependence of each equation $\left(\rho_{1}, \rho_{2}\right)$ take the same values as above and the variance covariance matrix design is fixed at $V_{1}$. Comparing the results from Table 1 to 8 we see that an increase of temporal size leads to (i) a decrease in NOMAD and NORMSQD in all estimators (see Figure 2); (ii) GM-IV-S3SLS give better results than GM-IV-S2SLS according to NOMAD and NORMSQD. 


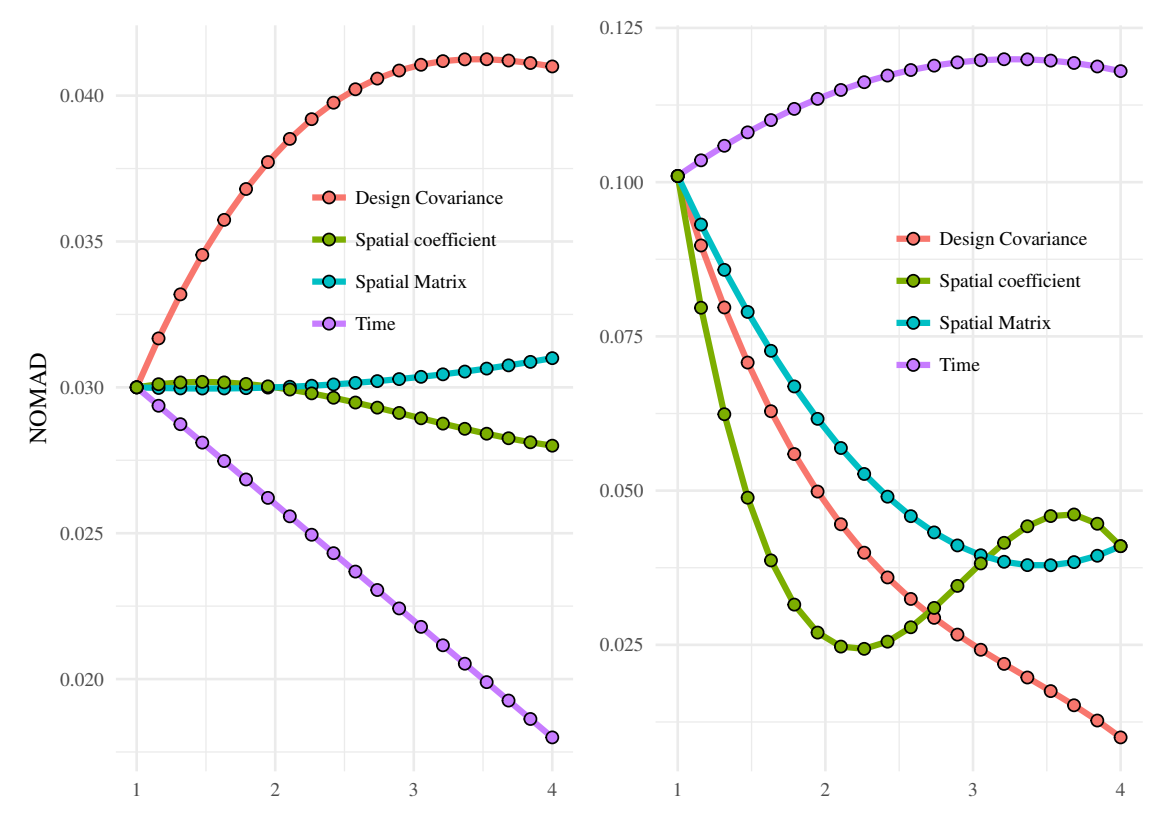

Figure 2: GM Estimators Average NOMAD path under different design.

\subsubsection{Change in coefficient of spatial dependence}

Tables 1, 9, 10 and 11 show the bias, the standard deviation, the RMSE, the NOMAD and the NORMSQD based on 200 replications $^{5}$. The structural parameters $\left(\alpha_{1}, \beta_{11}, \beta_{12}, \alpha_{2}, \beta_{21}, \beta_{22}\right)$ take the values $(-0.5,-2,1.5,-4,-3,1.8)$, the weighting matrix is fixed at $W_{3}$, we use the first covariance design $V_{1}$ and time dimension is fixed at 7 . In this investigation, $\rho_{2}$ is fixed at the value 0.8 . In the first table $\rho_{l}=-0.8$, in the second $\rho_{l}=-0.4$, in the third $\rho_{l}=0.4$ and in the fourth $\rho_{l}=0.8$. As we see in the first graph of Figure 2 when $\rho_{l}$ is negative, RMSE, NOMAD and NORMSQD are progressively decreasing while when this coefficient changes sign, NOMAD and NORMSQD progressively increase.

\subsubsection{GM Estimation of the coefficient of spatial dependence and variance- covariance components}

In Table 1 to 11 we also estimate coefficient of spatial dependence and variance covariance components of the disturbance. Results reveal that, when model of equation (1) holds, only GM classes gives better estimates and low biases of variance components than all estimators considered. When we focus on GM estimator of components of the disturbance, we note some points.

Firstly, the corrected GM-IV-S2SLS gives better results - low average bias- when estimating the spatial coefficient of each equation. This means that iterate GM procedure imply better estimates. For example, in table 1, the corrected S2SLS had an average gain in efficiency of $75.25 \%$ on the initial S2SLS and $75.49 \%$ on the initial S3SLS. Secondly, the corrected

\footnotetext{
${ }^{5}$ We only report the first and the last tables. The others are available on request.
} 
GM-IV-S2SLS also gives, in average, better estimates of variance covariance components. For example, in table 2, the corrected S2SLS had an average gain in efficiency of $13.59 \%$ on the initial S2SLS. Thirdly, the second graph of figure 2 shows different path of average bias for one spatial coefficient in different cases. In all cases -except time design- the average bias of spatial component decreases. It seems that GM estimate of the spatial coefficient is better when the corresponding spatial coefficient is -in absolute value- around of zero. We found that estimates are very good when $|\rho| \leq 0.4$.

\subsection{Application on African Data}

\subsubsection{The Empirical Model}

In this section our SGMM estimators are applied to 20 Sub-Saharan African countries. To estimate the link between per capita health care expenditure (HCE) and economic growth, we taking the lead from and specify the following spatial simultaneous empirical model:

$$
\left\{\begin{array}{l}
Y_{t i}=\beta_{01}+\alpha_{1} H_{t i}+\beta_{1} F_{t i}+\beta_{2} K_{t i}+\beta_{3} T_{t i}+v_{1, t i} \\
H_{t i}=\beta_{02}+\alpha_{2} Y_{t i}+\beta_{4} P_{t i}+\beta_{5} O_{t i}+\beta_{6} J_{t i}+v_{2, t i}
\end{array}\right.
$$

where $H_{t i}$ and $Y_{t i}$, the dependent variables of the system, respectively indicate, per capita health care expenditure and real GDP per capita for the ith country at time t; the exogenous variables of the model $X_{1}=[L, K, T]$ and $X_{2}=[P, O, J]$ respectively indicate labor force, physical capital, trade openness, public expenditure on health care, the dependency rates for old and young people, defined as the population aged 65 and over divided by the population aged 15-64, and the population aged 0-14 divided by the population aged 15-64. All variables in equation (40) are expressed in natural logarithm. The structural disturbances for each equation follows a SAR process defined as in equation (2) with $l=\{1,2\}$.

$$
v_{l}=\Lambda_{l} \epsilon_{l}=\left(I-\rho_{l} W\right)^{-1} \epsilon_{l}=A_{l}^{-1} \epsilon_{l}
$$

Where the nonnegative matrix $W_{N}=\left(\omega_{i j}\right)$, known as spatial weights matrix, provides information on the neighborhood linkages among Sub-Saharan African countries. In this study, we define neighborliness via a contiguity criterion, and assign $\omega_{i j}=1$ when country $i$ and $j$ share a common border or vertex, and $\omega_{i j}=0$ otherwise. This spatial matrix $W_{N}$ gives a non-zero rate of $13 \%$. The innovations $\epsilon_{l}$ follows a one-way error component model defined as in equation (3)

$$
\epsilon_{l}=Z_{\eta} \eta_{l}+\xi_{l}
$$

\subsubsection{Data}

We used annual data of 20 SSA countries over the period 1995 to 2015. The data comes from the World Development Indicators as published by the World Bank (2017). The selected 


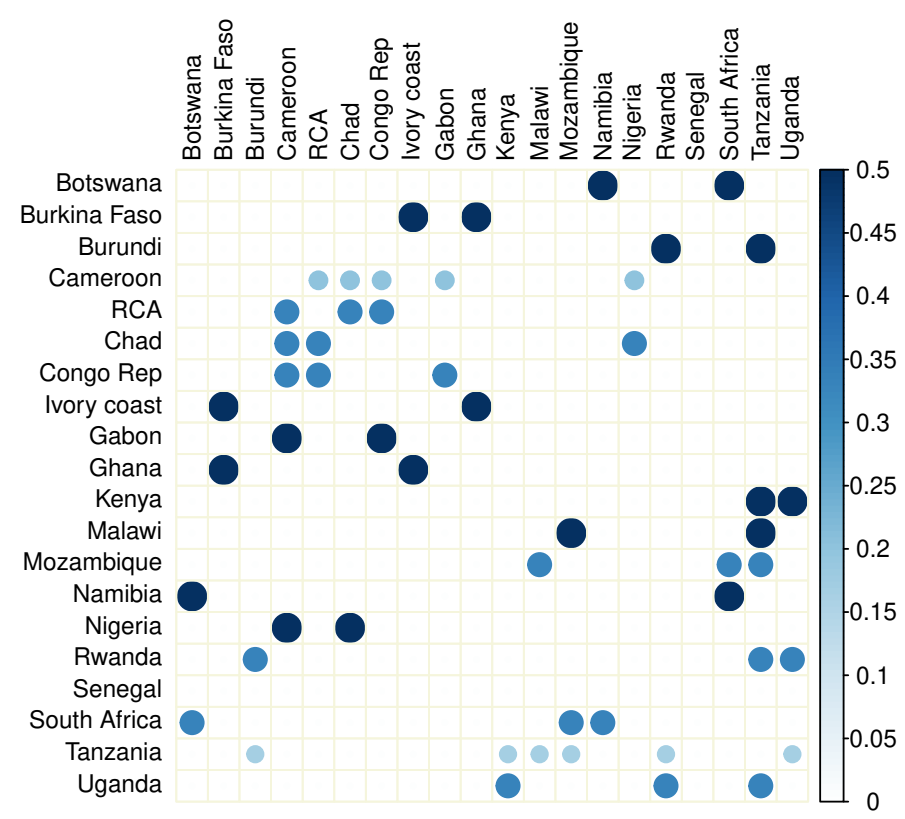

Figure 3: Spatial matrix of 20 SSA countries

countries under study and time span are dictated by data availability. Figure 4 displays the evolution of per capita HCE and per capita GDP for Sub-Saharan African countries.

We first made a preliminary exploratory data analysis this means: check whether our variables are nonstationary, then test their cointegrating properties and therefore, if they are linked in the long-run ${ }^{6}$.

\subsubsection{Results and Discussions}

Table 12 shows results from: Ordinary Least Squares (column 1), Two Stage Least Squares (column 2), Least Square Dummy Variable 2SLS (column 3), Error component 2SLS (column 4), Error Components 3SLS (column 5), Spatial Error Component 2SLS (column 6) and Spatial Error Component Three Stage Least Squares (column 7) estimations when income is the dependent variable in the regression (Equation 1), as well as when health expenditure is the dependent variable (Equation 2). Equation 1 reveals the following results. The impact of Health Care Expenditure on per capita income is negative in SSA; so an increment of $1 \%$ in HCE leads to a reduction of $0.037 \%$ in per capita GDP. Capital Stock and Trade Openness positively and significantly affect per capita Income; for example when we focus on 3EC-3SLS, an increase of $1 \%$ on capital stock (respectively Trade Openness) leads ceteris paribus in long run, to an increment of $0.305 \%$ (respectively $0.18 \%$ ) of per capita GDP. Interestingly, per capita GDP is negatively affected by Labor force. This can be explaining by the properties of real Income. Indeed, our dependent variable is per capita GDP this means gross domestic product of a country divide by the population of the same year. So

\footnotetext{
${ }^{6}$ We found that our variables are nonstationary in level, i.e, they are I(1). And the Johansen cointegration test reveals that they are cointegrated. For space requirement, results are not plot here but are availabe in request.
} 


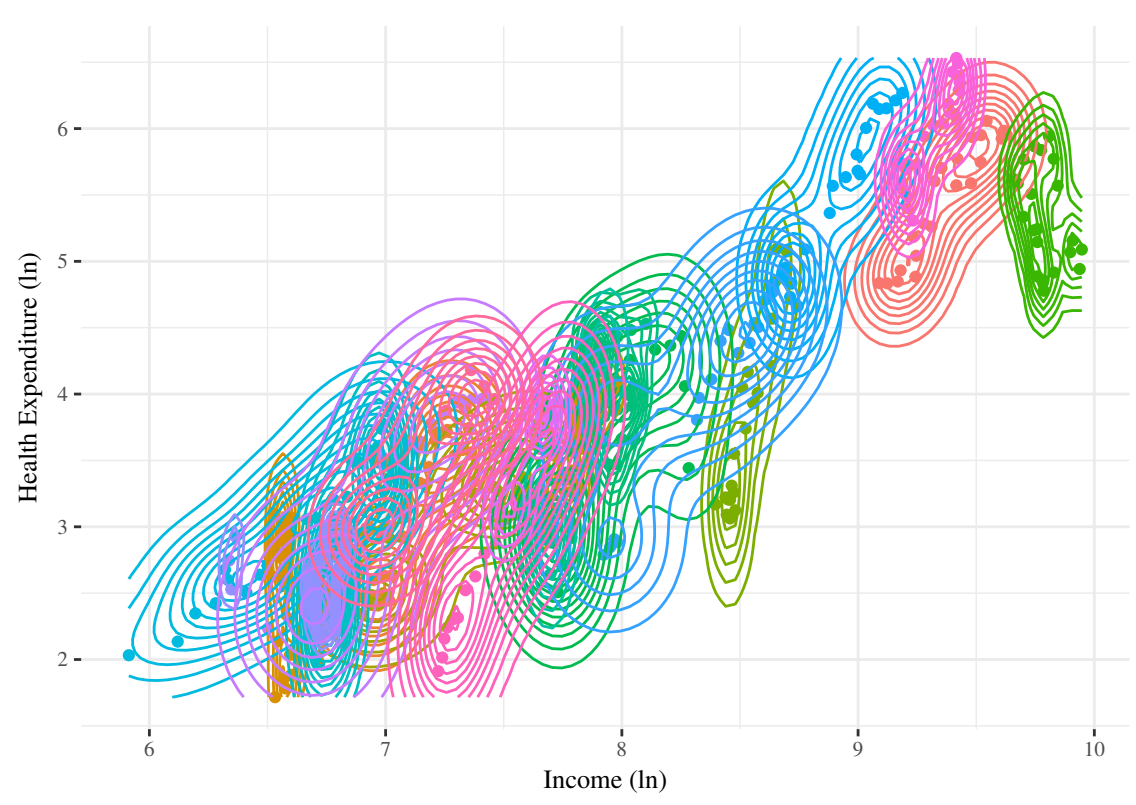

Figure 4: Health Expenditure and Income versus in SSA

a negative impact of Labor force on per capita GDP in Sub-Saharan Africa means that the total quantity value-added by Labor force is less than the quantity absorbed by the excess of the population in the same period. In others words, even if Labor force play a positive role on GDP, if the natural growth is significantly high, it can imply a reduction of per capita GDP. In the second equation 2 health expenditure is the dependent variable. As we can see, health care expenditure is positively impact by per capita GDP and the magnitude vary according to the estimator used. Indeed, a 1\% increase in per capita real income leads in long run to an increase of $0.894 \%$ in health care expenditure for 3EC-3SLS and $1.431 \%$ in HCE for 2EC-3SLS. Public expenditure positively and significantly affects health expenditure while old ratio dependency rate and young ratio dependency rate negatively affect Health care expenditure.

\section{Conclusion}

This paper develops estimation for a simultaneous panel data with spatially autocorrelated error componenent. For the disturbance, we considered SAR process developped by Kelejian and Prucha (2004) in which the global effect shock occurs because it is transmitted also to location that are "neigbours of neighbours" via the power of the spatial matrix. We also consider SMA process developped by Fingleton (2008) in which a shock at a specific location will only affect the directly interacting location. We derive a limited information estimator, termed GM-IV-S2SLS estimator, and a full information estimator, termed GM-IV-S3SLS. To derive each spatial error component estimators and spatial coefficient, we propose a simultaneous GM procedure.

The purpose of our Monte Carlo experiment were threefolds: Firstly, we study the small 
sample behavior of our estimators that can handle endogeneity, spatial error correlation and random individual effects in function of spatial coefficient, contiguity matrix, variance covariance of specific component and the increase of time. These estimators are compared with those that may ignore one or more of these symptoms. Secondly, we also investigate the gains in efficiency by comparing GM-IV spatial to others estimators. Thirdly, we study the sample properties of the spatial component $\rho_{l}$ in limited and full information cases. Results suggesting many conclusions. Our estimators are consistent. According to NOMAD and NORMSQD, GM-IV-S3SLS is better than GM-IV-S2SLS. When we estimate the coefficient of spatial dependence it seems better to use IV estimator that takes into account simultaneity. This means that when it is possible use 3SLS in lieu of 2SLS and after iterate to improve the quality of variance components.

Finally, we apply these estimators to real data of 20 Sub-Saharan African countries . We used these set of estimators to evaluate the modification of the magnitude in the model of health care expenditure and per capita real income.

In future research it should be of interest to extend the analysis of this paper to the case that contains spatial lag and spatially autocorrelated error components.

\section{A Tables}


Table 1: Efficient Criteria under $\sigma_{\xi_{l l}}^{2}=04, \sigma_{\eta_{l l}}^{2}=16, \mathrm{~T}=07, \mathrm{~N}=25, \rho_{1}=-0.8$ and $\mathrm{J}=03$

\begin{tabular}{|c|c|c|c|c|c|c|c|c|c|c|c|c|c|c|c|}
\hline Method & $\alpha_{1}$ & $\beta_{11}$ & $\beta_{12}$ & $\alpha_{2}$ & $\beta_{21}$ & $\beta_{22}$ & Nomad & $\rho_{1}$ & $\sigma_{\xi_{11}}^{2}$ & $\sigma_{\eta_{11}}^{2}$ & $\rho_{2}$ & $\sigma_{\xi_{22}}^{2}$ & $\sigma_{\eta_{22}}^{2}$ & $\sigma_{\xi_{12}}^{2}$ & $\sigma_{\eta_{12}}^{2}$ \\
\hline value & -0.5 & -2.0 & 1.5 & -4.0 & -3.0 & 1.8 & Normsqd & -0.8 & 04 & 16 & 0.8 & 04 & 16 & 02 & 08 \\
\hline $\begin{array}{l}\text { Usual Estiı } \\
\text { OLS }\end{array}$ & $\begin{array}{c}\text { nators } \\
0.102 \\
(0.01) \\
{[0.106]}\end{array}$ & $\begin{array}{l}0.814 \\
(0.095) \\
{[0.859]}\end{array}$ & $\begin{array}{l}0.603 \\
(0.077) \\
{[0.639]}\end{array}$ & $\begin{array}{l}0.035 \\
(0.029) \\
{[0.068]}\end{array}$ & $\begin{array}{l}0.042 \\
(0.088) \\
{[0.175]}\end{array}$ & $\begin{array}{l}0.037 \\
(0.08) \\
{[0.165]}\end{array}$ & $\begin{array}{l}0.193 \\
(0.438)\end{array}$ & & $\begin{array}{l}10.794 \\
{[11.288]}\end{array}$ & & & $\begin{array}{l}38.716 \\
{[41.728]}\end{array}$ & & & \\
\hline 2SLS & $\begin{array}{l}0.003 \\
(0.013) \\
{[0.04]}\end{array}$ & $\begin{array}{l}0.024 \\
(0.121) \\
{[0.345]}\end{array}$ & $\begin{array}{l}0.023 \\
(0.098) \\
{[0.276]}\end{array}$ & $\begin{array}{l}0.002 \\
(0.029) \\
{[0.063]}\end{array}$ & $\begin{array}{l}0.017 \\
(0.089) \\
{[0.156]}\end{array}$ & $\begin{array}{l}0.006 \\
(0.08) \\
{[0.157]}\end{array}$ & $\begin{array}{l}0.081 \\
(0.116)\end{array}$ & & $\begin{array}{l}20.253 \\
{[21.617]}\end{array}$ & & & $\begin{array}{l}39.347 \\
{[42.426]}\end{array}$ & & & \\
\hline 3SLS & $\begin{array}{l}0.003 \\
(0.018) \\
{[0.039]}\end{array}$ & $\begin{array}{l}0.02 \\
(0.153) \\
{[0.346]}\end{array}$ & $\begin{array}{l}0.021 \\
(0.12) \\
{[0.306]}\end{array}$ & $\begin{array}{l}0.003 \\
(0.03) \\
{[0.062]}\end{array}$ & $\begin{array}{l}0.013 \\
(0.089) \\
{[0.159]}\end{array}$ & $\begin{array}{l}0.013 \\
(0.077) \\
{[0.147]}\end{array}$ & $\begin{array}{l}0.081 \\
(0.121)\end{array}$ & & $\begin{array}{l}20.253 \\
{[21.617]}\end{array}$ & & & $\begin{array}{l}39.347 \\
{[42.426]}\end{array}$ & & $\begin{array}{l}7.908 \\
{[8.867]}\end{array}$ & \\
\hline \multicolumn{16}{|c|}{ Specific Estimators } \\
\hline FE-2SLS & $\begin{array}{l}0.002 \\
(0.019) \\
{[0.018]}\end{array}$ & $\begin{array}{l}0.006 \\
(0.162) \\
{[0.155]}\end{array}$ & $\begin{array}{l}0.005 \\
(0.129) \\
{[0.115]}\end{array}$ & $\begin{array}{l}0.006 \\
(0.039) \\
{[0.035]}\end{array}$ & $\begin{array}{l}0.006 \\
(0.113) \\
{[0.107]}\end{array}$ & $\begin{array}{l}0.009 \\
(0.103) \\
{[0.096]}\end{array}$ & $\begin{array}{l}0.041 \\
(0.054)\end{array}$ & & $\begin{array}{l}1.094 \\
{[1.364]}\end{array}$ & & & $\begin{array}{l}9.69 \\
{[10.093]}\end{array}$ & & & \\
\hline BE-2SLS & $\begin{array}{l}0.003 \\
(0.047) \\
{[0.047]}\end{array}$ & $\begin{array}{l}0.027 \\
(0.41) \\
{[0.385]}\end{array}$ & $\begin{array}{l}0.026 \\
(0.321) \\
{[0.324]}\end{array}$ & $\begin{array}{l}0.003 \\
(0.075) \\
{[0.082]}\end{array}$ & $\begin{array}{l}0.021 \\
(0.223) \\
{[0.185]}\end{array}$ & $\begin{array}{l}0.005 \\
(0.199) \\
{[0.207]}\end{array}$ & $\begin{array}{l}0.1 \\
(0.137)\end{array}$ & & & $\begin{array}{l}14.81 \\
{[16.439]}\end{array}$ & & & $\begin{array}{l}26.192 \\
{[29.582]}\end{array}$ & & \\
\hline $\begin{array}{c}\text { Error Com } \\
\text { EC-2SLS }\end{array}$ & $\begin{array}{l}\text { ponent } \\
0.006 \\
(0.017) \\
{[0.018]}\end{array}$ & $\begin{array}{l}\text { Estimat } \\
0.05 \\
(0.144) \\
{[0.149]}\end{array}$ & $\begin{array}{l}\text { rs } \\
0.035 \\
(0.115) \\
{[0.115]}\end{array}$ & $\begin{array}{l}0.005 \\
(0.033) \\
{[0.03]}\end{array}$ & $\begin{array}{l}0.001 \\
(0.097) \\
{[0.095]}\end{array}$ & $\begin{array}{l}0.01 \\
(0.089) \\
{[0.089]}\end{array}$ & $\begin{array}{l}0.04 \\
(0.053)\end{array}$ & & $\begin{array}{l}1.094 \\
{[1.364]}\end{array}$ & $\begin{array}{l}14.81 \\
{[16.439]}\end{array}$ & & $\begin{array}{l}9.69 \\
{[10.093]}\end{array}$ & $\begin{array}{l}26.192 \\
{[29.582]}\end{array}$ & & \\
\hline EC-3SLS & $\begin{array}{l}0.001 \\
(0.017) \\
{[0.016]}\end{array}$ & $\begin{array}{l}0.01 \\
(0.144) \\
{[0.151]}\end{array}$ & $\begin{array}{l}0.005 \\
(0.114) \\
{[0.122]}\end{array}$ & $\begin{array}{l}0.004 \\
(0.033) \\
{[0.029]}\end{array}$ & $\begin{array}{l}0.004 \\
(0.096) \\
{[0.092]}\end{array}$ & $\begin{array}{l}0.013 \\
(0.085) \\
{[0.089]}\end{array}$ & $\begin{array}{l}0.038 \\
(0.053)\end{array}$ & & $\begin{array}{l}1.094 \\
{[1.364]}\end{array}$ & $\begin{array}{l}14.81 \\
{[16.439]}\end{array}$ & & $\begin{array}{l}9.69 \\
{[10.093]}\end{array}$ & $\begin{array}{l}26.192 \\
{[29.582]}\end{array}$ & $\begin{array}{l}0.277 \\
{[0.532]}\end{array}$ & $\begin{array}{l}6.126 \\
{[7.271]}\end{array}$ \\
\hline \multicolumn{16}{|c|}{ Generalized Simultaneous Moments-IV spatial Estimator } \\
\hline S2SLS I & $\begin{array}{l}0.001 \\
(0.007) \\
{[0.014]}\end{array}$ & $\begin{array}{l}0.009 \\
(0.062) \\
{[0.126]}\end{array}$ & $\begin{array}{l}0.006 \\
(0.049) \\
{[0.103]}\end{array}$ & $\begin{array}{l}0.001 \\
(0.01) \\
{[0.02]}\end{array}$ & $\begin{array}{l}0.001 \\
(0.029) \\
{[0.062]}\end{array}$ & $\begin{array}{l}0 \\
(0.026) \\
{[0.053]}\end{array}$ & $\begin{array}{l}0.03 \\
(0.043)\end{array}$ & $\begin{array}{l}0.101 \\
{[0.2]}\end{array}$ & $\begin{array}{l}0.64 \\
{[1.238]}\end{array}$ & $\begin{array}{l}10.704 \\
{[12.055]}\end{array}$ & $\begin{array}{l}0.037 \\
{[0.069]}\end{array}$ & $\begin{array}{l}2.854 \\
{[3.036]}\end{array}$ & $\begin{array}{l}13.818 \\
{[14.633]}\end{array}$ & & \\
\hline S2SLS C & $\begin{array}{l}0.001 \\
(0.007) \\
{[0.013]}\end{array}$ & $\begin{array}{l}0.009 \\
(0.062) \\
{[0.117]}\end{array}$ & $\begin{array}{l}0.007 \\
(0.049) \\
{[0.089]}\end{array}$ & $\begin{array}{l}0.001 \\
(0.01) \\
{[0.019]}\end{array}$ & $\begin{array}{l}0.002 \\
(0.029) \\
{[0.061]}\end{array}$ & $\begin{array}{l}0 \\
(0.026) \\
{[0.054]}\end{array}$ & $\begin{array}{l}0.029 \\
(0.039)\end{array}$ & $\begin{array}{l}0.025 \\
{[0.164]}\end{array}$ & $\begin{array}{l}0.115 \\
{[0.561]}\end{array}$ & $\begin{array}{l}11.02 \\
{[12.093]}\end{array}$ & {$[0.047]$} & $\begin{array}{l}1.836 \\
{[1.904]}\end{array}$ & $\begin{array}{l}13.457 \\
{[14.193]}\end{array}$ & & \\
\hline S3SLS & $\begin{array}{l}0.001 \\
(0.015) \\
{[0.014]}\end{array}$ & $\begin{array}{l}0.009 \\
(0.126) \\
{[0.129]}\end{array}$ & $\begin{array}{l}0.006 \\
(0.1) \\
{[0.088]}\end{array}$ & $\begin{array}{l}0 \\
(0.021) \\
{[0.017]}\end{array}$ & $\begin{array}{l}0 \\
(0.059) \\
{[0.055]}\end{array}$ & $\begin{array}{l}0.003 \\
(0.052) \\
{[0.046]}\end{array}$ & $\begin{array}{l}0.028 \\
(0.039)\end{array}$ & $\begin{array}{l}0.102 \\
{[0.212]}\end{array}$ & $\begin{array}{l}0.631 \\
{[1.257]}\end{array}$ & $\begin{array}{l}10.913 \\
{[12.252]}\end{array}$ & $\begin{array}{l}0.036 \\
{[0.068]}\end{array}$ & $\begin{array}{l}2.83 \\
{[3.01]}\end{array}$ & $\begin{array}{l}14.021 \\
{[14.859]}\end{array}$ & $\begin{array}{l}0.014 \\
{[0.533]}\end{array}$ & $\begin{array}{l}5.694 \\
{[6.664]}\end{array}$ \\
\hline
\end{tabular}

${ }^{1}$ In each cell of columns 2-7, the upper number denotes the bias. The one in parentheses denotes the standard deviation.

2 The number in brackets denotes the RMSE. In each cell of column 8, the upper number denotes NOMAD. The lower one in parentheses denotes NORMSQD. 
Table 2: Efficient Criteria under $\sigma_{\xi_{l l}}^{2}=08, \sigma_{\eta_{l l}}^{2}=12, \mathrm{~T}=07, \mathrm{~N}=25, \rho_{1}=-0.8$ and $\mathrm{J}=03$

\begin{tabular}{|c|c|c|c|c|c|c|c|c|c|c|c|c|c|c|c|}
\hline Method & $\alpha_{1}$ & $\beta_{11}$ & $\beta_{12}$ & $\alpha_{2}$ & $\beta_{21}$ & $\beta_{22}$ & Nomad & $\rho_{1}$ & $\sigma_{\xi_{11}}^{2}$ & $\sigma_{\eta_{11}}^{2}$ & $\rho_{2}$ & $\sigma_{\xi_{22}}^{2}$ & $\sigma_{\eta_{22}}^{2}$ & $\sigma_{\xi_{12}}^{2}$ & $\sigma_{\eta_{12}}^{2}$ \\
\hline value & -0.5 & -2.0 & 1.5 & -4.0 & -3.0 & 1.8 & Normsqd & -0.8 & 08 & 12 & 0.8 & 08 & 12 & 04 & 06 \\
\hline \multicolumn{16}{|c|}{ Usual Estimators } \\
\hline OLS & $\begin{array}{l}0.103 \\
(0.01) \\
{[0.106]}\end{array}$ & $\begin{array}{l}0.83 \\
(0.096) \\
{[0.87]}\end{array}$ & $\begin{array}{l}0.615 \\
(0.078) \\
{[0.638]}\end{array}$ & $\begin{array}{l}0.042 \\
(0.031) \\
{[0.066]}\end{array}$ & $\begin{array}{l}0.054 \\
(0.093) \\
{[0.163]}\end{array}$ & $\begin{array}{l}0.043 \\
(0.084) \\
{[0.161]}\end{array}$ & $\begin{array}{l}0.195 \\
(0.444)\end{array}$ & & $\begin{array}{l}11.658 \\
{[11.996]}\end{array}$ & & & $\begin{array}{l}41.915 \\
{[44.041]}\end{array}$ & & & \\
\hline 2SLS & $\begin{array}{l}0.003 \\
(0.013) \\
{[0.038]}\end{array}$ & $\begin{array}{l}0.021 \\
(0.122) \\
{[0.318]}\end{array}$ & $\begin{array}{l}0.021 \\
(0.099) \\
{[0.255]}\end{array}$ & $\begin{array}{l}0.001 \\
(0.031) \\
{[0.059]}\end{array}$ & $\begin{array}{l}0.015 \\
(0.094) \\
{[0.145]}\end{array}$ & $\begin{array}{l}0.006 \\
(0.085) \\
{[0.149]}\end{array}$ & $\begin{array}{l}0.074 \\
(0.107)\end{array}$ & & $\begin{array}{l}21.355 \\
{[22.47]}\end{array}$ & & & $\begin{array}{l}42.618 \\
{[44.777]}\end{array}$ & & & \\
\hline 3SLS & $\begin{array}{l}0.002 \\
(0.018) \\
{[0.037]}\end{array}$ & $\begin{array}{l}0.017 \\
(0.155) \\
{[0.317]}\end{array}$ & $\begin{array}{l}0.018 \\
(0.122) \\
{[0.269]}\end{array}$ & $\begin{array}{l}0.002 \\
(0.032) \\
{[0.056]}\end{array}$ & $\begin{array}{l}0.012 \\
(0.094) \\
{[0.147]}\end{array}$ & $\begin{array}{l}0.013 \\
(0.082) \\
{[0.145]}\end{array}$ & $\begin{array}{l}0.073 \\
(0.11)\end{array}$ & & $\begin{array}{l}21.355 \\
{[22.47]}\end{array}$ & & & $\begin{array}{l}42.618 \\
{[44.777]}\end{array}$ & & $\begin{array}{l}8.623 \\
{[9.374]}\end{array}$ & \\
\hline \multicolumn{16}{|c|}{ Specific Estimators } \\
\hline FE-2SLS & $\begin{array}{l}0.002 \\
(0.027) \\
{[0.026]}\end{array}$ & $\begin{array}{l}0.01 \\
(0.231) \\
{[0.225]}\end{array}$ & $\begin{array}{l}0.007 \\
(0.184) \\
{[0.162]}\end{array}$ & $\begin{array}{l}0.008 \\
(0.055) \\
{[0.05]}\end{array}$ & $\begin{array}{l}0.008 \\
(0.159) \\
{[0.151]}\end{array}$ & $\begin{array}{l}0.013 \\
(0.146) \\
{[0.135]}\end{array}$ & $\begin{array}{l}0.057 \\
(0.077)\end{array}$ & & $\begin{array}{l}6.831 \\
{[7.109]}\end{array}$ & & & $\begin{array}{l}20.528 \\
{[21.34]}\end{array}$ & & & \\
\hline BE-2SLS & $\begin{array}{l}0.002 \\
(0.042) \\
{[0.043]}\end{array}$ & $\begin{array}{l}0.022 \\
(0.362) \\
{[0.353]}\end{array}$ & $\begin{array}{l}0.022 \\
(0.283) \\
{[0.294]}\end{array}$ & $\begin{array}{l}0.003 \\
(0.067) \\
{[0.071]}\end{array}$ & $\begin{array}{l}0.018 \\
(0.198) \\
{[0.168]}\end{array}$ & $\begin{array}{l}0.004 \\
(0.177) \\
{[0.187]}\end{array}$ & $\begin{array}{l}0.09 \\
(0.124)\end{array}$ & & & $\begin{array}{l}10.555 \\
{[11.978]}\end{array}$ & & & $\begin{array}{l}17.787 \\
{[20.832]}\end{array}$ & & \\
\hline \multicolumn{16}{|c|}{ Error Component Estimators } \\
\hline EC-2SLS & $\begin{array}{l}0.008 \\
(0.021) \\
{[0.023]}\end{array}$ & $\begin{array}{l}0.074 \\
(0.182) \\
{[0.194]}\end{array}$ & $\begin{array}{l}0.05 \\
(0.145) \\
{[0.155]}\end{array}$ & $\begin{array}{l}0.005 \\
(0.04) \\
{[0.037]}\end{array}$ & $\begin{array}{l}0.001 \\
(0.118) \\
{[0.117]}\end{array}$ & $\begin{array}{l}0.013 \\
(0.107) \\
{[0.116]}\end{array}$ & $\begin{array}{l}0.051 \\
(0.071)\end{array}$ & & $\begin{array}{l}6.831 \\
{[7.109]}\end{array}$ & $\begin{array}{l}10.555 \\
{[11.978]}\end{array}$ & & $\begin{array}{l}20.528 \\
{[21.34]}\end{array}$ & $\begin{array}{l}17.787 \\
{[20.832]}\end{array}$ & & \\
\hline EC-3SLS & $\begin{array}{l}0.001 \\
(0.021) \\
{[0.023]}\end{array}$ & $\begin{array}{l}0.014 \\
(0.183) \\
{[0.19]}\end{array}$ & $\begin{array}{l}0.006 \\
(0.145) \\
{[0.168]}\end{array}$ & $\begin{array}{l}0.004 \\
(0.04) \\
{[0.038]}\end{array}$ & $\begin{array}{l}0.006 \\
(0.116) \\
{[0.101]}\end{array}$ & $\begin{array}{l}0.016 \\
(0.103) \\
{[0.112]}\end{array}$ & $\begin{array}{l}0.049 \\
(0.07)\end{array}$ & & $\begin{array}{l}6.831 \\
{[7.109]}\end{array}$ & $\begin{array}{l}10.555 \\
{[11.978]}\end{array}$ & & $\begin{array}{l}20.528 \\
{[21.34]}\end{array}$ & $\begin{array}{l}17.787 \\
{[20.832]}\end{array}$ & $\begin{array}{l}2.838 \\
{[3.016]}\end{array}$ & $\begin{array}{l}3.909 \\
{[5.121]}\end{array}$ \\
\hline \multicolumn{16}{|c|}{ Generalized Simultaneous Moments-IV spatial Estimator } \\
\hline S2SLS I & $\begin{array}{l}0.002 \\
(0.006) \\
{[0.018]}\end{array}$ & $\begin{array}{l}0.011 \\
(0.055) \\
{[0.169]}\end{array}$ & $\begin{array}{l}0.01 \\
(0.044) \\
{[0.133]}\end{array}$ & $\begin{array}{l}0.001 \\
(0.009) \\
{[0.024]}\end{array}$ & $\begin{array}{l}0.001 \\
(0.026) \\
{[0.077]}\end{array}$ & $\begin{array}{l}0 \\
(0.024) \\
{[0.071]}\end{array}$ & $\begin{array}{l}0.038 \\
(0.056)\end{array}$ & $\begin{array}{l}0.048 \\
{[0.177]}\end{array}$ & $\begin{array}{l}5.056 \\
{[5.456]}\end{array}$ & $\begin{array}{l}7.406 \\
{[8.558]}\end{array}$ & $\begin{array}{l}0.018 \\
{[0.049]}\end{array}$ & $\begin{array}{l}5.738 \\
{[5.894]}\end{array}$ & $\begin{array}{l}9.117 \\
{[9.931]}\end{array}$ & & \\
\hline S2SLS C & $\begin{array}{l}0.002 \\
(0.006) \\
{[0.018]}\end{array}$ & $\begin{array}{l}0.013 \\
(0.056) \\
{[0.166]}\end{array}$ & $\begin{array}{l}0.011 \\
(0.045) \\
{[0.123]}\end{array}$ & $\begin{array}{l}0.001 \\
(0.009) \\
{[0.023]}\end{array}$ & $\begin{array}{l}0.002 \\
(0.026) \\
{[0.079]}\end{array}$ & $\begin{array}{l}0 \\
(0.024) \\
{[0.072]}\end{array}$ & $\begin{array}{l}0.038 \\
(0.054)\end{array}$ & $\begin{array}{l}0.021 \\
{[0.173]}\end{array}$ & $\begin{array}{l}4.369 \\
{[4.556]}\end{array}$ & $\begin{array}{l}7.729 \\
{[8.798]}\end{array}$ & {$[0.047]$} & $\begin{array}{l}4.867 \\
{[4.972]}\end{array}$ & $\begin{array}{l}8.783 \\
{[9.512]}\end{array}$ & & \\
\hline S3SLS & $\begin{array}{l}0.001 \\
(0.018) \\
{[0.018]}\end{array}$ & $\begin{array}{l}0.01 \\
(0.153) \\
{[0.173]}\end{array}$ & $\begin{array}{l}0.008 \\
(0.121) \\
{[0.121]}\end{array}$ & $\begin{array}{l}0 \\
(0.025) \\
{[0.023]}\end{array}$ & $\begin{array}{l}0 \\
(0.071) \\
{[0.071]}\end{array}$ & $\begin{array}{l}0.004 \\
(0.062) \\
{[0.06]}\end{array}$ & $\begin{array}{l}0.037 \\
(0.053)\end{array}$ & $\begin{array}{l}0.05 \\
{[0.181]}\end{array}$ & $\begin{array}{l}5.037 \\
{[5.422]}\end{array}$ & $\begin{array}{l}7.595 \\
{[8.708]}\end{array}$ & $\begin{array}{l}0.018 \\
{[0.05]}\end{array}$ & $\begin{array}{l}5.717 \\
{[5.875]}\end{array}$ & $\begin{array}{l}9.29 \\
{[10.103]}\end{array}$ & $\begin{array}{l}2.053 \\
{[2.252]}\end{array}$ & $\begin{array}{l}3.566 \\
{[4.582]}\end{array}$ \\
\hline
\end{tabular}

${ }^{1}$ In each cell of columns 2-7, the upper number denotes the bias. The middle one in parentheses denotes the standard deviation.

2 The bottom number denotes the RMSE. In each cell of column 8, the upper number denotes NOMAD. The lower one in parentheses denotes NORMSQD. 
Table 3: Efficient Criteria under $\sigma_{\xi_{l l}}^{2}=12, \sigma_{\eta_{l l}}^{2}=08, \mathrm{~T}=07, \mathrm{~N}=25, \rho_{1}=-0.8$ and $\mathrm{J}=03$

\begin{tabular}{|c|c|c|c|c|c|c|c|c|c|c|c|c|c|c|c|}
\hline Method & $\alpha_{1}$ & $\beta_{11}$ & $\beta_{12}$ & $\alpha_{2}$ & $\beta_{21}$ & $\beta_{22}$ & Nomad & $\rho_{1}$ & $\sigma_{\xi_{11}}^{2}$ & $\sigma_{\eta_{11}}^{2}$ & $\rho_{2}$ & $\sigma_{\xi_{22}}^{2}$ & $\sigma_{\eta_{22}}^{2}$ & $\sigma_{\xi_{12}}^{2}$ & $\sigma_{\eta_{12}}^{2}$ \\
\hline value & -0.5 & -2.0 & 1.5 & -4.0 & -3.0 & 1.8 & Normsqd & -0.8 & 12 & 08 & 0.8 & 12 & 08 & 06 & 04 \\
\hline \multicolumn{16}{|c|}{ Usual Estimators } \\
\hline OLS & $\begin{array}{l}0.106 \\
(0.01) \\
{[0.11]}\end{array}$ & $\begin{array}{l}0.852 \\
(0.096) \\
{[0.877]}\end{array}$ & $\begin{array}{l}0.631 \\
(0.078) \\
{[0.644]}\end{array}$ & $\begin{array}{l}0.037 \\
(0.03) \\
{[0.053]}\end{array}$ & $\begin{array}{l}0.049 \\
(0.09) \\
{[0.115]}\end{array}$ & $\begin{array}{l}0.033 \\
(0.082) \\
{[0.12]}\end{array}$ & $\begin{array}{l}0.193 \\
(0.452)\end{array}$ & & $\begin{array}{l}12.48 \\
{[12.702]}\end{array}$ & & & $\begin{array}{l}38.116 \\
{[39.35]}\end{array}$ & & & \\
\hline 2SLS & $\begin{array}{l}0.002 \\
(0.013) \\
{[0.033]}\end{array}$ & $\begin{array}{l}0.016 \\
(0.123) \\
{[0.254]}\end{array}$ & $\begin{array}{l}0.018 \\
(0.1) \\
{[0.233]}\end{array}$ & $\begin{array}{l}0 \\
(0.03) \\
{[0.035]}\end{array}$ & $\begin{array}{l}0.009 \\
(0.091) \\
{[0.104]}\end{array}$ & $\begin{array}{l}0 \\
(0.082) \\
{[0.108]}\end{array}$ & $\begin{array}{l}0.061 \\
(0.091)\end{array}$ & & $\begin{array}{l}22.478 \\
{[23.455]}\end{array}$ & & & $\begin{array}{l}38.572 \\
{[39.889]}\end{array}$ & & & \\
\hline 3SLS & $\begin{array}{l}0.002 \\
(0.018) \\
{[0.032]}\end{array}$ & $\begin{array}{l}0.014 \\
(0.156) \\
{[0.26]}\end{array}$ & $\begin{array}{l}0.016 \\
(0.122) \\
{[0.229]}\end{array}$ & $\begin{array}{l}0 \\
(0.031) \\
{[0.036]}\end{array}$ & $\begin{array}{l}0.007 \\
(0.091) \\
{[0.098]}\end{array}$ & $\begin{array}{l}0.007 \\
(0.079) \\
{[0.103]}\end{array}$ & $\begin{array}{l}0.061 \\
(0.09)\end{array}$ & & $\begin{array}{l}22.478 \\
{[23.455]}\end{array}$ & & & $\begin{array}{l}38.572 \\
{[39.889]}\end{array}$ & & $\begin{array}{l}9.358 \\
{[9.72]}\end{array}$ & \\
\hline \multicolumn{16}{|c|}{ Specific Estimators } \\
\hline FE-2SLS & $\begin{array}{l}0.003 \\
(0.033) \\
{[0.031]}\end{array}$ & $\begin{array}{l}0.012 \\
(0.287) \\
{[0.276]}\end{array}$ & $\begin{array}{l}0.009 \\
(0.228) \\
{[0.196]}\end{array}$ & $\begin{array}{l}0.01 \\
(0.067) \\
{[0.062]}\end{array}$ & $\begin{array}{l}0.01 \\
(0.195) \\
{[0.183]}\end{array}$ & $\begin{array}{l}0.016 \\
(0.178) \\
{[0.166]}\end{array}$ & $\begin{array}{l}0.07 \\
(0.095)\end{array}$ & & $\begin{array}{l}12.763 \\
{[13.214]}\end{array}$ & & & $\begin{array}{l}31.548 \\
{[32.752]}\end{array}$ & & & \\
\hline BE-2SLS & $\begin{array}{l}0.002 \\
(0.035) \\
{[0.037]}\end{array}$ & $\begin{array}{l}0.015 \\
(0.308) \\
{[0.303]}\end{array}$ & $\begin{array}{l}0.017 \\
(0.241) \\
{[0.257]}\end{array}$ & $\begin{array}{l}0.001 \\
(0.044) \\
{[0.042]}\end{array}$ & $\begin{array}{l}0.011 \\
(0.131) \\
{[0.12]}\end{array}$ & $\begin{array}{l}0.004 \\
(0.117) \\
{[0.132]}\end{array}$ & $\begin{array}{l}0.073 \\
(0.105)\end{array}$ & & & $\begin{array}{l}7.447 \\
{[8.67]}\end{array}$ & & & $\begin{array}{l}2.382 \\
{[5.665]}\end{array}$ & & \\
\hline \multicolumn{16}{|c|}{ Error Component Estimators } \\
\hline EC-2SLS & $\begin{array}{l}0.009 \\
(0.022) \\
{[0.026]}\end{array}$ & $\begin{array}{l}0.079 \\
(0.194) \\
{[0.206]}\end{array}$ & $\begin{array}{l}0.053 \\
(0.155) \\
{[0.169]}\end{array}$ & $\begin{array}{l}0.003 \\
(0.035) \\
{[0.032]}\end{array}$ & $\begin{array}{l}0.004 \\
(0.103) \\
{[0.106]}\end{array}$ & $\begin{array}{l}0.006 \\
(0.093) \\
{[0.097]}\end{array}$ & $\begin{array}{l}0.052 \\
(0.074)\end{array}$ & & $\begin{array}{l}12.763 \\
{[13.214]}\end{array}$ & $\begin{array}{l}7.447 \\
{[8.67]}\end{array}$ & & $\begin{array}{l}31.548 \\
{[32.752]}\end{array}$ & $\begin{array}{l}2.382 \\
{[5.665]}\end{array}$ & & \\
\hline EC-3SLS & $\begin{array}{l}0.001 \\
(0.023) \\
{[0.025]}\end{array}$ & $\begin{array}{l}0.015 \\
(0.195) \\
{[0.205]}\end{array}$ & $\begin{array}{l}0.006 \\
(0.154) \\
{[0.175]}\end{array}$ & $\begin{array}{l}0.001 \\
(0.035) \\
{[0.032]}\end{array}$ & $\begin{array}{l}0.005 \\
(0.1) \\
{[0.101]}\end{array}$ & $\begin{array}{l}0.01 \\
(0.087) \\
{[0.101]}\end{array}$ & $\begin{array}{l}0.051 \\
(0.073)\end{array}$ & & $\begin{array}{l}12.763 \\
{[13.214]}\end{array}$ & $\begin{array}{l}7.447 \\
{[8.67]}\end{array}$ & & $\begin{array}{l}31.548 \\
{[32.752]}\end{array}$ & $\begin{array}{l}2.382 \\
{[5.665]}\end{array}$ & $\begin{array}{l}5.46 \\
{[5.685]}\end{array}$ & $\begin{array}{l}1.748 \\
{[2.831]}\end{array}$ \\
\hline \multicolumn{16}{|c|}{ Generalized Simultaneous Moments-IV spatial Estimator } \\
\hline S2SLS I & $\begin{array}{l}0.002 \\
(0.006) \\
{[0.021]}\end{array}$ & $\begin{array}{l}0.011 \\
(0.048) \\
{[0.187]}\end{array}$ & $\begin{array}{l}0.011 \\
(0.039) \\
{[0.144]}\end{array}$ & $\begin{array}{l}0.001 \\
(0.007) \\
{[0.019]}\end{array}$ & $\begin{array}{l}0.001 \\
(0.02) \\
{[0.078]}\end{array}$ & $\begin{array}{l}0.001 \\
(0.018) \\
{[0.067]}\end{array}$ & $\begin{array}{l}0.041 \\
(0.06)\end{array}$ & $\begin{array}{l}0.025 \\
{[0.173]}\end{array}$ & $\begin{array}{l}9.499 \\
{[9.836]}\end{array}$ & $\begin{array}{l}5.416 \\
{[6.298]}\end{array}$ & $\begin{array}{l}0.008 \\
{[0.048]}\end{array}$ & $\begin{array}{l}8.548 \\
{[8.68]}\end{array}$ & $\begin{array}{l}0.872 \\
{[1.924]}\end{array}$ & & \\
\hline S2SLS C & $\begin{array}{l}0.002 \\
(0.006) \\
{[0.02]}\end{array}$ & $\begin{array}{l}0.014 \\
(0.049) \\
{[0.185]}\end{array}$ & $\begin{array}{l}0.013 \\
(0.039) \\
{[0.133]}\end{array}$ & $\begin{array}{l}0.001 \\
(0.007) \\
{[0.019]}\end{array}$ & $\begin{array}{l}0.001 \\
(0.02) \\
{[0.08]}\end{array}$ & $\begin{array}{l}0.001 \\
(0.018) \\
{[0.067]}\end{array}$ & $\begin{array}{l}0.041 \\
(0.058)\end{array}$ & $\begin{array}{l}0.016 \\
{[0.172]}\end{array}$ & $\begin{array}{l}8.972 \\
{[9.18]}\end{array}$ & $\begin{array}{l}5.591 \\
{[6.404]}\end{array}$ & $\begin{array}{l}0.001 \\
{[0.047]}\end{array}$ & $\begin{array}{l}8.142 \\
{[8.274]}\end{array}$ & $\begin{array}{l}0.55 \\
{[1.59]}\end{array}$ & & \\
\hline S3SLS & $\begin{array}{l}0.001 \\
(0.018) \\
{[0.02]}\end{array}$ & $\begin{array}{l}0.005 \\
(0.157) \\
{[0.174]}\end{array}$ & $\begin{array}{l}0.006 \\
(0.124) \\
{[0.136]}\end{array}$ & $\begin{array}{l}0 \\
(0.022) \\
{[0.02]}\end{array}$ & $\begin{array}{l}0 \\
(0.063) \\
{[0.063]}\end{array}$ & $\begin{array}{l}0.004 \\
(0.054) \\
{[0.052]}\end{array}$ & $\begin{array}{l}0.038 \\
(0.056)\end{array}$ & $\begin{array}{l}0.026 \\
{[0.166]}\end{array}$ & $\begin{array}{l}9.457 \\
{[9.805]}\end{array}$ & $\begin{array}{l}5.576 \\
{[6.435]}\end{array}$ & $\begin{array}{l}0.008 \\
{[0.048]}\end{array}$ & $\begin{array}{l}8.529 \\
{[8.667]}\end{array}$ & $\begin{array}{l}1.005 \\
{[1.989]}\end{array}$ & $\begin{array}{l}4.167 \\
{[4.307]}\end{array}$ & $\begin{array}{l}1.564 \\
{[2.476]}\end{array}$ \\
\hline
\end{tabular}

${ }^{1}$ In each cell of columns 2-7, the upper number denotes the bias. The middle one in parentheses denotes the standard deviation.

2 The bottom number denotes the RMSE. In each cell of column 8, the upper number denotes NOMAD. The lower one in parentheses denotes NORMSQD. 
Table 4: Efficient Criteria under $\sigma_{\xi_{l l}}^{2}=16, \sigma_{\eta_{l l}}^{2}=04, \mathrm{~T}=07, \mathrm{~N}=25, \rho_{1}=-0.8$ and $\mathrm{J}=03$

\begin{tabular}{|c|c|c|c|c|c|c|c|c|c|c|c|c|c|c|c|}
\hline Method & $\alpha_{1}$ & $\beta_{11}$ & $\beta_{12}$ & $\alpha_{2}$ & $\beta_{21}$ & $\beta_{22}$ & Nomad & $\rho_{1}$ & $\sigma_{\xi_{11}}^{2}$ & $\sigma_{\eta_{11}}^{2}$ & $\rho_{2}$ & $\sigma_{\xi_{22}}^{2}$ & $\sigma_{\eta_{22}}^{2}$ & $\sigma_{\xi_{12}}^{2}$ & $\sigma_{\eta_{12}}^{2}$ \\
\hline value & -0.5 & -2.0 & 1.5 & -4.0 & -3.0 & 1.8 & Normsqd & -0.8 & 16 & 04 & 0.8 & 16 & 04 & 08 & 02 \\
\hline \multicolumn{16}{|c|}{ Usual Estimators } \\
\hline OLS & $\begin{array}{l}0.106 \\
(0.01) \\
{[0.107]}\end{array}$ & $\begin{array}{l}0.854 \\
(0.096) \\
{[0.866]}\end{array}$ & $\begin{array}{l}0.633 \\
(0.078) \\
{[0.64]}\end{array}$ & $\begin{array}{l}0.057 \\
(0.033) \\
{[0.073]}\end{array}$ & $\begin{array}{l}0.078 \\
(0.101) \\
{[0.142]}\end{array}$ & $\begin{array}{l}0.054 \\
(0.092) \\
{[0.13]}\end{array}$ & $\begin{array}{l}0.196 \\
(0.446)\end{array}$ & & $\begin{array}{l}13.637 \\
{[13.818]}\end{array}$ & & & $\begin{array}{l}48.513 \\
{[50.052]}\end{array}$ & & & \\
\hline 2SLS & $\begin{array}{l}0.002 \\
(0.013) \\
{[0.026]}\end{array}$ & $\begin{array}{l}0.012 \\
(0.123) \\
{[0.237]}\end{array}$ & $\begin{array}{l}0.014 \\
(0.1) \\
{[0.178]}\end{array}$ & $\begin{array}{l}0.001 \\
(0.033) \\
{[0.039]}\end{array}$ & $\begin{array}{l}0.009 \\
(0.102) \\
{[0.114]}\end{array}$ & $\begin{array}{l}0.005 \\
(0.093) \\
{[0.109]}\end{array}$ & $\begin{array}{l}0.055 \\
(0.078)\end{array}$ & & $\begin{array}{l}23.749 \\
{[24.372]}\end{array}$ & & & $\begin{array}{l}49.506 \\
{[51.11]}\end{array}$ & & & \\
\hline 3SLS & $\begin{array}{l}0.001 \\
(0.018) \\
{[0.026]}\end{array}$ & $\begin{array}{l}0.009 \\
(0.157) \\
{[0.243]}\end{array}$ & $\begin{array}{l}0.012 \\
(0.123) \\
{[0.181]}\end{array}$ & $\begin{array}{l}0 \\
(0.035) \\
{[0.039]}\end{array}$ & $\begin{array}{l}0.009 \\
(0.103) \\
{[0.102]}\end{array}$ & $\begin{array}{l}0.01 \\
(0.09) \\
{[0.104]}\end{array}$ & $\begin{array}{l}0.054 \\
(0.079)\end{array}$ & & $\begin{array}{l}23.749 \\
{[24.372]}\end{array}$ & & & $\begin{array}{l}49.506 \\
{[51.11]}\end{array}$ & & $\begin{array}{l}10.198 \\
{[10.5]}\end{array}$ & \\
\hline \multicolumn{16}{|c|}{ Specific Estimators } \\
\hline FE-2SLS & $\begin{array}{l}0.003 \\
(0.039) \\
{[0.036]}\end{array}$ & $\begin{array}{l}0.015 \\
(0.334) \\
{[0.314]}\end{array}$ & $\begin{array}{l}0.011 \\
(0.266) \\
{[0.22]}\end{array}$ & $\begin{array}{l}0.011 \\
(0.078) \\
{[0.071]}\end{array}$ & $\begin{array}{l}0.012 \\
(0.226) \\
{[0.211]}\end{array}$ & $\begin{array}{l}0.018 \\
(0.206) \\
{[0.193]}\end{array}$ & $\begin{array}{l}0.081 \\
(0.108)\end{array}$ & & $\begin{array}{l}18.983 \\
{[19.713]}\end{array}$ & & & $\begin{array}{l}42.662 \\
{[44.305]}\end{array}$ & & & \\
\hline BE-2SLS & $\begin{array}{l}0.001 \\
(0.028) \\
{[0.032]}\end{array}$ & $\begin{array}{l}0.008 \\
(0.246) \\
{[0.268]}\end{array}$ & $\begin{array}{l}0.011 \\
(0.193) \\
{[0.213]}\end{array}$ & $\begin{array}{l}0.001 \\
(0.047) \\
{[0.046]}\end{array}$ & $\begin{array}{l}0.012 \\
(0.138) \\
{[0.12]}\end{array}$ & $\begin{array}{l}0.001 \\
(0.123) \\
{[0.129]}\end{array}$ & $\begin{array}{l}0.064 \\
(0.091)\end{array}$ & & & $\begin{array}{l}2.507 \\
{[3.787]}\end{array}$ & & & $\begin{array}{l}1.316 \\
{[5.972]}\end{array}$ & & \\
\hline \multicolumn{16}{|c|}{ Error Component Estimators } \\
\hline EC-2SLS & $\begin{array}{l}0.008 \\
(0.021) \\
{[0.024]}\end{array}$ & $\begin{array}{l}0.069 \\
(0.186) \\
{[0.213]}\end{array}$ & $\begin{array}{l}0.044 \\
(0.148) \\
{[0.163]}\end{array}$ & $\begin{array}{l}0.003 \\
(0.038) \\
{[0.036]}\end{array}$ & $\begin{array}{l}0.004 \\
(0.112) \\
{[0.116]}\end{array}$ & $\begin{array}{l}0.009 \\
(0.101) \\
{[0.107]}\end{array}$ & $\begin{array}{l}0.051 \\
(0.074)\end{array}$ & & $\begin{array}{l}18.983 \\
{[19.713]}\end{array}$ & $\begin{array}{l}2.507 \\
{[3.787]}\end{array}$ & & $\begin{array}{l}42.662 \\
{[44.305]}\end{array}$ & $\begin{array}{l}1.316 \\
{[5.972]}\end{array}$ & & \\
\hline EC-3SLS & $\begin{array}{l}0.001 \\
(0.021) \\
{[0.024]}\end{array}$ & $\begin{array}{l}0.013 \\
(0.186) \\
{[0.196]}\end{array}$ & $\begin{array}{l}0.003 \\
(0.147) \\
{[0.172]}\end{array}$ & $\begin{array}{l}0.001 \\
(0.038) \\
{[0.036]}\end{array}$ & $\begin{array}{l}0.007 \\
(0.11) \\
{[0.109]}\end{array}$ & $\begin{array}{l}0.012 \\
(0.096) \\
{[0.106]}\end{array}$ & $\begin{array}{l}0.051 \\
(0.072)\end{array}$ & & $\begin{array}{l}18.983 \\
{[19.713]}\end{array}$ & $\begin{array}{l}2.507 \\
{[3.787]}\end{array}$ & & $\begin{array}{l}42.662 \\
{[44.305]}\end{array}$ & $\begin{array}{l}1.316 \\
{[5.972]}\end{array}$ & $\begin{array}{l}8.19 \\
{[8.462]}\end{array}$ & $\begin{array}{l}0.359 \\
{[1.705]}\end{array}$ \\
\hline \multicolumn{16}{|c|}{ Generalized Simultaneous Moments-IV spatial Estimator } \\
\hline S2SLS I & $\begin{array}{l}0.001 \\
(0.005) \\
{[0.02]}\end{array}$ & $\begin{array}{l}0.011 \\
(0.04) \\
{[0.187]}\end{array}$ & $\begin{array}{l}0.011 \\
(0.032) \\
{[0.137]}\end{array}$ & $\begin{array}{l}0.001 \\
(0.007) \\
{[0.026]}\end{array}$ & $\begin{array}{l}0.002 \\
(0.019) \\
{[0.087]}\end{array}$ & $\begin{array}{l}0 \\
(0.017) \\
{[0.077]}\end{array}$ & $\begin{array}{l}0.041 \\
(0.06)\end{array}$ & $\begin{array}{l}0.01 \\
{[0.162]}\end{array}$ & $\begin{array}{l}14.073 \\
{[14.356]}\end{array}$ & $\begin{array}{l}1.623 \\
{[2.431]}\end{array}$ & $\begin{array}{l}0.007 \\
{[0.049]}\end{array}$ & $\begin{array}{l}11.932 \\
{[12.083]}\end{array}$ & $\begin{array}{l}0.451 \\
{[1.794]}\end{array}$ & & \\
\hline S2SLS C & $\begin{array}{l}0.002 \\
(0.005) \\
{[0.02]}\end{array}$ & $\begin{array}{l}0.013 \\
(0.04) \\
{[0.183]}\end{array}$ & $\begin{array}{l}0.013 \\
(0.032) \\
{[0.135]}\end{array}$ & $\begin{array}{l}0.001 \\
(0.006) \\
{[0.026]}\end{array}$ & $\begin{array}{l}0.001 \\
(0.019) \\
{[0.087]}\end{array}$ & $\begin{array}{l}0 \\
(0.017) \\
{[0.076]}\end{array}$ & $\begin{array}{l}0.041 \\
(0.059)\end{array}$ & $\begin{array}{l}0.013 \\
{[0.167]}\end{array}$ & $\begin{array}{l}13.755 \\
{[14.002]}\end{array}$ & $\begin{array}{l}1.633 \\
{[2.458]}\end{array}$ & $\begin{array}{l}0.001 \\
{[0.046]}\end{array}$ & $\begin{array}{l}11.484 \\
{[11.648]}\end{array}$ & $\begin{array}{l}0.064 \\
{[1.567]}\end{array}$ & & \\
\hline S3SLS & $\begin{array}{l}0.001 \\
(0.017) \\
{[0.019]}\end{array}$ & $\begin{array}{l}0.005 \\
(0.152) \\
{[0.178]}\end{array}$ & $\begin{array}{l}0.007 \\
(0.12) \\
{[0.134]}\end{array}$ & $\begin{array}{l}0 \\
(0.025) \\
{[0.023]}\end{array}$ & $\begin{array}{l}0 \\
(0.071) \\
{[0.07]}\end{array}$ & $\begin{array}{l}0.005 \\
(0.062) \\
{[0.061]}\end{array}$ & $\begin{array}{l}0.039 \\
(0.056)\end{array}$ & $\begin{array}{l}0.012 \\
{[0.163]}\end{array}$ & $\begin{array}{l}14.047 \\
{[14.349]}\end{array}$ & $\begin{array}{l}1.737 \\
{[2.48]}\end{array}$ & $\begin{array}{l}0.007 \\
{[0.049]}\end{array}$ & $\begin{array}{l}11.923 \\
{[12.089]}\end{array}$ & $\begin{array}{l}0.541 \\
{[1.959]}\end{array}$ & $\begin{array}{l}6.4 \\
{[6.589]}\end{array}$ & $\begin{array}{l}0.357 \\
{[1.478]}\end{array}$ \\
\hline
\end{tabular}

${ }^{1}$ In each cell of columns 2-7, the upper number denotes the bias. The middle one in parentheses denotes the standard deviation.

2 The bottom number denotes the RMSE. In each cell of column 8, the upper number denotes NOMAD. The lower one in parentheses denotes NORMSQD. 
Table 5: Efficient Criteria under $\sigma_{\xi_{l l}}^{2}=04, \sigma_{\eta_{l l}}^{2}=16, \mathrm{~T}=07, \mathrm{~N}=25, \rho_{1}=-0.8$ and $\mathrm{J}=07$

\begin{tabular}{|c|c|c|c|c|c|c|c|c|c|c|c|c|c|c|c|}
\hline Method & $\alpha_{1}$ & $\beta_{11}$ & $\beta_{12}$ & $\alpha_{2}$ & $\beta_{21}$ & $\beta_{22}$ & Nomad & $\rho_{1}$ & $\sigma_{\xi_{11}}^{2}$ & $\sigma_{\eta_{11}}^{2}$ & $\rho_{2}$ & $\sigma_{\xi_{22}}^{2}$ & $\sigma_{\eta_{22}}^{2}$ & $\sigma_{\xi_{12}}^{2}$ & $\sigma_{\eta_{12}}^{2}$ \\
\hline value & -0.5 & -2.0 & 1.5 & -4.0 & -3.0 & 1.8 & Normsqd & -0.8 & 04 & 16 & 0.8 & 04 & 16 & 02 & 08 \\
\hline \multicolumn{16}{|c|}{ Usual Estimators } \\
\hline OLS & $\begin{array}{l}0.093 \\
(0.01) \\
{[0.099]}\end{array}$ & $\begin{array}{l}0.745 \\
(0.093) \\
{[0.786]}\end{array}$ & $\begin{array}{l}0.552 \\
(0.075) \\
{[0.597]}\end{array}$ & $\begin{array}{l}0.009 \\
(0.023) \\
{[0.047]}\end{array}$ & $\begin{array}{l}0.006 \\
(0.07) \\
{[0.14]}\end{array}$ & $\begin{array}{l}0.009 \\
(0.063) \\
{[0.11]}\end{array}$ & $\begin{array}{l}0.172 \\
(0.383)\end{array}$ & & $\begin{array}{l}9.258 \\
{[9.811]}\end{array}$ & & & $\begin{array}{l}23.016 \\
{[24.052]}\end{array}$ & & & \\
\hline 2SLS & $\begin{array}{l}0.003 \\
(0.013) \\
{[0.039]}\end{array}$ & $\begin{array}{l}0.024 \\
(0.115) \\
{[0.326]}\end{array}$ & $\begin{array}{l}0.021 \\
(0.093) \\
{[0.253]}\end{array}$ & $\begin{array}{l}0.004 \\
(0.023) \\
{[0.048]}\end{array}$ & $\begin{array}{l}0.013 \\
(0.07) \\
{[0.129]}\end{array}$ & $\begin{array}{l}0.001 \\
(0.063) \\
{[0.116]}\end{array}$ & $\begin{array}{l}0.071 \\
(0.106)\end{array}$ & & $\begin{array}{l}16.447 \\
{[17.82]}\end{array}$ & & & $\begin{array}{l}23.106 \\
{[24.142]}\end{array}$ & & & \\
\hline \multirow[t]{3}{*}{ 3SLS } & 0.003 & 0.021 & 0.019 & 0.004 & 0.01 & 0.005 & 0.07 & & 16.447 & & & 23.106 & & 6.999 & \\
\hline & $(0.016)$ & $(0.14)$ & $(0.109)$ & $(0.024)$ & $(0.069)$ & $(0.06)$ & $(0.108)$ & & {$[17.82]$} & & & {$[24.142]$} & & {$[7.982]$} & \\
\hline & {$[0.038]$} & {$[0.33]$} & {$[0.27]$} & {$[0.047]$} & {$[0.116]$} & {$[0.103]$} & & & & & & & & & \\
\hline \multicolumn{16}{|c|}{ Specific Estimators } \\
\hline \multirow[t]{2}{*}{ FE-2SLS } & $\begin{array}{l}0.001 \\
(0.017)\end{array}$ & $\begin{array}{l}0.006 \\
(0.15)\end{array}$ & $\begin{array}{l}0.004 \\
(0.119)\end{array}$ & $\begin{array}{l}0.005 \\
(0.033)\end{array}$ & $\begin{array}{l}0.006 \\
(0.095)\end{array}$ & $\begin{array}{l}0.009 \\
(0.087)\end{array}$ & $\begin{array}{l}0.036 \\
(0.048)\end{array}$ & & $\begin{array}{l}0.349 \\
{[0.733]}\end{array}$ & & & $\begin{array}{l}6.291 \\
{[6.686]}\end{array}$ & & & \\
\hline & {$[0.017]$} & {$[0.135]$} & {$[0.104]$} & {$[0.03]$} & {$[0.092]$} & {$[0.085]$} & & & & & & & & & \\
\hline \multirow[t]{3}{*}{ BE-2SLS } & 0.003 & 0.026 & 0.023 & 0.005 & 0.016 & 0.004 & 0.088 & & & 11.833 & & & 14.08 & & \\
\hline & $(0.043)$ & $(0.372)$ & $(0.291)$ & $(0.058)$ & $(0.171)$ & $(0.154)$ & $(0.135)$ & & & {$[13.491]$} & & & {$[15.193]$} & & \\
\hline & {$[0.046]$} & {$[0.423]$} & {$[0.32]$} & {$[0.059]$} & {$[0.152]$} & {$[0.147]$} & & & & & & & & & \\
\hline \multicolumn{16}{|c|}{ Error Component Estimators } \\
\hline \multirow[t]{3}{*}{ EC-2SLS } & 0.005 & 0.041 & 0.03 & 0.003 & & 0.007 & 0.035 & & 0.349 & 11.833 & & 6.291 & 14.08 & & \\
\hline & $(0.015)$ & $(0.133)$ & $(0.106)$ & $(0.028)$ & $(0.081)$ & $(0.074)$ & $(0.048)$ & & {$[0.733]$} & {$[13.491]$} & & {$[6.686]$} & [15.193] & & \\
\hline & {$[0.017]$} & {$[0.135]$} & {$[0.113]$} & {$[0.026]$} & {$[0.07]$} & {$[0.069]$} & & & & & & & & & \\
\hline \multirow[t]{3}{*}{ EC-3SLS } & & 0.006 & 0.003 & 0.002 & 0.003 & 0.01 & 0.034 & & 0.349 & 11.833 & & 6.291 & 14.08 & 0.079 & 5.463 \\
\hline & $(0.015)$ & $(0.133)$ & $(0.105)$ & $(0.027)$ & $(0.079)$ & $(0.069)$ & $(0.048)$ & & {$[0.733]$} & {$[13.491]$} & & {$[6.686]$} & {$[15.193]$} & {$[0.412]$} & [6.594] \\
\hline & {$[0.016]$} & {$[0.137]$} & {$[0.114]$} & {$[0.025]$} & {$[0.079]$} & {$[0.074]$} & & & & & & & & & \\
\hline \multicolumn{16}{|c|}{ Generalized Simultaneous Moments-IV spatial Estimator } \\
\hline \multirow[t]{3}{*}{ S2SLS I } & 0.001 & 0.01 & 0.008 & 0.001 & 0 & 0 & 0.03 & 0.06 & 0.451 & 10.031 & 0.032 & 2.36 & 12.423 & & \\
\hline & $(0.007)$ & $(0.063)$ & $(0.05)$ & $(0.01)$ & $(0.029)$ & $(0.027)$ & $(0.044)$ & {$[0.323]$} & [1.244] & {$[11.412]$} & {$[0.07]$} & {$[2.45]$} & [13.094] & & \\
\hline & {$[0.015]$} & {$[0.131]$} & {$[0.102]$} & {$[0.02]$} & {$[0.063]$} & {$[0.061]$} & & & & & & & & & \\
\hline \multirow[t]{2}{*}{ S2SLS C } & $\begin{array}{l}0.001 \\
(0.007)\end{array}$ & $\begin{array}{l}0.011 \\
(0.064)\end{array}$ & $\begin{array}{l}0.008 \\
(0.051)\end{array}$ & $\begin{array}{l}0.002 \\
(0.01)\end{array}$ & $\begin{array}{l}0 \\
(0.03)\end{array}$ & $\begin{array}{l}0.001 \\
(0.027)\end{array}$ & $\begin{array}{l}0.03 \\
(0.042)\end{array}$ & $\begin{array}{l}0.076 \\
{[0.329]}\end{array}$ & $\begin{array}{l}0.114 \\
{[0.539]}\end{array}$ & $\begin{array}{l}10.95 \\
{[12.012]}\end{array}$ & $\begin{array}{l}0.014 \\
{[0.066]}\end{array}$ & $\begin{array}{l}1.855 \\
{[1.906]}\end{array}$ & $\begin{array}{l}13.481 \\
{[14.2355}\end{array}$ & & \\
\hline & {$[0.014]$} & {$[0.123]$} & {$[0.096]$} & {$[0.02]$} & {$[0.061]$} & {$[0.06]$} & & & & & & & & & \\
\hline \multirow[t]{3}{*}{ S3SLS } & 0.001 & 0.012 & 0.008 & 0 & 0.003 & 0.003 & 0.029 & 0.064 & 0.434 & 10.171 & 0.032 & 2.332 & 12.596 & 0.035 & 5.588 \\
\hline & $(0.015)$ & $(0.128)$ & $(0.101)$ & $(0.02)$ & $(0.058)$ & $(0.051)$ & $(0.042)$ & {$[0.308]$} & {$[1.252]$} & {$[11.584]$} & {$[0.069]$} & {$[2.418]$} & {$[13.326]$} & {$[0.485]$} & [6.679] \\
\hline & {$[0.014]$} & {$[0.127]$} & {$[0.101]$} & {$[0.018]$} & {$[0.056]$} & {$[0.052]$} & & & & & & & & & \\
\hline
\end{tabular}

\footnotetext{
${ }^{1}$ In each cell of columns 2-7, the upper number denotes the bias. The one in parentheses denotes the standard deviation.

2 The number in brackets denotes the RMSE. In each cell of column 8, the upper number denotes NOMAD. The lower one in parentheses denotes NORMSQD.
} 
Table 6: Efficient Criteria under $\sigma_{\xi_{l l}}^{2}=04, \sigma_{\eta_{l l}}^{2}=16, \mathrm{~T}=07, \mathrm{~N}=25, \rho_{1}=-0.8$ and $\mathrm{J}=09$

\begin{tabular}{|c|c|c|c|c|c|c|c|c|c|c|c|c|c|c|c|}
\hline Method & $\alpha_{1}$ & $\beta_{11}$ & $\beta_{12}$ & $\alpha_{2}$ & $\beta_{21}$ & $\beta_{22}$ & Nomad & $\rho_{1}$ & $\sigma_{\xi_{11}}^{2}$ & $\sigma_{\eta_{11}}^{2}$ & $\rho_{2}$ & $\sigma_{\xi_{22}}^{2}$ & $\sigma_{\eta_{22}}^{2}$ & $\overline{\sigma_{\xi_{12}}^{2}}$ & $\overline{\sigma_{\eta_{12}}^{2}}$ \\
\hline value & -0.5 & -2.0 & 1.5 & -4.0 & -3.0 & 1.8 & Normsqd & -0.8 & 04 & 16 & 0.8 & 04 & 16 & 02 & 08 \\
\hline \multicolumn{16}{|c|}{ Usual Estimators } \\
\hline \multirow[t]{2}{*}{ OLS } & $\begin{array}{l}0.092 \\
(0.01) \\
{[0.097]}\end{array}$ & $\begin{array}{l}0.736 \\
(0.093) \\
{[0.783]}\end{array}$ & $\begin{array}{l}0.545 \\
(0.075)\end{array}$ & $\begin{array}{l}0.006 \\
(0.022)\end{array}$ & $\begin{array}{l}0.002 \\
(0.067)\end{array}$ & $\begin{array}{l}0.005 \\
(0.06)\end{array}$ & $\begin{array}{l}0.169 \\
(0.373)\end{array}$ & & $\begin{array}{l}9.064 \\
{[9.52]}\end{array}$ & & & $\begin{array}{l}20.517 \\
{[21.226]}\end{array}$ & & & \\
\hline & $\begin{array}{l}{[0.097]} \\
0.003\end{array}$ & $\begin{array}{l}{[0.783]} \\
0.025\end{array}$ & $\begin{array}{l}{[0.581]} \\
0.022\end{array}$ & $\begin{array}{l}{[0.044]} \\
0.003\end{array}$ & $\begin{array}{l}{[0.126]} \\
0.012\end{array}$ & $\begin{array}{l}{[0.105]} \\
0.002\end{array}$ & 0.069 & & 16.02 & & & 20.571 & & & \\
\hline \multirow{2}{*}{$2 \mathrm{SLS}$} & $(0.013)$ & $(0.115)$ & $(0.092)$ & $(0.022)$ & $(0.067)$ & $(0.06)$ & $(0.103)$ & & {$[17.34]$} & & & {$[21.26]$} & & & \\
\hline & {$[0.037]$} & {$[0.312]$} & {$[0.258]$} & {$[0.044]$} & {$[0.119]$} & {$[0.104]$} & & & & & & & & & \\
\hline \multirow[t]{3}{*}{ 3SLS } & 0.003 & 0.023 & 0.019 & 0.003 & 0.008 & 0.004 & 0.068 & & 16.02 & & & 20.571 & & 6.868 & \\
\hline & $(0.016)$ & $(0.139)$ & $(0.108)$ & $(0.023)$ & $(0.066)$ & $(0.057)$ & $(0.107)$ & & {$[17.34]$} & & & {$[21.26]$} & & {$[7.777]$} & \\
\hline & {$[0.037]$} & {$[0.329]$} & {$[0.27]$} & {$[0.045]$} & {$[0.107]$} & {$[0.103]$} & & & & & & & & & \\
\hline \multicolumn{16}{|c|}{ Specific Estimators } \\
\hline \multirow[t]{3}{*}{ FE-2SLS } & 0.002 & 0.008 & 0.006 & 0.004 & 0.006 & 0.009 & 0.035 & & 0.263 & & & 5.768 & & & \\
\hline & $(0.017)$ & $(0.148)$ & $(0.118)$ & $(0.032)$ & $(0.092)$ & $(0.084)$ & $(0.048)$ & & {$[0.697]$} & & & {$[6.203]$} & & & \\
\hline & {$[0.016]$} & {$[0.138]$} & {$[0.103]$} & {$[0.029]$} & {$[0.085]$} & {$[0.089]$} & & & & & & & & & \\
\hline \multirow[t]{3}{*}{ BE-2SLS } & 0.003 & 0.027 & 0.023 & 0.004 & 0.014 & 0.004 & 0.086 & & & 11.503 & & & 12.186 & & \\
\hline & $(0.042)$ & $(0.369)$ & $(0.288)$ & $(0.055)$ & $(0.162)$ & $(0.145)$ & $(0.128)$ & & & {$[13.003]$} & & & {$[12.885]$} & & \\
\hline & {$[0.044]$} & {$[0.394]$} & {$[0.313]$} & {$[0.056]$} & {$[0.142]$} & {$[0.135]$} & & & & & & & & & \\
\hline \multicolumn{16}{|c|}{ Error Component Estimators } \\
\hline \multirow[t]{3}{*}{ EC-2SLS } & 0.004 & 0.037 & 0.027 & 0.002 & 0 & 0.007 & 0.034 & & 0.263 & 11.503 & & 5.768 & 12.186 & & \\
\hline & $(0.015)$ & $(0.132)$ & $(0.105)$ & $(0.027)$ & $(0.078)$ & $(0.071)$ & $(0.046)$ & & {$[0.697]$} & {$[13.003]$} & & {$[6.203]$} & {$[12.885]$} & & \\
\hline & {$[0.016]$} & {$[0.135]$} & {$[0.104]$} & {$[0.025]$} & {$[0.069]$} & {$[0.066]$} & & & & & & & & & \\
\hline \multirow[t]{3}{*}{ EC-3SLS } & 0 & 0.003 & 0.001 & 0.002 & 0.002 & 0.01 & 0.033 & & 0.263 & 11.503 & & 5.768 & 12.186 & 0.046 & 5.369 \\
\hline & $(0.015)$ & $(0.132)$ & $(0.104)$ & $(0.026)$ & $(0.076)$ & $(0.066)$ & $(0.047)$ & & {$[0.697]$} & {$[13.003]$} & & {$[6.203]$} & {$[12.885]$} & {$[0.388]$} & [6.391] \\
\hline & {$[0.015]$} & {$[0.135]$} & {$[0.111]$} & {$[0.024]$} & {$[0.071]$} & {$[0.066]$} & & & & & & & & & \\
\hline \multicolumn{16}{|c|}{ Generalized Simultaneous Moments-IV spatial Estimator } \\
\hline \multirow[t]{3}{*}{ S2SLS I } & 0.001 & 0.009 & 0.007 & 0.001 & 0.001 & & 0.031 & 0.041 & 0.442 & 9.988 & 0.036 & 2.284 & 12.191 & & \\
\hline & $(0.007)$ & $(0.063)$ & $(0.05)$ & $(0.01)$ & $(0.029)$ & $(0.027)$ & $(0.046)$ & {$[0.372]$} & {$[1.269]$} & {$[11.25]$} & {$[0.073]$} & {$[2.363]$} & {$[12.87]$} & & \\
\hline & {$[0.016]$} & {$[0.141]$} & {$[0.104]$} & {$[0.02]$} & {$[0.065]$} & {$[0.062]$} & & & & & & & & & \\
\hline \multirow[t]{3}{*}{ S2SLS C } & 0.001 & 0.009 & 0.006 & 0.002 & 0 & 0 & 0.03 & 0.104 & 0.12 & 10.936 & 0.021 & 1.861 & 13.445 & & \\
\hline & $(0.007)$ & $(0.064)$ & $(0.051)$ & $(0.01)$ & $(0.03)$ & $(0.027)$ & $(0.044)$ & {$[0.363]$} & {$[0.561]$} & [11.898] & {$[0.068]$} & [1.911] & {$[14.173]$} & & \\
\hline & {$[0.015]$} & {$[0.142]$} & {$[0.098]$} & {$[0.02]$} & {$[0.064]$} & {$[0.06]$} & & & & & & & & & \\
\hline \multirow[t]{3}{*}{ S3SLS } & 0.001 & 0.011 & 0.007 & 0 & 0.002 & 0.003 & 0.03 & 0.045 & 0.421 & 10.093 & 0.035 & 2.26 & 12.386 & 0.027 & 5.605 \\
\hline & $(0.015)$ & $(0.129)$ & $(0.101)$ & $(0.02)$ & $(0.058)$ & $(0.051)$ & $(0.045)$ & {$[0.364]$} & {$[1.245]$} & {$[11.447]$} & {$[0.073]$} & {$[2.327]$} & {$[13.082]$} & {$[0.477]$} & [6.565] \\
\hline & {$[0.015]$} & {$[0.142]$} & {$[0.107]$} & {$[0.019]$} & {$[0.057]$} & {$[0.053]$} & & & & & & & & & \\
\hline
\end{tabular}

${ }^{1}$ In each cell of columns 2-7, the upper number denotes the bias. The one in parentheses denotes the standard deviation.

2 The number in brackets denotes the RMSE. In each cell of column 8, the upper number denotes NOMAD. The lower one in parentheses denotes NORMSQD. 
Table 7: Efficient Criteria under $\sigma_{\xi_{l l}}^{2}=04, \sigma_{\eta_{l l}}^{2}=16, \mathrm{~T}=10, \mathrm{~N}=25, \rho_{1}=-0.8$ and $\mathrm{J}=03$

\begin{tabular}{|c|c|c|c|c|c|c|c|c|c|c|c|c|c|c|c|}
\hline Method & $\alpha_{1}$ & $\beta_{11}$ & $\beta_{12}$ & $\alpha_{2}$ & $\beta_{21}$ & $\beta_{22}$ & Nomad & $\rho_{1}$ & $\sigma_{\xi_{11}}^{2}$ & $\sigma_{\eta_{11}}^{2}$ & $\rho_{2}$ & $\sigma_{\xi_{22}}^{2}$ & $\sigma_{\eta_{22}}^{2}$ & $\sigma_{\xi_{12}}^{2}$ & $\sigma_{\eta_{12}}^{2}$ \\
\hline value & -0.5 & -2.0 & 1.5 & -4.0 & -3.0 & 1.8 & Normsqd & -0.8 & 04 & 16 & 0.8 & 04 & 16 & 02 & 08 \\
\hline $\begin{array}{l}\text { Usual Estiı } \\
\text { OLS }\end{array}$ & $\begin{array}{l}\text { nators } \\
0.1 \\
(0.009) \\
{[0.103]}\end{array}$ & $\begin{array}{l}0.795 \\
(0.079) \\
{[0.808]}\end{array}$ & $\begin{array}{l}0.612 \\
(0.064) \\
{[0.643]}\end{array}$ & $\begin{array}{l}0.033 \\
(0.024) \\
{[0.078]}\end{array}$ & $\begin{array}{l}0.044 \\
(0.073) \\
{[0.183]}\end{array}$ & $\begin{array}{l}0.018 \\
(0.067) \\
{[0.147]}\end{array}$ & $\begin{array}{l}0.191 \\
(0.419)\end{array}$ & & $\begin{array}{l}10.844 \\
{[11.384]}\end{array}$ & & & $\begin{array}{l}38.709 \\
{[41.23]}\end{array}$ & & & \\
\hline 2SLS & $\begin{array}{l}0.003 \\
(0.011) \\
{[0.039]}\end{array}$ & $\begin{array}{l}0.03 \\
(0.1) \\
{[0.357]}\end{array}$ & $\begin{array}{l}0.007 \\
(0.082) \\
{[0.25]}\end{array}$ & $\begin{array}{l}0.006 \\
(0.025) \\
{[0.07]}\end{array}$ & $\begin{array}{l}0.013 \\
(0.073) \\
{[0.187]}\end{array}$ & $\begin{array}{l}0.017 \\
(0.068) \\
{[0.149]}\end{array}$ & $\begin{array}{l}0.081 \\
(0.114)\end{array}$ & & $\begin{array}{l}20.187 \\
{[22.127]}\end{array}$ & & & $\begin{array}{l}39.397 \\
{[41.959]}\end{array}$ & & & \\
\hline $3 \mathrm{SLS}$ & $\begin{array}{l}0.003 \\
(0.015) \\
{[0.039]}\end{array}$ & $\begin{array}{l}0.03 \\
(0.126) \\
{[0.365]}\end{array}$ & $\begin{array}{l}0.01 \\
(0.099) \\
{[0.257]}\end{array}$ & $\begin{array}{l}0.006 \\
(0.026) \\
{[0.072]}\end{array}$ & $\begin{array}{l}0.012 \\
(0.073) \\
{[0.192]}\end{array}$ & $\begin{array}{l}0.004 \\
(0.066) \\
{[0.149]}\end{array}$ & $\begin{array}{l}0.081 \\
(0.116)\end{array}$ & & $\begin{array}{l}20.187 \\
{[22.127]}\end{array}$ & & & $\begin{array}{l}39.397 \\
{[41.959]}\end{array}$ & & $\begin{array}{l}7.864 \\
{[9.102]}\end{array}$ & \\
\hline \multicolumn{16}{|c|}{ Specific Estimators } \\
\hline FE-2SLS & $\begin{array}{l}0.001 \\
(0.015) \\
{[0.016]}\end{array}$ & $\begin{array}{l}0.009 \\
(0.132) \\
{[0.145]}\end{array}$ & $\begin{array}{l}0.004 \\
(0.105) \\
{[0.112]}\end{array}$ & $\begin{array}{l}0.003 \\
(0.032) \\
{[0.031]}\end{array}$ & $\begin{array}{l}0.012 \\
(0.093) \\
{[0.095]}\end{array}$ & $\begin{array}{l}0.014 \\
(0.085) \\
{[0.087]}\end{array}$ & $\begin{array}{l}0.036 \\
(0.05)\end{array}$ & & $\begin{array}{l}1.136 \\
{[1.345]}\end{array}$ & & & $\begin{array}{l}9.94 \\
{[10.22]}\end{array}$ & & & \\
\hline BE-2SLS & $\begin{array}{l}0.003 \\
(0.047) \\
{[0.051]}\end{array}$ & $\begin{array}{l}0.032 \\
(0.4) \\
{[0.423]}\end{array}$ & $\begin{array}{l}0.006 \\
(0.317) \\
{[0.318]}\end{array}$ & $\begin{array}{l}0.009 \\
(0.076) \\
{[0.086]}\end{array}$ & $\begin{array}{l}0.02 \\
(0.218) \\
{[0.238]}\end{array}$ & $\begin{array}{l}0.017 \\
(0.201) \\
{[0.195]}\end{array}$ & $\begin{array}{l}0.103 \\
(0.143)\end{array}$ & & & $\begin{array}{l}14.888 \\
{[17.253]}\end{array}$ & & & $\begin{array}{l}26.24 \\
{[30.557]}\end{array}$ & & \\
\hline $\begin{array}{c}\text { Error Com } \\
\text { EC-2SLS }\end{array}$ & $\begin{array}{l}\text { ponent } \\
0.003 \\
(0.014) \\
{[0.016]}\end{array}$ & $\begin{array}{l}\text { Estimat } \\
0.027 \\
(0.121) \\
{[0.146]}\end{array}$ & $\begin{array}{l}\text { rs } \\
0.024 \\
(0.097) \\
{[0.115]}\end{array}$ & $\begin{array}{l}0.002 \\
(0.029) \\
{[0.032]}\end{array}$ & $\begin{array}{l}0.009 \\
(0.083) \\
{[0.09]}\end{array}$ & $\begin{array}{l}0.012 \\
(0.076) \\
{[0.083]}\end{array}$ & $\begin{array}{l}0.036 \\
(0.051)\end{array}$ & & $\begin{array}{l}1.136 \\
{[1.345]}\end{array}$ & $\begin{array}{l}14.888 \\
{[17.253]}\end{array}$ & & $\begin{array}{l}9.94 \\
{[10.22]}\end{array}$ & $\begin{array}{l}26.24 \\
{[30.557]}\end{array}$ & & \\
\hline EC-3SLS & $\begin{array}{l}0 \\
(0.014) \\
{[0.016]}\end{array}$ & $\begin{array}{l}0.001 \\
(0.121) \\
{[0.155]}\end{array}$ & $\begin{array}{l}0.005 \\
(0.096) \\
{[0.11]}\end{array}$ & $\begin{array}{l}0.001 \\
(0.029) \\
{[0.031]}\end{array}$ & $\begin{array}{l}0.008 \\
(0.082) \\
{[0.098]}\end{array}$ & $\begin{array}{l}0.01 \\
(0.073) \\
{[0.082]}\end{array}$ & $\begin{array}{l}0.035 \\
(0.051)\end{array}$ & & $\begin{array}{l}1.136 \\
{[1.345]}\end{array}$ & $\begin{array}{l}14.888 \\
{[17.253]}\end{array}$ & & $\begin{array}{l}9.94 \\
{[10.22]}\end{array}$ & $\begin{array}{l}26.24 \\
{[30.557]}\end{array}$ & $\begin{array}{l}0.352 \\
{[0.496]}\end{array}$ & $\begin{array}{l}6.101 \\
{[7.407]}\end{array}$ \\
\hline \multicolumn{16}{|c|}{ Generalized Simultaneous Moments-IV spatial Estimator } \\
\hline S2SLS I & $\begin{array}{l}0.001 \\
(0.006) \\
{[0.013]}\end{array}$ & $\begin{array}{l}0.001 \\
(0.052) \\
{[0.114]}\end{array}$ & $\begin{array}{l}0.002 \\
(0.041) \\
{[0.087]}\end{array}$ & $\begin{array}{l}0 \\
(0.008) \\
{[0.019]}\end{array}$ & $\begin{array}{l}0.001 \\
(0.024) \\
{[0.054]}\end{array}$ & $\begin{array}{l}0.005 \\
(0.022) \\
{[0.049]}\end{array}$ & $\begin{array}{l}0.026 \\
(0.037)\end{array}$ & $\begin{array}{l}0.114 \\
{[0.207]}\end{array}$ & $\begin{array}{l}0.666 \\
{[1.277]}\end{array}$ & $\begin{array}{l}10.792 \\
{[12.137]}\end{array}$ & $\begin{array}{l}0.034 \\
{[0.06]}\end{array}$ & $\begin{array}{l}2.864 \\
{[2.949]}\end{array}$ & $\begin{array}{l}13.785 \\
{[14.602]}\end{array}$ & & \\
\hline S2SLS C & $\begin{array}{l}0.001 \\
(0.006) \\
{[0.012]}\end{array}$ & $\begin{array}{l}0.002 \\
(0.052) \\
{[0.107]}\end{array}$ & $\begin{array}{l}0 \\
(0.041) \\
{[0.088]}\end{array}$ & $\begin{array}{l}0 \\
(0.008) \\
{[0.019]}\end{array}$ & $\begin{array}{l}0.001 \\
(0.024) \\
{[0.051]}\end{array}$ & $\begin{array}{l}0.005 \\
(0.022) \\
{[0.048]}\end{array}$ & $\begin{array}{l}0.025 \\
(0.036)\end{array}$ & $\begin{array}{l}0.019 \\
{[0.144]}\end{array}$ & $\begin{array}{l}0.097 \\
{[0.421]}\end{array}$ & $\begin{array}{l}11.03 \\
{[11.932]}\end{array}$ & $\begin{array}{l}0.002 \\
{[0.037]}\end{array}$ & $\begin{array}{l}1.937 \\
{[1.972]}\end{array}$ & $\begin{array}{l}13.536 \\
{[14.227]}\end{array}$ & & \\
\hline S3SLS & $\begin{array}{l}0.001 \\
(0.012) \\
{[0.012]}\end{array}$ & $\begin{array}{l}0.004 \\
(0.106) \\
{[0.108]}\end{array}$ & $\begin{array}{l}0 \\
(0.083) \\
{[0.075]}\end{array}$ & $\begin{array}{l}0 \\
(0.017) \\
{[0.018]}\end{array}$ & $\begin{array}{l}0.001 \\
(0.05) \\
{[0.049]}\end{array}$ & $\begin{array}{l}0.002 \\
(0.044) \\
{[0.048]}\end{array}$ & $\begin{array}{l}0.024 \\
(0.034)\end{array}$ & $\begin{array}{l}0.115 \\
{[0.211]}\end{array}$ & $\begin{array}{l}0.676 \\
{[1.298]}\end{array}$ & $\begin{array}{l}11.026 \\
{[12.418]}\end{array}$ & $\begin{array}{l}0.033 \\
{[0.056]}\end{array}$ & $\begin{array}{l}2.842 \\
{[2.929]}\end{array}$ & $\begin{array}{l}13.996 \\
{[14.838]}\end{array}$ & $\begin{array}{l}0.011 \\
{[0.465]}\end{array}$ & $\begin{array}{l}5.641 \\
{[7.012]}\end{array}$ \\
\hline
\end{tabular}

${ }^{1}$ In each cell of columns 2-7, the upper number denotes the bias. The one in parentheses denotes the standard deviation.

2 The number in brackets denotes the RMSE. In each cell of column 8, the upper number denotes NOMAD. The lower one in parentheses denotes NORMSQD. 
Table 8: Efficient Criteria under $\sigma_{\xi_{l l}}^{2}=04, \sigma_{\eta_{l l}}^{2}=16, \mathrm{~T}=15, \mathrm{~N}=25, \rho_{1}=-0.8$ and $\mathrm{J}=03$

\begin{tabular}{|c|c|c|c|c|c|c|c|c|c|c|c|c|c|c|c|}
\hline Method & $\alpha_{1}$ & $\beta_{11}$ & $\beta_{12}$ & $\alpha_{2}$ & $\beta_{21}$ & $\beta_{22}$ & Nomad & $\rho_{1}$ & $\sigma_{\xi_{11}}^{2}$ & $\sigma_{\eta_{11}}^{2}$ & $\rho_{2}$ & $\sigma_{\xi_{22}}^{2}$ & $\sigma_{\eta_{22}}^{2}$ & $\sigma_{\xi_{12}}^{2}$ & $\sigma_{\eta_{12}}^{2}$ \\
\hline value & -0.5 & -2.0 & 1.5 & -4.0 & -3.0 & 1.8 & Normsqd & -0.8 & 04 & 16 & 0.8 & 04 & 16 & 02 & 08 \\
\hline \multicolumn{16}{|c|}{ Usual Estimators } \\
\hline OLS & $\begin{array}{l}0.102 \\
(0.007) \\
0.105]\end{array}$ & $\begin{array}{l}0.822 \\
(0.062) \\
{[0.8581}\end{array}$ & $\begin{array}{l}0.615 \\
(0.052) \\
{[0.649]}\end{array}$ & $\begin{array}{l}0.041 \\
(0.02) \\
0.066]\end{array}$ & $\begin{array}{l}0.05 \\
(0.06) \\
{[0.186]}\end{array}$ & $\begin{array}{l}0.026 \\
(0.055) \\
0.159]\end{array}$ & $\begin{array}{l}0.193 \\
(0.443)\end{array}$ & & $\begin{array}{l}10.401 \\
{[11.002]}\end{array}$ & & & $\begin{array}{l}38.625 \\
{[40.715]}\end{array}$ & & & \\
\hline 2SLS & $\begin{array}{l}0.004 \\
(0.009) \\
0.035]\end{array}$ & $\begin{array}{l}0.044 \\
(0.078) \\
{[0.263]}\end{array}$ & $\begin{array}{l}0.024 \\
(0.065) \\
{[0.255]}\end{array}$ & $\begin{array}{l}0.005 \\
(0.02) \\
{[0.06]}\end{array}$ & $\begin{array}{l}0.005 \\
(0.06) \\
{[0.174]}\end{array}$ & $\begin{array}{l}0.007 \\
(0.055) \\
{[0.17]}\end{array}$ & $\begin{array}{l}0.075 \\
(0.106)\end{array}$ & & $\begin{array}{l}19.028 \\
{[20.36]}\end{array}$ & & & $\begin{array}{l}39.221 \\
{[41.43]}\end{array}$ & & & \\
\hline \multirow[t]{3}{*}{ 3SLS } & 0.004 & 0.043 & 0.021 & 0.004 & 0.003 & 0.005 & 0.075 & & 19.028 & & & 39.221 & & 8.11 & \\
\hline & $(0.011)$ & $(0.098)$ & $(0.078)$ & $(0.021)$ & $(0.06)$ & $(0.053)$ & $(0.105)$ & & {$[20.36]$} & & & [41.43] & & {$[9.263]$} & \\
\hline & {$[0.035]$} & {$[0.273]$} & {$[0.245]$} & {$[0.058]$} & {$[0.192]$} & {$[0.156]$} & & & & & & & & & \\
\hline \multicolumn{16}{|c|}{ Specific Estimators } \\
\hline \multirow[t]{2}{*}{ FE-2SLS } & $\begin{array}{l}0.001 \\
(0.012)\end{array}$ & $\begin{array}{l}0.006 \\
(0.105)\end{array}$ & $\begin{array}{l}0.001 \\
(0.084)\end{array}$ & $\begin{array}{l}0.005 \\
(0.026)\end{array}$ & $\begin{array}{l}0.001 \\
(0.074)\end{array}$ & $\begin{array}{l}0.001 \\
(0.068)\end{array}$ & $\begin{array}{l}0.025 \\
(0.034)\end{array}$ & & $\begin{array}{l}1.13 \\
{[1.263]}\end{array}$ & & & $\begin{array}{l}9.855 \\
{[10.07]}\end{array}$ & & & \\
\hline & {$[0.01]$} & {$[0.09]$} & {$[0.073]$} & {$[0.028]$} & {$[0.08]$} & {$[0.067]$} & & & & & & & & & \\
\hline \multirow[t]{3}{*}{ BE-2SLS } & 0.006 & 0.056 & 0.032 & 0.007 & 0.007 & 0.012 & 0.096 & & & 13.844 & & & 26.465 & & \\
\hline & $(0.044)$ & $(0.377)$ & $(0.303)$ & $(0.074)$ & $(0.22)$ & $(0.201)$ & $(0.136)$ & & & {$[15.668]$} & & & [30] & & \\
\hline & {$[0.042]$} & {$[0.349]$} & {$[0.313]$} & {$[0.072]$} & {$[0.215]$} & {$[0.219]$} & & & & & & & & & \\
\hline \multicolumn{16}{|c|}{ Error Component Estimators } \\
\hline \multirow[t]{2}{*}{ EC-2SLS } & 0.004 & 0.037 & 0.024 & 0.003 & 0.001 & 0.002 & 0.026 & & 1.13 & 13.844 & & 9.855 & 26.465 & & \\
\hline & $(0.011)$ & $\begin{array}{l}(0.099) \\
{[0.0951}\end{array}$ & $\begin{array}{l}(0.079) \\
{[0.0771}\end{array}$ & $\begin{array}{l}(0.024) \\
{[0.026]}\end{array}$ & $\begin{array}{l}(0.069) \\
{[0.071]}\end{array}$ & $\begin{array}{l}(0.063) \\
{[0.059]}\end{array}$ & $(0.035)$ & & {$[1.263]$} & {$[15.668]$} & & {$[10.07]$} & & & \\
\hline \multirow[t]{3}{*}{ EC-3SLS } & 0.002 & 0.018 & 0.01 & 0.003 & 0.001 & 0.003 & 0.024 & & 1.13 & 13.844 & & 9.855 & 26.465 & 0.339 & 6.348 \\
\hline & $(0.011)$ & $(0.099)$ & $(0.078)$ & $(0.024)$ & $(0.068)$ & $(0.061)$ & $(0.033)$ & & {$[1.263]$} & {$[15.668]$} & & {$[10.07]$} & {$[30]$} & {$[0.447]$} & [7.746] \\
\hline & {$[0.01]$} & {$[0.088]$} & {$[0.071]$} & {$[0.026]$} & {$[0.071]$} & {$[0.061]$} & & & & & & & & & \\
\hline \multicolumn{16}{|c|}{ Generalized Simultaneous Moments-IV spatial Estimator } \\
\hline \multirow[t]{3}{*}{ S2SLS I } & 0.001 & 0.009 & 0.003 & 0 & 0 & 0.002 & 0.018 & 0.118 & 0.466 & 10.248 & 0.033 & 2.758 & 13.736 & & \\
\hline & $(0.005)$ & $(0.042)$ & $(0.034)$ & $(0.007)$ & $(0.02)$ & $(0.018)$ & $(0.025)$ & {$[0.188]$} & [0.971] & [11.483] & {$[0.051]$} & {$[2.848]$} & [14.545] & & \\
\hline & {$[0.008]$} & {$[0.076]$} & {$[0.057]$} & {$[0.014]$} & {$[0.04]$} & {$[0.033]$} & & & & & & & & & \\
\hline \multirow[t]{2}{*}{ S2SLS C } & 0.001 & 0.006 & 0.002 & 0 & 0 & 0.002 & 0.018 & 0.008 & 0.067 & 11.026 & 0.002 & 1.914 & 13.673 & & \\
\hline & $\begin{array}{l}(0.005) \\
{[0.008]}\end{array}$ & $\begin{array}{l}(0.042) \\
{[0.08]}\end{array}$ & $\begin{array}{l}(0.033) \\
{[0.056]}\end{array}$ & $\begin{array}{l}(0.007) \\
{[0.014]}\end{array}$ & $\begin{array}{l}(0.02) \\
{[0.037]}\end{array}$ & $\begin{array}{l}(0.018) \\
{[0.033]}\end{array}$ & $(0.025)$ & {$[0.109]$} & {$[0.357]$} & [11.78] & {$[0.031]$} & [1.944] & [14.384] & & \\
\hline \multirow[t]{3}{*}{ S3SLS } & 0.001 & 0.008 & 0.003 & 0 & 0 & 0.003 & 0.017 & 0.118 & 0.469 & 10.544 & 0.032 & 2.748 & 14.04 & 0.066 & 5.824 \\
\hline & $(0.01)$ & $(0.084)$ & $(0.067)$ & $(0.014)$ & $(0.04)$ & $(0.035)$ & $(0.024)$ & {$[0.181]$} & {$[0.939]$} & {$[11.715]$} & {$[0.048]$} & {$[2.835]$} & {$[14.872]$} & {$[0.4]$} & [7.129] \\
\hline & {$[0.007]$} & {$[0.07]$} & {$[0.055]$} & {$[0.014]$} & {$[0.045]$} & {$[0.032]$} & & & & & & & & & \\
\hline
\end{tabular}

\footnotetext{
${ }^{1}$ In each cell of columns 2-7, the upper number denotes the bias. The one in parentheses denotes the standard deviation.

2 The number in brackets denotes the RMSE. In each cell of column 8, the upper number denotes NOMAD. The lower one in parentheses denotes NORMSQD.
} 
Table 9: Efficient Criteria under $\sigma_{\xi_{l l}}^{2}=04, \sigma_{\eta_{l l}}^{2}=16, \mathrm{~T}=07, \mathrm{~N}=25, \rho_{1}=-0.4$ and $\mathrm{J}=03$

\begin{tabular}{|c|c|c|c|c|c|c|c|c|c|c|c|c|c|c|c|}
\hline Method & $\alpha_{1}$ & $\beta_{11}$ & $\beta_{12}$ & $\alpha_{2}$ & $\beta_{21}$ & $\beta_{22}$ & Nomad & $\rho_{1}$ & $\sigma_{\xi_{11}}^{2}$ & $\sigma_{\eta_{11}}^{2}$ & $\rho_{2}$ & $\sigma_{\xi_{22}}^{2}$ & $\sigma_{\eta_{22}}^{2}$ & $\sigma_{\xi_{12}}^{2}$ & $\sigma_{\eta_{12}}^{2}$ \\
\hline value & -0.5 & -2.0 & 1.5 & -4.0 & -3.0 & 1.8 & Normsqd & -0.8 & 04 & 16 & 0.8 & 04 & 16 & 02 & 08 \\
\hline \multicolumn{16}{|c|}{ Usual Estimators } \\
\hline OLS & $\begin{array}{l}0.088 \\
(0.01) \\
{[0.094]}\end{array}$ & $\begin{array}{l}0.705 \\
(0.093) \\
{[0.746]}\end{array}$ & $\begin{array}{l}0.522 \\
(0.075) \\
{[0.562]}\end{array}$ & $\begin{array}{l}0.036 \\
(0.029) \\
{[0.07]}\end{array}$ & $\begin{array}{l}0.043 \\
(0.088) \\
{[0.173]}\end{array}$ & $\begin{array}{l}0.038 \\
(0.08) \\
{[0.167]}\end{array}$ & $\begin{array}{l}0.171 \\
(0.352)\end{array}$ & & $\begin{array}{l}9.24 \\
{[9.725]}\end{array}$ & & & $\begin{array}{l}38.703 \\
{[41.704]}\end{array}$ & & & \\
\hline 2SLS & $\begin{array}{l}0.003 \\
(0.012) \\
{[0.038]}\end{array}$ & $\begin{array}{l}0.024 \\
(0.113) \\
{[0.306]}\end{array}$ & $\begin{array}{l}0.023 \\
(0.091) \\
{[0.248]}\end{array}$ & $\begin{array}{l}0.002 \\
(0.029) \\
0.063]\end{array}$ & $\begin{array}{l}0.017 \\
(0.089) \\
{[0.155]}\end{array}$ & $\begin{array}{l}0.006 \\
(0.08) \\
0.157]\end{array}$ & $\begin{array}{l}0.076 \\
(0.105)\end{array}$ & & $\begin{array}{l}15.744 \\
{[16.859]}\end{array}$ & & & $\begin{array}{l}39.32 \\
{[42.372]}\end{array}$ & & & \\
\hline 3SLS & $\begin{array}{l}0.003 \\
(0.016) \\
{[0.037]}\end{array}$ & $\begin{array}{l}0.021 \\
(0.138) \\
{[0.315]}\end{array}$ & $\begin{array}{l}0.02 \\
(0.108) \\
{[0.269]}\end{array}$ & $\begin{array}{l}0.003 \\
(0.03) \\
{[0.061]}\end{array}$ & $\begin{array}{l}0.014 \\
(0.089) \\
{[0.16]}\end{array}$ & $\begin{array}{l}0.013 \\
(0.077) \\
{[0.147]}\end{array}$ & $\begin{array}{l}0.075 \\
(0.11)\end{array}$ & & $\begin{array}{l}15.744 \\
{[16.859]}\end{array}$ & & & $\begin{array}{l}39.32 \\
{[42.372]}\end{array}$ & & $\begin{array}{l}7.889 \\
{[8.936]}\end{array}$ & \\
\hline \multicolumn{16}{|c|}{ Specific Estimators } \\
\hline FE-2SLS & $\begin{array}{l}0.001 \\
(0.017) \\
{[0.016]}\end{array}$ & $\begin{array}{l}0.006 \\
(0.147) \\
0.145]\end{array}$ & $\begin{array}{l}0.004 \\
(0.117) \\
0.106]\end{array}$ & $\begin{array}{l}0.006 \\
(0.039) \\
{[0.035]}\end{array}$ & $\begin{array}{l}0.006 \\
(0.113) \\
{[0.107]}\end{array}$ & $\begin{array}{l}0.009 \\
(0.103) \\
0.096]\end{array}$ & $\begin{array}{l}0.038 \\
(0.051)\end{array}$ & & $\begin{array}{l}0.219 \\
{[0.64]}\end{array}$ & & & $\begin{array}{l}9.69 \\
{[10.095]}\end{array}$ & & & \\
\hline BE-2SLS & $\begin{array}{l}0.003 \\
(0.042) \\
{[0.046]}\end{array}$ & $\begin{array}{l}0.027 \\
(0.366) \\
{[0.37]}\end{array}$ & $\begin{array}{l}0.026 \\
(0.287) \\
{[0.307]}\end{array}$ & $\begin{array}{l}0.003 \\
(0.075) \\
{[0.081]}\end{array}$ & $\begin{array}{l}0.021 \\
(0.222) \\
{[0.183]}\end{array}$ & $\begin{array}{l}0.005 \\
(0.198) \\
{[0.206]}\end{array}$ & $\begin{array}{l}0.094 \\
(0.131)\end{array}$ & & & $\begin{array}{l}11.305 \\
{[12.679]}\end{array}$ & & & $\begin{array}{l}26.162 \\
{[29.519]}\end{array}$ & & \\
\hline \multicolumn{16}{|c|}{ Error Component Estimators } \\
\hline EC-2SLS & $\begin{array}{l}0.004 \\
(0.015) \\
{[0.016]}\end{array}$ & $\begin{array}{l}0.038 \\
(0.131) \\
{[0.135]}\end{array}$ & $\begin{array}{l}0.027 \\
(0.105) \\
{[0.108]}\end{array}$ & $\begin{array}{l}0.005 \\
(0.033) \\
{[0.03]}\end{array}$ & $\begin{array}{l}0.001 \\
(0.097) \\
{[0.095]}\end{array}$ & $\begin{array}{l}0.01 \\
(0.089) \\
{[0.088]}\end{array}$ & $\begin{array}{l}0.037 \\
(0.05)\end{array}$ & & $\begin{array}{l}0.219 \\
{[0.64]}\end{array}$ & $\begin{array}{l}11.305 \\
{[12.679]}\end{array}$ & & $\begin{array}{l}9.69 \\
{[10.095]}\end{array}$ & $\begin{array}{l}26.162 \\
{[29.519]}\end{array}$ & & \\
\hline EC-3SLS & $\begin{array}{l}0 \\
(0.015) \\
{[0.015]}\end{array}$ & $\begin{array}{l}0.005 \\
(0.131) \\
{[0.134]}\end{array}$ & $\begin{array}{l}0.002 \\
(0.104) \\
{[0.11]}\end{array}$ & $\begin{array}{l}0.004 \\
(0.033) \\
{[0.029]}\end{array}$ & $\begin{array}{l}0.004 \\
(0.095) \\
{[0.087]}\end{array}$ & $\begin{array}{l}0.013 \\
(0.084) \\
{[0.086]}\end{array}$ & $\begin{array}{l}0.036 \\
(0.049)\end{array}$ & & $\begin{array}{l}0.219 \\
{[0.64]}\end{array}$ & $\begin{array}{l}11.305 \\
{[12.679]}\end{array}$ & & $\begin{array}{l}9.69 \\
{[10.095]}\end{array}$ & $\begin{array}{l}26.162 \\
{[29.519]}\end{array}$ & $\begin{array}{l}0.313 \\
{[0.587]}\end{array}$ & $\begin{array}{l}6.07 \\
{[7.38]}\end{array}$ \\
\hline \multicolumn{16}{|c|}{ Generalized Simultaneous Moments-IV spatial Estimator } \\
\hline S2SLS I & $\begin{array}{l}0.001 \\
(0.007) \\
{[0.015]}\end{array}$ & $\begin{array}{l}0.01 \\
(0.064) \\
{[0.138]}\end{array}$ & $\begin{array}{l}0.007 \\
(0.051) \\
0.105]\end{array}$ & $\begin{array}{l}0.001 \\
(0.01) \\
{[0.019]}\end{array}$ & $\begin{array}{l}0.001 \\
(0.029) \\
{[0.062]}\end{array}$ & $\begin{array}{l}0 \\
(0.026) \\
{[0.053]}\end{array}$ & $\begin{array}{l}0.03 \\
(0.045)\end{array}$ & $\begin{array}{l}0.026 \\
{[0.153]}\end{array}$ & $\begin{array}{l}0.419 \\
{[1.185]}\end{array}$ & $\begin{array}{l}10.023 \\
{[11.231]}\end{array}$ & $\begin{array}{l}0.037 \\
{[0.069]}\end{array}$ & $\begin{array}{l}2.844 \\
{[3.012]}\end{array}$ & $\begin{array}{l}13.797 \\
{[14.624]}\end{array}$ & & \\
\hline S2SLS C & $\begin{array}{l}0.001 \\
(0.007) \\
{[0.014]}\end{array}$ & $\begin{array}{l}0.01 \\
(0.064) \\
{[0.132]}\end{array}$ & $\begin{array}{l}0.007 \\
(0.051) \\
{[0.098]}\end{array}$ & $\begin{array}{l}0.001 \\
(0.01) \\
{[0.019]}\end{array}$ & $\begin{array}{l}0.002 \\
(0.029) \\
{[0.061]}\end{array}$ & $\begin{array}{l}0 \\
(0.026) \\
{[0.054]}\end{array}$ & $\begin{array}{l}0.029 \\
(0.042)\end{array}$ & $\begin{array}{l}0.024 \\
{[0.157]}\end{array}$ & $\begin{array}{l}0.101 \\
{[0.533]}\end{array}$ & $\begin{array}{l}11.042 \\
{[12.092]}\end{array}$ & {$[0.046]$} & $\begin{array}{l}1.834 \\
{[1.901]}\end{array}$ & $\begin{array}{l}13.45 \\
{[14.187]}\end{array}$ & & \\
\hline S3SLS & $\begin{array}{l}0.001 \\
(0.015) \\
{[0.014]}\end{array}$ & $\begin{array}{l}0.01 \\
(0.128) \\
{[0.135]}\end{array}$ & $\begin{array}{l}0.007 \\
(0.101) \\
{[0.094]}\end{array}$ & $\begin{array}{l}0 \\
(0.021) \\
{[0.018]}\end{array}$ & $\begin{array}{l}0 \\
(0.06) \\
{[0.056]}\end{array}$ & $\begin{array}{l}0.003 \\
(0.052) \\
{[0.047]}\end{array}$ & $\begin{array}{l}0.029 \\
(0.041)\end{array}$ & $\begin{array}{l}0.027 \\
{[0.145]}\end{array}$ & $\begin{array}{l}0.41 \\
{[1.157]}\end{array}$ & $\begin{array}{l}10.221 \\
{[11.417]}\end{array}$ & $\begin{array}{l}0.036 \\
{[0.07]}\end{array}$ & $\begin{array}{l}2.81 \\
{[2.977]}\end{array}$ & $\begin{array}{l}13.947 \\
{[14.792]}\end{array}$ & $\begin{array}{l}0.006 \\
{[0.503]}\end{array}$ & $\begin{array}{l}5.702 \\
{[6.738]}\end{array}$ \\
\hline
\end{tabular}

\footnotetext{
${ }^{1}$ In each cell of columns 2-7, the upper number denotes the bias. The one in parentheses denotes the standard deviation.

2 The number in brackets denotes the RMSE. In each cell of column 8, the upper number denotes NOMAD. The lower one in parentheses denotes NORMSQD.
} 
Table 10: Efficient Criteria under $\sigma_{\xi_{l l}}^{2}=04, \sigma_{\eta_{l l}}^{2}=16, \mathrm{~T}=07, \mathrm{~N}=25, \rho_{1}=0.4$ and $\mathrm{J}=03$

\begin{tabular}{|c|c|c|c|c|c|c|c|c|c|c|c|c|c|c|c|}
\hline Method & $\alpha_{1}$ & $\beta_{11}$ & $\beta_{12}$ & $\alpha_{2}$ & $\beta_{21}$ & $\beta_{22}$ & Nomad & $\rho_{1}$ & $\sigma_{\xi_{11}}^{2}$ & $\sigma_{\eta_{11}}^{2}$ & $\rho_{2}$ & $\sigma_{\xi_{22}}^{2}$ & $\sigma_{\eta_{22}}^{2}$ & $\sigma_{\xi_{12}}^{2}$ & $\sigma_{\eta_{12}}^{2}$ \\
\hline value & -0.5 & -2.0 & 1.5 & -4.0 & -3.0 & 1.8 & Normsqd & -0.8 & 04 & 16 & 0.8 & 04 & 16 & 02 & 08 \\
\hline \multirow[t]{2}{*}{ OLS } & $\begin{array}{l}0.086 \\
(0.011)\end{array}$ & $\begin{array}{l}0.687 \\
(0.095)\end{array}$ & $\begin{array}{l}0.509 \\
(0.077)\end{array}$ & $\begin{array}{l}0.027 \\
(0.029)\end{array}$ & $\begin{array}{l}0.029 \\
(0.089)\end{array}$ & $\begin{array}{l}0.03 \\
(0.08)\end{array}$ & $\begin{array}{l}0.167 \\
(0.337)\end{array}$ & & $\begin{array}{l}9.441 \\
{[10.019]}\end{array}$ & & & $\begin{array}{l}38.852 \\
{[41.996]}\end{array}$ & & & \\
\hline & {$[0.09]$} & {$[0.733]$} & {$[0.543]$} & {$[0.068]$} & {$[0.169]$} & {$[0.165]$} & & & & & & & & & \\
\hline \multirow[t]{2}{*}{ 2SLS } & $\begin{array}{l}0.003 \\
(0.013)\end{array}$ & $\begin{array}{l}0.028 \\
(0.114)\end{array}$ & $\begin{array}{l}0.025 \\
(0.092)\end{array}$ & $\begin{array}{l}0.002 \\
(0.029)\end{array}$ & $\begin{array}{l}0.017 \\
(0.089)\end{array}$ & $\begin{array}{l}0.006 \\
(0.08)\end{array}$ & $\begin{array}{l}0.074 \\
(0.102)\end{array}$ & & $\begin{array}{l}15.431 \\
{[16.769]}\end{array}$ & & & $\begin{array}{l}39.264 \\
{[42.449]}\end{array}$ & & & \\
\hline & {$[0.037]$} & {$[0.292]$} & {$[0.248]$} & {$[0.063]$} & {$[0.154]$} & {$[0.154]$} & & & & & & & & & \\
\hline \multicolumn{16}{|c|}{ Specific Estimators } \\
\hline \multirow[t]{2}{*}{ FE-2SLS } & $\begin{array}{l}0.001 \\
(0.017)\end{array}$ & $\begin{array}{l}0.007 \\
(0.152)\end{array}$ & $\begin{array}{l}0.003 \\
(0.12)\end{array}$ & $\begin{array}{l}0.006 \\
(0.039)\end{array}$ & $\begin{array}{l}0.006 \\
(0.113)\end{array}$ & $\begin{array}{l}0.009 \\
(0.103)\end{array}$ & $\begin{array}{l}0.039 \\
(0.052)\end{array}$ & & $\begin{array}{l}0.466 \\
{[0.818]}\end{array}$ & & & $\begin{array}{l}9.698 \\
{[10.105]}\end{array}$ & & & \\
\hline & {$[0.017]$} & {$[0.158]$} & {$[0.098]$} & {$[0.036]$} & {$[0.107]$} & {$[0.096]$} & & & & & & & & & \\
\hline BE-2SLS & $\begin{array}{l}0.003 \\
(0.041)\end{array}$ & $\begin{array}{l}0.031 \\
(0.357)\end{array}$ & $\begin{array}{l}0.028 \\
(0.28)\end{array}$ & $\begin{array}{l}0.003 \\
(0.075)\end{array}$ & $\begin{array}{l}0.02 \\
(0.222)\end{array}$ & $\begin{array}{l}0.005 \\
(0.198)\end{array}$ & $\begin{array}{l}0.092 \\
(0.128)\end{array}$ & & & $\begin{array}{l}10.724 \\
{[12.218]}\end{array}$ & & & $\begin{array}{l}26.099 \\
{[29.545]}\end{array}$ & & \\
\hline \multirow[t]{2}{*}{ EC-3SLS } & 0 & 0.003 & 0.001 & 0.003 & 0.004 & 0.013 & $\begin{array}{l}0.036 \\
(0.048)\end{array}$ & & $\begin{array}{l}0.466 \\
{[0.818]}\end{array}$ & $\begin{array}{l}10.724 \\
{[12218]}\end{array}$ & & $\begin{array}{l}9.698 \\
{[10105]}\end{array}$ & 26.099 & $\begin{array}{l}1.109 \\
{[1.437]}\end{array}$ & 7.585 \\
\hline & $\begin{array}{l}(0.015) \\
{[0.016]}\end{array}$ & $\begin{array}{l}(0.133) \\
{[0.134]}\end{array}$ & $\begin{array}{l}(0.105) \\
{[0.106]}\end{array}$ & $\begin{array}{l}(0.033) \\
{[0.029]}\end{array}$ & $\begin{array}{l}(0.094) \\
{[0.091]}\end{array}$ & {$[0.086]$} & & & & & & & & & \\
\hline \multicolumn{16}{|c|}{ Generalized Simultaneous Moments-IV spatial Estimator } \\
\hline \multirow[t]{3}{*}{ S2SLS I } & 0.002 & 0.01 & 0.008 & 0.001 & 0.001 & & 0.029 & 0.037 & 0.434 & 9.992 & 0.036 & 2.827 & 13.767 & & \\
\hline & $(0.007)$ & $(0.064)$ & $(0.051)$ & $(0.01)$ & $(0.029)$ & $(0.026)$ & $(0.042)$ & {$[0.106]$} & {$[1.262]$} & [11.269] & {$[0.069]$} & {$[2.994]$} & {$[14.561]$} & & \\
\hline & {$[0.015]$} & {$[0.129]$} & {$[0.097]$} & {$[0.019]$} & {$[0.062]$} & {$[0.053]$} & & & & & & & & & \\
\hline \multirow{3}{*}{ S2SLS C } & 0.002 & 0.009 & 0.008 & 0.001 & 0.002 & 0 & 0.028 & 0.012 & 0.076 & 11.118 & & 1.833 & 13.443 & & \\
\hline & $(0.007)$ & $(0.065)$ & $(0.051)$ & $(0.01)$ & $(0.029)$ & $(0.026)$ & $(0.04)$ & {$[0.1]$} & {$[0.522]$} & [12.301] & {$[0.045]$} & {$[1.899]$} & [14.165] & & \\
\hline & {$[0.014]$} & {$[0.12]$} & {$[0.091]$} & {$[0.019]$} & {$[0.061]$} & {$[0.054]$} & & & & & & & & & \\
\hline \multirow[t]{3}{*}{ S3SLS } & 0.002 & 0.011 & 0.007 & 0 & 0 & 0.003 & 0.029 & 0.037 & 0.415 & 10.116 & 0.034 & 2.762 & 13.814 & 0.079 & 5.923 \\
\hline & $(0.015)$ & $(0.131)$ & $(0.103)$ & $(0.021)$ & $(0.06)$ & $(0.052)$ & $(0.043)$ & {$[0.103]$} & [1.278] & [11.381] & {$[0.067]$} & {$[2.923]$} & [14.59] & {$[0.492]$} & {$[6.97]$} \\
\hline & {$[0.014]$} & {$[0.133]$} & {$[0.101]$} & {$[0.019]$} & {$[0.056]$} & {$[0.049]$} & & & & & & & & & \\
\hline
\end{tabular}

\footnotetext{
${ }^{1}$ In each cell of columns 2-7, the upper number denotes the bias. The one in parentheses denotes the standard deviation.

2 The number in brackets denotes the RMSE. In each cell of column 8, the upper number denotes NOMAD. The lower one in parentheses denotes NORMSQD.
} 
Table 11: Efficient Criteria under $\sigma_{\xi_{l l}}^{2}=04, \sigma_{\eta_{l l}}^{2}=16, \mathrm{~T}=07, \mathrm{~N}=25, \rho_{1}=0.8$ and $\mathrm{J}=03$

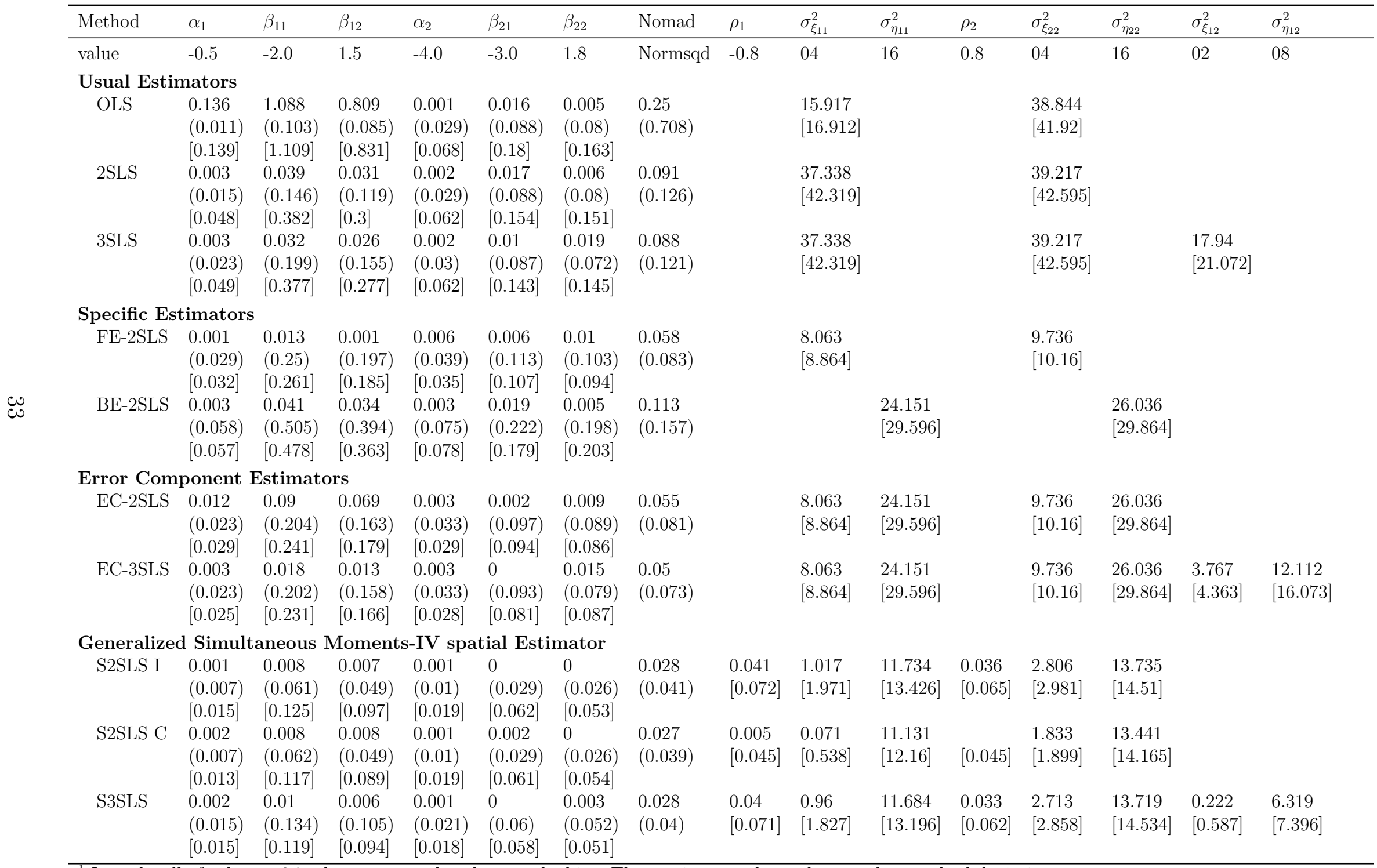

\footnotetext{
${ }^{1}$ In each cell of columns 2-7, the upper number denotes the bias. The one in parentheses denotes the standard deviation.

2 The number in brackets denotes the RMSE. In each cell of column 8, the upper number denotes NOMAD. The lower one in parentheses denotes NORMSQD.
} 
Table 12: Health and Income in SSA SPE-SAR Estimates ${ }^{1}$

\begin{tabular}{|c|c|c|c|c|c|c|c|}
\hline Variables & OLS & 2SLS & LSDV & EC2SLS & EC3SLS & GMS2SLS & GMS3SLS \\
\hline \multicolumn{8}{|c|}{ Real Income } \\
\hline Constant & $\begin{array}{l}8.062^{*} \\
(0.433)\end{array}$ & $\begin{array}{l}10.664^{*} \\
(0.702)\end{array}$ & $\begin{array}{l}0.349 \\
(190.776)\end{array}$ & $\begin{array}{l}8.445^{*} \\
(3.279)\end{array}$ & $\begin{array}{l}10.459^{*} \\
(2.99)\end{array}$ & $\begin{array}{l}8.734^{*} \\
(3.242)\end{array}$ & $\begin{array}{l}7.048^{*} \\
(3.258)\end{array}$ \\
\hline Health & $\begin{array}{l}0.324^{*} \\
(0.032)\end{array}$ & $\begin{array}{l}-0.101 \\
(0.087)\end{array}$ & $\begin{array}{l}-0.099 \\
(0.056)\end{array}$ & $\begin{array}{l}-0.024 \\
(0.069)\end{array}$ & $\begin{array}{l}-0.003 \\
(0.064)\end{array}$ & $\begin{array}{l}-0.019 \\
(0.068)\end{array}$ & $\begin{array}{l}-0.037 \\
(0.068)\end{array}$ \\
\hline Labour & $\begin{array}{l}-0.463^{*} \\
(0.034)\end{array}$ & $\begin{array}{c}-0.804^{*} \\
(0.075)\end{array}$ & $\begin{array}{l}0.336^{*} \\
(0.113)\end{array}$ & $\begin{array}{l}-0.281 \\
(0.234)\end{array}$ & $\begin{array}{l}-0.45^{*} \\
(0.213)\end{array}$ & $\begin{array}{l}-0.3 \\
(0.231)\end{array}$ & $\begin{array}{l}-0.196 \\
(0.232)\end{array}$ \\
\hline Capital & $\begin{array}{l}0.424^{*} \\
(0.033)\end{array}$ & $\begin{array}{l}0.789^{*} \\
(0.077)\end{array}$ & $\begin{array}{l}0.201 * \\
(0.024)\end{array}$ & $\begin{array}{l}0.288^{*} \\
(0.031)\end{array}$ & $\begin{array}{l}0.337^{*} \\
(0.029)\end{array}$ & $\begin{array}{l}0.289^{*} \\
(0.03)\end{array}$ & $\begin{array}{l}0.305^{*} \\
(0.03)\end{array}$ \\
\hline Openness & $\begin{array}{l}0.255^{*} \\
(0.049)\end{array}$ & $\begin{array}{l}0.325^{*} \\
(0.06)\end{array}$ & $\begin{array}{l}0.112^{*} \\
(0.034)\end{array}$ & $\begin{array}{l}0.181^{*} \\
(0.034)\end{array}$ & $\begin{array}{l}0.203^{*} \\
(0.032)\end{array}$ & $\begin{array}{l}0.18^{*} \\
(0.034)\end{array}$ & $\begin{array}{l}0.18^{*} \\
(0.032)\end{array}$ \\
\hline \multicolumn{8}{|c|}{ Health Expenditure } \\
\hline Constant & $\begin{array}{l}-5.653^{*} \\
(0.472)\end{array}$ & $\begin{array}{c}-6.239^{*} \\
(0.516)\end{array}$ & $\begin{array}{l}-16.314 \\
(14.198)\end{array}$ & $\begin{array}{l}-11.155^{*} \\
(0.917)\end{array}$ & $\begin{array}{l}-9.351^{*} \\
(0.887)\end{array}$ & $\begin{array}{l}-12.004^{*} \\
(0.868)\end{array}$ & $\begin{array}{l}-6.143^{*} \\
(1.01)\end{array}$ \\
\hline Income & $\begin{array}{l}1.005^{*} \\
(0.032)\end{array}$ & $\begin{array}{l}1.064^{*} \\
(0.038)\end{array}$ & $\begin{array}{l}2.264^{*} \\
(0.094)\end{array}$ & $\begin{array}{l}1.784^{*} \\
(0.078)\end{array}$ & $\begin{array}{l}1.663^{*} \\
(0.073)\end{array}$ & $\begin{array}{l}1.886^{*} \\
(0.077)\end{array}$ & $\begin{array}{l}1.327^{*} \\
(0.091)\end{array}$ \\
\hline Public & $\begin{array}{l}0.583^{*} \\
(0.044)\end{array}$ & $\begin{array}{l}0.607^{*} \\
(0.045)\end{array}$ & $\begin{array}{l}0.53^{*} \\
(0.044)\end{array}$ & $\begin{array}{l}0.673^{*} \\
(0.042)\end{array}$ & $\begin{array}{l}0.682^{*} \\
(0.042)\end{array}$ & $\begin{array}{l}0.646^{*} \\
(0.039)\end{array}$ & $\begin{array}{l}0.528^{*} \\
(0.041)\end{array}$ \\
\hline Old & $\begin{array}{l}-0.353^{*} \\
(0.125)\end{array}$ & $\begin{array}{c}-0.411^{*} \\
(0.127)\end{array}$ & $\begin{array}{l}-0.604^{*} \\
(0.21)\end{array}$ & $\begin{array}{l}-0.157 \\
(0.233)\end{array}$ & $\begin{array}{l}0.134 \\
(0.224)\end{array}$ & $\begin{array}{l}-0.171 \\
(0.213)\end{array}$ & $\begin{array}{l}0.256 \\
(0.205)\end{array}$ \\
\hline Young & $\begin{array}{l}-0.486^{*} \\
(0.184)\end{array}$ & $\begin{array}{l}-0.242 \\
(0.204)\end{array}$ & $\begin{array}{l}-1.28^{*} \\
(0.264)\end{array}$ & $\begin{array}{l}-0.227 \\
(0.262)\end{array}$ & $\begin{array}{l}-0.226 \\
(0.267)\end{array}$ & $\begin{array}{l}-0.432 \\
(0.242)\end{array}$ & $\begin{array}{l}-0.043 \\
(0.255)\end{array}$ \\
\hline
\end{tabular}

\footnotetext{
${ }^{1}$ Simultaneous Panel Equation with Spatial Autoregressive Error.

2 The number in parentheses denotes the standard deviation.

$3 *$ Denote significance at $5 \%$ of the parameter.
}

\section{B Compliance with Ethical Standards}

\section{Conflict of Interest}

Author Marius Claude Oyon Amba declares that he has no conflict of interest. Author Taoufiki Mbratana declares that he has no conflict of interest.

\section{Ethical Approval}

This article does not contain any studies with human participants or animals performed by any of the authors.

\section{References}

Anselin, L. (2006). Spatial econometrics in: Mills tc, patterson k (eds) palgrave hand'book of econometrics: Volume 1, econometric theory.

Baltagi, B. (2008). Econometric analysis of panel data. John Wiley \& Sons. 
Baltagi, B. H. (1984). A monte carlo study for pooling time series of cross-section data in the simultaneous equations model. International Economic Review, pages 603-624.

Baltagi, B. H. and Deng, Y. (2015). Ec3sls estimator for a simultaneous system of spatial autoregressive equations with random effects. Econometric Reviews, 34(6-10):659-694.

Baltagi, B. H., Egger, P., and Pfaffermayr, M. (2013). A generalized spatial panel data model with random effects. Econometric Reviews, 32(5-6):650-685.

Fingleton, B. (2008). A generalized method of moments estimator for a spatial model with moving average errors, with application to real estate prices. Empirical Economics, $34(1): 35-57$.

Kapoor, M., Kelejian, H. H., and Prucha, I. R. (2007). Panel data models with spatially correlated error components. Journal of Econometrics, 140(1):97-130.

Kelejian, H. H. and Prucha, I. R. (1998). A generalized spatial two-stage least squares procedure for estimating a spatial autoregressive model with autoregressive disturbances. The Journal of Real Estate Finance and Economics, 17(1):99-121.

Kelejian, H. H. and Prucha, I. R. (1999). A generalized moments estimator for the autoregressive parameter in a spatial model. International Economic Review, 40(2):509-533.

Kelejian, H. H. and Prucha, I. R. (2004). Estimation of simultaneous systems of spatially interrelated cross sectional equations. Journal of Econometrics, 118(1):27-50.

Kelejian, H. H., Prucha, I. R., and Yuzefovich, Y. (2004). Instrumental variable estimation of a spatial autoregressive model with autoregressive disturbances: Large and small sample results. In James, P. L. and Kelley, R. P., editors, Spatial and spatiotemporal econometrics, volume 18, pages 163-198. Emerald Group Publishing Limited.

Liu, X. (2014). Identification and efficient estimation of simultaneous equations network models. Journal of Business $6 \mathcal{G}$ Economic Statistics, 32(4):516-536.

Liu, X. and Saraiva, P. (2017). Gmm estimation of spatial autoregressive models in a system of simultaneous equations with heteroskedasticity. Econometric Reviews, (just-accepted).

Prucha, I. R., Drukker, D. M., and Egger, P. H. (2016). Simultaneous equations models with higher-order spatial or social network interactions. Technical report, Working paper, Department of Economics, University of Maryland. http://econweb. umd. edu/ prucha/papers/WP IRP PHE DMD 2016. pdf.

Sasser, W. E. (1969). A finite-sample study of various simultaneous equation estimators... Duke University.

Wang, L., Li, K., and Wang, Z. (2014). Quasi maximum likelihood estimation for simultaneous spatial autoregressive models. University Library of Munich, Germany.

Yang, K. and Lee, L.-f. (2017). Identification and qml estimation of multivariate and simultaneous equations spatial autoregressive models. Journal of Econometrics, 196(1):196-214. 
Zenou, Y. (2017). Multivariate choices and identification of social interactions. Journal of Applied Econometrics, pages 1-37. 